\title{
PRISCILLA CUKIER
}

\section{Estudo dos genes TTF-1 e EAP1 em pacientes com distúrbios puberais centrais e avaliação neurológica e neurocognitiva de pacientes com hamartoma hipotalâmico}

Tese apresentada à Faculdade de Medicina da Universidade de São Paulo para obtenção de título de Doutor em Ciências

Programa de: Endocrinologia

Orientador: Dr. Vinicius Nahime Brito

\section{São Paulo}




\section{Dados Internacionais de Catalogação na Publicação (CIP)}

Preparada pela Biblioteca da

Faculdade de Medicina da Universidade de São Paulo

Creprodução autorizada pelo autor

\section{Cukier, Priscilla}

Estudo dos genes TTF-1 e EAP1 em pacientes com distúrbios puberais centrais e avaliação neurológica e neurocognitiva de pacientes com hamartoma hipotalâmico / Priscilla Cukier. -- São Paulo, 2010.

Tese(doutorado)--Faculdade de Medicina da Universidade de São Paulo. Programa de Endocrinologia.

Orientador: Vinicius Nahime Brito.

Descritores: 1.Puberdade precoce 2.Hipogonadismo 3.Hamartoma hipotalâmico 4.TTF-1 5.EAP1 6.Manifestações neurológicas 7.Neurocognitivo 8.Epilepsia

USP/FM/DBD-453/10 
Este trabalho foi realizado na Unidade de Endocrinologia do Desenvolvimento e no Laboratório de Hormônios e Genética Molecular LIM/42 da Disciplina de Endocrinologia do Hospital das Clínicas da Faculdade de Medicina da Universidade de São Paulo, com o apoio da FAPESP (processos 06/56531-0, 05/04726-0) 


\section{Dedicatória}


Dedico esta tese às minhas filhas Ariela e à segundinha, que ainda está em meu útero; sem dúvida as presenças mais constantes durante a confecção deste trabalho, e ao Leandro, meu querido marido, que possibilitou essas realizações, tanto de meus anjos, quanto da tese. 
Agradecimentos 
Agradeço a todos os que direta ou indiretamente contribuíram para a realização deste trabalho; sobretudo:

A meu orientador Vinicius Nahime de Brito, sempre disposto a me ensinar, apoiando e corrigindo-me. Um verdadeiro amigo que, por entender e dosar muito bem os aspectos importantes da vida, possibilitou uma extraordinária convivência.

À Dra. Ana Claudia Latronico que sempre esteve por perto, com sua experiência, conhecimento, bom senso e bons "fluidos", auxiliando e enriquecendo o trabalho.

Em especial, à Dra. Berenice Bilharinho de Mendonça que me apoiou e incentivou de forma constante, além de ser um exemplo de competência e persistência.

Ao Dr. Ivo JP Arnhold e ao Dr. Alex Jorge, sempre disponíveis, que me auxiliaram com comentários pertinentes.

A todos os meus colegas pós-graduados e pós-graduandos que tornaram o dia a dia mais prazeroso, além de me auxiliarem diretamente no trabalho; em especial à Letícia, Ana Paula, Milena, Daiane, Cintia, Luciana Brito, Ericka, Rocio, Maíra, Everlainy, Alexsandra, Marisa, Aline, Marcela, Luciana Montenegro, Acácio, Fernanda, Adriana, Mariana, Helena, Luciane, Luciani, Michele.

À Anna Elisa Billerbeck e à Dra. Tânia Bachega que despertaram meu interesse pela pesquisa e pela Biologia Molecular.

A todos os funcionários do LIM42 e da Endocrinologia que tornaram muito mais simples a confecção desta tese, em especial à Nilda, Cida, Cristina, Rosana e Fran.

Aos meus pais Marisa e Alberto que me incentivaram a ser quem sou e estar onde estou, todo o meu amor e gratidão.

Novamente à minha mãe pela paciência de revisar e corrigir este trabalho. À minha querida irmã Sabrina, minha sempre e melhor companheira. 
Aos meus queridos avós Gabriel, Diane, Max e Stefa, meus melhores exemplos de vida. 
Sumário 


\section{Sumário}

Pág.

Lista de figuras

Lista de tabelas

Lista de abreviaturas

Resumo

Summary

1. Introdução 1

1.1. Fisiologia da puberdade humana normal 2

1.2. Distúrbios puberais e defeitos genéticos em humanos 4

1.2.1. Puberdade precoce 5

1.2.2. Atraso puberal e hipogonadismo hipogonadotrófico 6

1.2.3. Base genética dos distúrbios puberais $\quad 7$

1.2.4. Puberdade precoce central causada por hamartoma hipotalâmico 10

1.3. Hierarquia gênica que regula a secreção de $\mathrm{GnRH}$

1.3.1. TTF-1 e controle da secreção de GnRH 14

1.3.2. EAP1 e controle da secreção de GnRH 16

$\begin{array}{ll}\text { 2. Objetivos } & 19\end{array}$

3. Pacientes e métodos 21

3.1. Casuística 22

3.2. Avaliação hormonal 32

3.3. Modo de herança e taxa de penetrância dos pacientes com PPC 33 idiopática

3.4. Estudo molecular 34

3.4.1. Extração do DNA genômico de leucócitos periféricos 34 
3.4.2. Amplificação de DNA genômico por reação em cadeia da 35 polimerase (PCR)

3.4.3. Sequenciamento automático $\quad 37$

3.4.3. Estudo das regiões poliglutamina (poliQ) e polialanina (poliAla) 38 do EAP1

3.5. Avaliação neurológica e neurocognitiva dos pacientes com PPC 39 devido a hamartoma hipotalâmico

3.6. Análise estatística 40

4. Resultados $\quad 42$

4.1. Puberdade precoce central forma familial: modo de herança e taxa 43 de penetrância

4.2. Estudo molecular 44

4.2.1. TTF-1 44

4.2.2. EAP1 44

4.3. Avaliação neurológica e neurocognitiva dos pacientes com PPC 49 devido a hamartoma hipotalâmico

5. Discussão

54

6. Conclusões

63

7. Referências

65 


\section{Lista de figuras}


1. Hierarquia gênica da secreção de GnRH 13

2. Representação esquemática do gene TTF-1 14

3. Representação esquemática do gene EAP-1 16

4. Heredogramas de 14 famílias de pacientes com PPC idiopática 43

5. Eletroferograma das variantes alélicas identificadas no EAP1 45

6. Estudo do número de repetições glutaminas (região poliglutamina) 47 no EAP1

7. Estudo do número de repetições alaninas (região polialanina 5' 48 distal) no EAP1

8. Quoeficiente de inteligência nos pacientes com hamartoma 52 hipotalâmico com e sem epilepsia 


\section{Lista de tabelas}


1. Defeitos genéticos associados ao hipogonadismo 9 hipogonadotrófico

2. Dados clínicos e hormonais dos pacientes com PPC idiopática

3. Dados clínicos e hormonais dos pacientes com PPC devido a hamartoma hipotalâmico

4. Dados clínicos e hormonais de pacientes com hipogonadismo hipogonadotrófico isolado normósmico

5. Valores normais de testosterona e LH no sexo masculino, obtidos nos ensaios IFMA e RIE em pré-púberes e em adultos

6. Valores normais de estradiol e LH no sexo feminino, obtidos nos ensaios de IFMA e RIE em pré-púberes e em adultos

7. Oligonucleotídeos usados para amplificação do gene TTF-1

8. Oligonucleotídeos usados para amplificação do gene EAP1

9. Frequência alélica e genotípica das variantes alélicas sinônimas do EAP1

10. Distribuição alélica das variantes da região poliAla 5' distal nos distúrbios puberais centrais

11. Dados neurológicos e neurocognitivos dos pacientes com PPC devido a hamartoma hipotalâmico 


\section{Lista de abreviaturas}




\section{Lista de abreviaturas}

ACCD

$\mathrm{CRH}$

CHD7

DAX-1

DMSO4

dNTP

DP

EAP-1

EDTA

EEG

EGF

ErbB-1

FGF8

FGFR1

FOXC1

$\mathrm{FSH}$

FSHR

GABA

GABRA1

GLI 3

$\mathrm{GnRH}$

GnRHR

GPR54

GWAS

$\mathrm{HCl}$

HESX1

$\mathrm{HHIn}$

IC
Atraso constitucional do crescimento e desenvolvimento Hormônio liberador de corticotrofina Proteína de ligação ao DNA do cromodomínio helicase 7 Gene 1 da reversão sexual dose-sensível, hipoplasia adrenal congênita, região crítica no cromossomo $X$

Dimetilsulfato

Desoxiribonucleotídeos

Desvio-padrão

Enhanced at puberty

Ácido etilenodiamino tetracético

Eletroencefalograma

Fator de crescimento epitelial

Receptor do fator de crescimento de transformação a

Fator 8 de crescimento de fibroblastos

Receptor 1 do fator de crescimento de fibroblastos

Gene forkhead box C1

Hormônio folículo-estimulante

Receptor do hormônio folículo-estimulante

Ácido gama-aminobutírico

Gene que codifica a subunidade $\alpha 1$ do receptor $G_{A B A}$ GLI family zinc finger 3 Hormônio liberador de gonadotrofinas

Receptor de GnRH

Receptor acoplado a proteína G-54 (KISS1R)

Estudos de genome wide association

Ácido clorídrico

Gene homeobox da bolsa de Rathke

Hipogonadismo hipogonadotrófico isolado normósmico Idade cronológica 


$\begin{array}{ll}\text { IFMA } & \text { Ensaio imunofluorométrico } \\ \text { IO } & \text { Idade óssea } \\ \text { IL-1 } & \text { Interleucina 1 } \\ \text { IL-6 } & \text { Interleucina 6 } \\ \text { KAL1 } & \text { Anosmina } \\ \text { KISS1 } & \text { Gene que codifica a kisspeptina } \\ \text { Kb } & \text { Kilobases } \\ \text { LH } & \text { Hormônio luteinizante } \\ \text { LHR } & \text { Receptor do hormônio luteinizante } \\ \text { LHX3 } & \text { Gene homeobox LIM 3 } \\ \text { LEP } & \text { Gene que codifica a leptina } \\ \text { LEPR } & \text { Gene que codifica o receptor da leptina } \\ \text { LIN28B } & \text { Gene Lin -28 homólogo B } \\ \text { NaCl } & \text { Cloreto de sódio } \\ \text { NCBI } & \text { National Center for Biotechnology and Information } \\ \text { NELF } & \text { Fator embrionário nasal liberador de LH } \\ \text { NPY } & \text { Neuropeptídeo Y } \\ \text { NPYR1 } & \text { Gene que codifica o receptor tipo 1 do neuropeptídeo Y } \\ \text { NPYR5 } & \text { Gene que codifica o receptor tipo 5 do neuropeptídeo Y } \\ \text { PB } & \text { Pares de base } \\ \text { PC1 } & \text { Gene que codifica a enzima pró-convertase 1 } \\ \text { PCR } & \text { Reação em cadeia da polimerase } \\ \text { PPC } & \text { Puberdade precoce central } \\ \text { PROK2 } & \text { Proquinecitina 2 } \\ \text { PROKR2 } & \text { Receptor 2 da proquinecitina } \\ \text { PROP-1 } & \text { Gene profeta do fator de transcrição específico da pituitária } \\ \text { QI } & \text { Quoeficiente de inteligência } \\ \text { QIE } & \text { Quoeficiente de inteligência de execução } \\ \text { QIV } & \text { Quoeficiente de inteligência verbal } \\ & \end{array}$




$\begin{array}{ll}\text { QIT } & \text { Quoeficiente de inteligência total } \\ \text { RIE } & \text { Radioimunoensaio } \\ \text { RNAm } & \text { RNA mensageiro } \\ \text { RM } & \text { Ressonância magnética } \\ \text { RPM } & \text { Rotações por minuto } \\ \text { SDS } & \text { Sulfato dodecil de sódio } \\ \text { SF-1 } & \text { Fator esteroidogênico 1 } \\ \text { SNC } & \text { Sistema nervoso central } \\ \text { SOX2 } & \text { Gene SRY-box 2 } \\ \text { TE } & \text { Tampão de Tris e EDTA } \\ \text { TGF- } \alpha & \text { Fator de crescimento de transformação } \alpha \\ \text { TGF- }-3 & \text { Fator de crescimento de transformação B } \\ \text { TAC3 } & \text { Neurokinina B } \\ \text { TACR3 } & \text { Receptor da neurokinina B } \\ \text { Tris } & \text { Trisaminometano } \\ \text { TTF-1 } & \text { Thyroid transcription factor 1 } \\ \text { WAIS-III } & \text { Escala de inteligência de Wechsler para adultos } \\ \text { WISC-III } & \text { Escala de inteligência de Wechsler para crianças } \\ \text { WPPSI-R } & \text { Escala de inteligência de Wechsler para pré-escolares revisada } \\ \text { VIP } & \text { Peptídeo intestinal vasoativo }\end{array}$




\section{Resumo}


Cukier, P. Estudo dos genes TTF-1 e EAP1 em pacientes com distúrbios puberais centrais e avaliação neurológica e neurocognitiva de pacientes com hamartoma hipotalâmico. [tese]. São Paulo. Faculdade de Medicina, Universidade de São Paulo; 2010. 84 p.

O mecanismo de controle da secreção de GnRH inclui diversas vias neuronais. Estudos em modelos animais identificaram genes que codificam fatores de transcrição, tais como TTF-1 (thyroid transcription factor 1) e EAP1 (enhanced at puberty), que atuam no controle transcricional de genes codificadores de fatores excitatórios (KiSS1 e $G n R H$ ) e inibitórios (preproencefalinas) regulando a secreção de GnRH. Em primatas, a expressão de EAP1 e TTF-1 aumenta, no início da puberdade, nas regiões hipotalâmicas envolvidas na secreção de GnRH. Nos modelos animais, a deleção pós-natal de TTF-1 e o silenciamento do EAP1 provocam atraso puberal e prejuízo na função reprodutiva. TTF-1 também está envolvido na morfogênese diencefálica, por meio da via de sinalização da família Sonic-Hedgehog. Anormalidades na secreção de GnRH resultam em distúrbios puberais, que variam de puberdade precoce central (PPC) a hipogonadismo hipogonadotrófico. Hipotetizamos que anormalidades genéticas no TTF-1 e EAP1 estejam envolvidas na patogênese dos distúrbios puberais centrais. A PPC pode ser idiopática ou devido a causas orgânicas, sendo o hamartoma hipotalâmico, uma malformação congênita não neoplásica, a mais conhecida. Os pacientes com PPC devido a hamartoma hipotalâmico podem cursar com alterações neurológicas e cognitivas. Nossos objetivos foram: estudar as regiões codificadora do TTF-1 e do EAP1 e a região promotora do TTF-1 em pacientes com distúrbios puberais centrais; estabelecer a prevalência, taxa de penetrância e modo de herança da forma familial de PPC e caracterizar as manifestações neurológicas e neurocognitivas de pacientes com PPC devido a hamartoma hipotalâmico. Foram selecionados 133 pacientes com distúrbios puberais centrais - PPC idiopática $(n=71)$, PPC devido a hamartoma hipotalâmico $(n=15)$ e hipogonadismo hipogonadotrópico isolado normósmico (HHIn) ( $n=47)$ - e controles $(n=53)$. Os genes TTF-1 e EAP1 foram amplificados e submetidos a sequenciamento automático. Os tratos de poliglutamina e polialanina no EAP1 foram estudados por software de análise de tamanho de fragmento (GeneScan). A avaliação neurológica e neurocognitiva dos pacientes com PPC devido a hamartoma hipotalâmico consistiu de exame neurológico, eletroencefalograma, ressonância magnética de encéfalo e aplicação da escala de inteligência (WISC-III, WAIS-III, WPPSIR). Identificamos $25 \%$ de casos familiais de PPC, com modo de herança autossômica dominante e taxa de penetrância de 67,5\%. Variantes alélicas no TTF-1 não foram identificadas nos pacientes estudados. No gene EAP1 foram identificadas quatro variantes alélicas sinônimas: p.E87E, p.A163A, p.Y415Y e uma nova variante alélica p.C758C, encontradas em pacientes com PPC e HHIn. A distribuição das frequências alélica e genotípica das variantes alélicas do EAP1 não diferiram entre pacientes com PPC, HHIn e controles $(p>0,05)$. Nas regiões poliglutamina e polialanina 5' distal foi identificada variação similar 
no número de repetições glutamina e alanina em pacientes e controles. Não houve diferença significativa da frequência alélica em relação ao número de repetições glutamina e alanina entre os grupos PPC e HHIn $(p>0,05)$. A avaliação neurológica dos pacientes com PPC devido a hamartoma hipotalâmico revelou epilepsia gelástica e crises focais com generalização em $3 / 15$ (20\%) pacientes. Não houve diferença significativa entre a mediana do maior diâmetro dos hamartomas dos pacientes com PPC com e sem epilepsia (13 e $10 \mathrm{~mm}$, respectivamente). Quanto à forma, 10 hamartomas eram sésseis e 5 pedunculados, sendo que a forma pedunculada foi detectada exclusivamente em pacientes sem epilepsia. A avaliação neurocognitiva em 11 dos 15 pacientes com PPC devido a hamartoma hipotalâmico detectou 2 pacientes com epilepsia com QI significativamente menor que o grupo sem epilepsia $(p<0,05)$. Em conclusão, (i) a considerável prevalência de casos familiais de PPC reforça a influência dos fatores genéticos na puberdade humana; (ii) mutações germinativas no TTF-1 e no EAP1 não estão envolvidas na patogênese dos distúrbios puberais centrais; (iii) a função neurocognitiva reduzida nos pacientes com hamartoma e epilepsia sugere um efeito deletério das crises convulsivas no sistema nervoso central.

Descritores: puberdade precoce; hipogonadismo; hamartoma hipotalâmico; TTF-1; EAP1; manifestações neurológicas; neurocognitivo; epilepsia. 
Abstract 
Cukier, P. Analysis of TTF-1 and EAP1 genes in patients with central pubertal disorders and neurologic and neurocognitive evaluation of patients with hypothalamic hamartoma. [tese]. São Paulo. Faculdade de Medicina, Universidade de São Paulo; 2010. 84 p.

GnRH secretion control involves multiple neuronal pathways. Animal studies have identified genes which codifies transcription factors, such as TTF-1 (thyroid transcription factor 1) and EAP1 (enhanced at puberty), that act in the transcriptional control of genes that codifies excitatory (KiSS1 and GnRH) and inhibitory factors (preproenkephalines) regulating $\mathrm{GnRH}$ secretion. In nonhuman primates, expression of EAP1 and TTF-1 are increased at the hypothalamic regions involved in $\mathrm{GnRH}$ secretion, at the beginning of puberty. In animal models, post-natal TTF-1 deletion and silencing of EAP1 lead to pubertal delay and damage of reproductive function. TTF-1 is also involved in diencephalic morphogenesis, through signalization via Sonic-Hedgehog family. Abnormalities in GnRH secretion are responsible for pubertal disorders, varying from central precocious puberty (CPP) to hypogonadotropic hypogonadism. We hypothesized that genetic anomalies at TTF-1 and EAP1 are involved in the pathogenesis of central pubertal disorders. CPP may be idiopathic or due to organic alterations and hypothalamic hamartoma, a non-neoplasic congenital malformation, is the most frequent known organic cause. Patients with CPP due to hypothalamic hamartoma may have neurological and cognitive disfunctions. Our aims were: to evaluated the codifying region of TTF-1 and EAP1 and the promoter region of TTF-1 in patients with central pubertal disorders; to establish the prevalence, penetrance rate and inheritance mode of familial CPP and to characterize neurologic and neurocognitive aspects of patients with CPP due to hypothalamic hamartoma. We selected 133 patients with central pubertal disorders - idiopathic CPP $(n=71)$, CPP due to hypothalamic hamartoma $(n=15)$ and normosmic isolated hypogonadropic hypogonadism $(\mathrm{nlHH})(n=47)-$ and controls $(n=53)$. TTF-1 and EAP1 genes were amplified and sequenced. Polyglutamine and polyalanine tracts of EAP1 were studied by a fragment size analyser software (GeneScan). Neurologic and neurocognitive evaluation of CPP patients due to hypothalamic hamartoma consisted of neurologic exam, electroencephalogram, brain magnetic resonance and application of intelligence scale (WISC-III, WAIS-III, WPPSI-R). We identified $25 \%$ of familial CPP cases with autosomal dominant mode of inheritance and penetrance rate of $67.5 \%$. No TTF-1 allelic variants were identified in the patients analysed. At EAP1 gene, four synonimous allelic variants were identified: p.E87E, p.A163A, p.Y415Y and a new allelic variant p.C758C, found in CPP and nIHH patients. The allelic and genotypic distribution of theses variants of EAP1 did not differ among patients with CPP and $\mathrm{nIHH}$, and controls $(p>0.05)$. At polyglutamine and 5 ' distal polyalanine region, similar glutamine and alanine repeats variation was found. No significative difference of allelic frequency distribution regarding the number of glutamines and alanines repeats was found among the studied groups ( $p$ $>0.05$ ). Neurologic evaluation of CPP patients due to hypothalamic hamartoma 
revealed epilepsy and focal crisis with generalization in 3/15 (20\%) of the patients. No significant difference between the median of the larger diameter of hypothalamic hamartoma of CPP patients with and without epilepsy was found (10 $\mathrm{mm}$ and $13 \mathrm{~mm}$, respectively). Regarding the shape, 10 hamartomas were sessile and 5 pedunculated, and the pedunculated shape was found only in non epileptic patients. Neurocognitive evaluation performed in 11 of the 15 patients with CPP due to hypothalamic hamartoma detected 2 patients with epilepsy whose IQ were significantly lower than the IQ found in the group without epilepsy $(p<0.05)$. In conclusion, (i) the considerable prevalence of familial CPP cases reinforce the influence of genetic factors in human puberty; (ii) germinative mutations in TTF-1 and EAP1 are not involved in the pathogenesis of central pubertal disorders; (iii) reduced neurocognitive function in patients with hypothalamic hamartoma and epilepsy suggests a deleterious effect of crisis at the central nervous system

Key words: precocious puberty; hypogonadism; hypothalamic hamartoma; TTF1; EAP1; neurologic manifestations; neurocognitive; epilepsy. 


\section{1 - Introdução}




\section{1- INTRODUÇÃO}

\section{1- Fisiologia da puberdade humana normal}

A puberdade humana compreende o período de transição entre a infância e a vida adulta e é determinada pelo desenvolvimento dos caracteres sexuais secundários, aceleração da velocidade de crescimento e maturação das gônadas para aquisição das funções reprodutivas (1). Além destes eventos fisiológicos, esse período também se caracteriza por profundas modificações psicológicas.

O evento hormonal determinante do início da puberdade é o aumento da frequência e da amplitude da secreção pulsátil do decapeptídeo hipotalâmico liberador de gonadotrofinas $(\mathrm{GnRH})$ que, atuando no seu receptor específico (GnRHR) no gonadotrofo hipofisário, estimula a síntese e a secreção das gonadotrofinas hipofisárias - hormônio luteinizante (LH) e hormônio folículoestimulante (FSH) que, por sua vez, ligando-se a seus receptores (LHR e FSHR), estimulam a síntese e a secreção dos esteroides sexuais, estradiol no sexo feminino e testosterona no sexo masculino, pelos ovários e testículos, respectivamente.

A compreensão dos mecanismos regulatórios da secreção pulsátil do $\mathrm{GnRH}$, assim como seu papel fundamental no início da puberdade têm sido parcialmente elucidados nas últimas duas décadas com importante contribuição de estudos em modelos animais $(2,3)$. A secreção do $\mathrm{GnRH}$ é elevada na fase fetal e neonatal em decorrência da imaturidade do sistema inibitório intrínseco do sistema nervoso central (SNC) (3). Esta fase, também denominada minipuberdade, é caracterizada pelo padrão de secreção hormonal com valores elevados de gonadotrofinas e esteroides sexuais, no entanto, sem as manifestações clínicas da puberdade (3). A partir dos 6 meses de idade, no sexo masculino e, em torno de 24 meses, no sexo feminino, passa a predominar a inibição da secreção de $\mathrm{GnRH}$, que é realizada por peptídeos inibitórios, representados principalmente pelo sistema GABAérgico, 
neuropeptídeo $\mathrm{Y}$ e a família de opioides, principalmente as preproencefalinas (3). Este período de quiescência do eixo gonadotrófico é caracterizado por pulsos de $\mathrm{GnRH}$ com baixa frequência e amplitude, mantendo a liberação de esteroides sexuais em valores pré-puberais, o que determina o período da infância (1). O processo puberal resulta da reemergência dos pulsos do $\mathrm{GnRH}$ hipotalâmico que ocorre em idade variável em ambos os sexos. Considera-se normal a puberdade que se inicia entre 8 e 13 anos no sexo feminino e entre 9 e 14 anos no sexo masculino (1).

A secreção de $\mathrm{GnRH}$ hipotalâmico é coordenada por uma rede neuronal complexa, constituída não só de neurônios estimulatórios e/ou inibitórios mas também pela ativação recíproca de mecanismos de comunicação glia-neurônio (3-5). Além do sistema GABAérgico e dos opioides, o peptídeo intestinal vasoativo (VIP), o hormônio liberador de corticotrofina $(\mathrm{CRH})$ e a melatonina também pertencem ao sistema inibitório da secreção de $\mathrm{GnRH}$. Em contrapartida, o sistema excitatório tem como principal elemento a kisspeptina que, ligando-se a seu receptor denominado KiSS1R (também chamado GPR54), estimula a secreção de GnRH (6). Participam também outros neurotransmissores excitatórios tais como glutamato, glicina, norepinefrina, dopamina e serotonina $(3,6)$. Ao neuropeptídeo Y (NPY) são atribuídas tanto uma atividade excitatória quanto inibitória sobre a secreção de GnRH (7). As células da glia e os fatores de crescimento tais como fator de crescimento transformante alfa e beta (TGF $\alpha$ e $\beta$ ), fator de crescimento epidermal (EGF), citoquinas e interleucinas (IL-1 e IL-6) também estão presentes neste complexo mecanismo regulatório da secreção de $\operatorname{GnRH}(4,5)$. A leptina, hormônio secretado principalmente pelos adipócitos, tem sido envolvida no início da puberdade humana. No entanto, as evidências obtidas por meio de estudos em modelos animais e em humanos apontam para um papel permissivo deste hormônio no eixo reprodutivo (8). A leptina atua como moduladora do tônus excitatório de $\mathrm{GnRH}$, e não como desencadeadora do processo puberal (8). 
Os esteroides sexuais atuam nos tecidos periféricos, estimulando o aparecimento dos caracteres sexuais secundários, mas eles também agem no hipotálamo $(9,10)$. Em fêmeas, o feedback positivo do estrógeno induz o pico pré-ovulatório de LH (11), enquanto o feedback negativo do estrógeno e da testosterona inibe a secreção de $\mathrm{GnRH}(10,11)$. Este fenômeno ocorre desde a infância, quando já estão presentes esteroides sexuais em valores indosáveis $(12,13)$. Embora sejam contestadas, há teorias de que, no momento do início da puberdade, ocorra menor sensibilidade hipotalâmica ao esteroide sexual com posterior secreção de $\mathrm{GnRH}(14,15)$. A regulação hipotâlamica pelos esteroides sexuais é, no entanto, fundamental para a modulação do início puberal bem como para a reprodução $(11,14)$.

\section{2 - Distúrbios puberais e defeitos genéticos em humanos}

Fisiologicamente, a idade de início da puberdade humana varia amplamente e segue uma distribuição normal ou Gaussiana (1). Tal variabilidade é determinada pela interação de um conjunto de fatores que inclui aspectos genéticos, étnicos, nutricionais, ambientais e socioeconômicos (1). Reforçam o papel dos fatores genéticos na modulação do eixo gonadotrófico o padrão familiar da variação etária do início da puberdade (16 - 19), a idade da menarca semelhante entre mães e filhas e a maior concordância do desenvolvimento puberal entre gêmeos monozigóticos quando comparados a dizigóticos $(20,21)$, sendo que evidências sugerem que $50 \%$ a $95 \%$ da variabilidade na idade de início da puberdade seja controlada geneticamente $(20,21)$. De acordo com estudos populacionais europeus da década de 1960, a puberdade normal ocorre entre 8 anos e 13 anos na menina, e entre 9 anos e 14 anos no menino (1).

$\mathrm{Na}$ última década, diversos elementos incluindo receptores hormonais, proteínas de matriz, neurotransmissores e fatores de transcrição foram estudados e anormalidades gênicas foram identificadas em condições de precocidade e de atraso puberal (22 - 24). Essas descobertas propiciaram um 
grande avanço na compreensão da fisiologia e da fisiopatologia do eixo hipotálamo-hipófise-gonadal nesta importante fase de transição da vida, além de contribuírem positivamente para a prática clínica da medicina reprodutiva.

\subsection{1 - Puberdade Precoce}

Classicamente, a puberdade é considerada precoce quando se inicia antes dos 8 anos nas meninas e dos 9 anos nos meninos (dois desvios-padrão abaixo da média populacional). A menarca antes dos 9 anos é considerada critério adicional no sexo feminino $(25,26)$.

A puberdade precoce pode ser central ( $\mathrm{GnRH}$-dependente) ou periférica ( $\mathrm{GnRH}$-independente). Denomina-se puberdade precoce central (PPC) quando o desenvolvimento dos caracteres sexuais secundários é consequência da ativação prematura do eixo hipotálamo-hipófise-gonadal, e puberdade precoce $\mathrm{GnRH}$-independente quando $\mathrm{o}$ aparecimento dos caracteres sexuais secundários é uma consequência da produção dos esteroides sexuais não controlada pelo $\mathrm{GnRH}$, como produção autônoma pelas gônadas, adrenal ou tumores (25). Clinicamente, ambas são caracterizadas por desenvolvimento precoce dos caracteres sexuais secundários, aceleração do crescimento linear e avanço da idade óssea, com consequente prejuízo da estatura final (25).

A prevalência estimada de PPC é de $0,01 \%$ a $0,05 \%$ (27). A PPC é aproximadamente dez vezes mais prevalente em meninas do que em meninos, sendo que na população dinamarquesa a prevalência estimada é de cerca de $0,2 \%$ em meninas e menos de $0,05 \%$ em meninos (28). No Brasil não há dados disponíveis sobre a incidência e prevalência desta doença. Nas meninas, a grande maioria dos casos de puberdade precoce é de origem central, e mais de 90\% dos casos não apresentam causas orgânicas detectáveis e são considerados idiopáticos (1, 29). Em contraste, até dois terços dos meninos com PPC apresentam lesões do SNC. As causas orgânicas de PPC incluem hamartomas hipotalâmicos (a mais conhecida e frequente), lesões tumorais, infecções, traumas e irradiação do SNC $(10,29)$. 
Recentemente, de Vries e cols. (19) estudaram retrospectivamente um grande número de crianças israelenses com puberdade precoce. De 453 pacientes estudados, 156 apresentavam puberdade precoce central. Destas, 147 eram do sexo feminino e 9, do sexo masculino. Quarenta e três crianças (27\%) preenchiam os critérios para puberdade precoce familial (19). Após análise de segregação dessas famílias, foi possível estabelecer um padrão de herança autossômico dominante com penetrância incompleta e sexodependente (19), sugerindo que fatores genéticos tenham papel determinante no início da puberdade, mesmo em situações patológicas.

\subsection{2 - Atraso puberal e hipogonadismo hipogonadotrófico}

O atraso puberal é caracterizado pela ausência dos caracteres sexuais secundários após os 13 anos nas meninas e 14 anos nos meninos (dois desvios-padrão acima da média populacional) (1, 30).

Etiologicamente, o atraso puberal pode ser classificado em três grupos: 1- atraso constitucional do crescimento e desenvolvimento (ACCD), caracterizado pelo início tardio da puberdade normal ou pela atenuação da sua progressão, seguido de maturação completa, sendo esta a causa mais comum de atraso puberal $(31,32)$; 2- hipogonadismo hipogonadotrófico, caracterizado pela diminuição da síntese e da secreção dos esteroides sexuais associados à secreção baixa ou inapropriada de gonadotrofinas para os baixos níveis de esteroides sexuais e 3- hipogonadismo hipergonadotrófico, definido pela disfunção gonadal primária, com consequente elevação das gonadotrofinas (30).

O hipogonadismo hipogonadotrófico deve-se a várias causas orgânicas e genéticas (tabela 1), podendo a deficiência de gonadotrofinas ser combinada a outros hormônios ou isolada. Na ausência de condições patológicas associadas ao hipogonadismo, e de lesões orgânicas centrais ou mutações nos diferentes genes envolvidos na secreção e ação do $\mathrm{GnRH}$, esta condição é denominada idiopática. O diagnóstico diferencial entre hipogonadismo hipogonadotrófico 
isolado idiopático e ACCD pode ser difícil, pois nas duas situações ocorre a superposição de achados clínicos e laboratoriais (30), sendo necessário o seguimento prolongado para a apropriada distinção das duas condições. Recentemente, casos reversíveis de hipogonadismo hipogonadotrófico têm sido descritos, abrindo novas perspectivas para a compreensão dos mecanismos envolvidos $(33-36)$.

\subsection{3 - Base genética dos distúrbios puberais}

Inúmeras mutações inativadoras em genes que interferem no eixo gonadotrófico foram relacionadas ao hipogonadismo hipogonadotrófico (tabela 1). Tais alterações podem ser classificadas em genes que interferem na migração neuronal do $\mathrm{GnRH}$, na síntese de $\mathrm{GnRH}$ e, finalmente, na ação do $\mathrm{GnRH}$. Mutações inativadoras relacionadas à síndrome de Kallmann (hipogonadismo hipogonadotrófico associado a alterações olfatórias) foram inicialmente identificadas nos genes $\operatorname{KAL} 1$ e FGFR1 $(37,38)$. Esses dois fatores são essenciais para a adequada migração dos neurônios de $\mathrm{GnRH}$ para o hipotálamo. Mutações nos genes KAL1 e FGFR1 causam, respectivamente, síndrome de Kallmann de herança ligada ao X e autossômica dominante (37 39). Mais recentemente, mutações no receptor acoplado à proteína $G, P R O K R 2$ e seu ligante, proquineticina-2 (PROK2) e no gene FGF8 também foram relacionadas à síndrome de Kallmann (40 - 43). Mutações no gene CHD7 que levam à síndrome CHARGE, caracterizada por anormalidades congênitas como coloboma, defeitos cardíacos, atresia cloanal, atraso do desenvolvimento e crescimento, hipoplasia genital, malformações da orelha, surdez, paralisia facial, palato fendido e fístula traqueoesofágica podem também causar o fenótipo da síndrome de Kallmann (44).

No entanto, um estudo de associação entre variantes gênicas no $K A L 1$, FGFR1, PROK2 e PROK2R e idade de menarca não demonstrou efeito destes polimorfismos sobre a época da menarca (45), sugerindo que, apesar de 
importantes para o início da puberdade, estes genes não têm papel crucial na modulação da puberdade normal.

As primeiras mutações inativadoras relacionadas ao hipogonadismo hipogonadotrófico isolado normósmico $(\mathrm{HHIn})$ foram descritas no gene do receptor do hormônio liberador de gonadotrofinas, GnRHR (46) e, posteriormente, no gene do receptor acoplado à proteína G, KISS1R (GPR54), gene associado à secreção do $\mathrm{GnRH}(47$ - 50). Mais recentemente foi descrita mutação em frameshift no gene GnRH em uma família com HHIn (51).

Mutações inativadoras no gene do receptor FGFR1 também foram descritas nos pacientes com HHIn (52).

Mutações inativadoras nos genes que codificam as subunidades beta das gonadotrofinas, FSH e LH, relacionadas a defeitos na ação das gonadotrofinas, também constituem uma causa rara de $\mathrm{HHIn}(53,54)$. Os genes TAC3 e TACR3 que codificam a neurokinina B e seu receptor, respectivamente, foram também envolvidos no $\mathrm{HHIn}$ (55). No entanto, atualmente, apenas $30 \%$ dos pacientes com hipogonadismo hipogonadotrófico isolado têm sua base genética esclarecida (56). 
Tabela 1 - Defeitos genéticos associados ao hipogonadismo hipogonadotrófico

\begin{tabular}{|c|c|c|c|c|c|}
\hline Gene & Locus & Produto gênico & $\begin{array}{l}\text { Função no eixo } \\
\text { reprodutivo }\end{array}$ & Herança & Fenótipo \\
\hline KAL1 & Xp22.3 & Anosmina & $\begin{array}{c}\text { Migração dos } \\
\text { neurônios de GnRH }\end{array}$ & Ligada ao X & S. Kallmann \\
\hline FGF8 & $10 q 25$ & $\begin{array}{l}\text { Fator de crescimento } \\
\text { de fibroblasto } 8\end{array}$ & $\begin{array}{c}\text { Migração dos } \\
\text { neurônios de GnRH }\end{array}$ & $\begin{array}{l}\text { Autossômica } \\
\text { dominante }\end{array}$ & $\begin{array}{l}\text { S. Kallmann ou } \\
\text { HHIn }\end{array}$ \\
\hline FGFR1 & $8 p 12$ & $\begin{array}{l}\text { Receptor } 1 \text { do fator de } \\
\text { crescimento de } \\
\text { fibroblasto }\end{array}$ & $\begin{array}{c}\text { Migração dos } \\
\text { neurônios de GnRH }\end{array}$ & $\begin{array}{l}\text { Autossômica } \\
\text { dominante }\end{array}$ & $\begin{array}{l}\text { S. Kallmann ou } \\
\text { HHIn }\end{array}$ \\
\hline NELF & $9 q 34.3$ & $\begin{array}{c}\text { Fator LHRH } \\
\text { embriônico nasal }\end{array}$ & $\begin{array}{c}\text { Migração dos } \\
\text { neurônios de GnRH }\end{array}$ & $\begin{array}{l}\text { Autossômica } \\
\text { dominante? }\end{array}$ & S. Kallmann \\
\hline PROK2 & $3 p 21.1$ & Prokinecitina 2 & $\begin{array}{c}\text { Migração dos } \\
\text { neurônios de GnRH }\end{array}$ & $\begin{array}{l}\text { Autossômico } \\
\text { recessivo }\end{array}$ & $\begin{array}{l}\text { S. Kallmann ou } \\
\text { HHIn }\end{array}$ \\
\hline PROKR2 & 20p12.3 & $\begin{array}{l}\text { Receptor da } \\
\text { Prokinecitina } 2\end{array}$ & $\begin{array}{c}\text { Migração dos } \\
\text { neurônios de GnRH }\end{array}$ & $\begin{array}{l}\text { Autossômico } \\
\text { recessivo }\end{array}$ & $\begin{array}{l}\text { S. Kallmann ou } \\
\text { HHIn }\end{array}$ \\
\hline GNRHR & $4 q 13.2-3$ & Receptor de GnRH & Sinalização do GnRH & $\begin{array}{l}\text { Autossômico } \\
\text { recessivo }\end{array}$ & $\mathrm{HHIn}$ \\
\hline GNRH & $8 p 21$ & $\mathrm{GnRH}$ & Síntese de $\mathrm{GnRH}$ & $\begin{array}{l}\text { Autossômico } \\
\text { recessivo }\end{array}$ & $\mathrm{HHIn}$ \\
\hline KISS1R & $19 p 13.3$ & Receptor do KISS1 & Secreção de GnRH & $\begin{array}{l}\text { Autossômico } \\
\text { recessivo }\end{array}$ & $\mathrm{HHIn}$ \\
\hline TAC3 & $\begin{array}{c}12 q 13- \\
12\end{array}$ & Neurokinina B & Desconhecida & $\begin{array}{l}\text { Autossômico } \\
\text { recessivo }\end{array}$ & $\mathrm{HHIn}$ \\
\hline TACR3 & $4 q 25$ & $\begin{array}{l}\text { Receptor da } \\
\text { Neurokinina B }\end{array}$ & Desconhecida & $\begin{array}{l}\text { Autossômico } \\
\text { recessivo }\end{array}$ & $\mathrm{HHIn}$ \\
\hline CHD7 & $8 q 12.1$ & $\begin{array}{l}\text { Proteína de ligação } \\
\text { ao DNA do } \\
\text { cromodomínio } \\
\text { helicase } 7\end{array}$ & $\begin{array}{l}\text { Desenvolvimento do } \\
\text { neurônio de GnRH }\end{array}$ & $\begin{array}{l}\text { Autossômico } \\
\text { dominante }\end{array}$ & $\begin{array}{l}\text { S. CHARGE, S } \\
\text { Kallmann, HHIn }\end{array}$ \\
\hline
\end{tabular}

Outros genes causadores de hipogonadismo hipogonadotrófico associado a outras deficiências hormonais incluem fatores de transcrição hipofisária (HESX1, LHX3, PROP-1), receptores nucleares órfãos (DAX-1, associado com hipoplasia adrenal ligada ao $X$, e $S F-1$ ) e genes envolvidos no metabolismo energético (LEP, LEPR e PC-1) (57).

Outro estudo de associação com variantes gênicas e haplótipos dos genes GnRHR e $\mathrm{GnRH}$ em pacientes com atraso constitucional do desenvolvimento em uma coorte multiétnica do Havaí e Califórnia, com 
representantes de todas as faixas de puberdade, não confirmou o papel destes polimorfismos no atraso puberal (58). Além disso, a idade de menarca também foi analisada e não se correlacionou a polimorfismos nestes dois genes, em dois estudos independentes $(50,59)$.

A identificação de genes envolvidos no controle do princípio da puberdade representa uma etapa importante na compreensão dos mecanismos que iniciam a puberdade humana $(1,3)$. Entretanto, até o momento, são raríssimas as alterações estruturais em genes que afetam o eixo gonadotrófico causando PPC, ao contrário do que ocorre no hipogonadismo. Em 2008, Teles e cols. (60) identificaram uma mutação no gene GPR54 (p.R386P) que resulta em uma ativação não constitutiva do receptor, associada ao fenótipo de PPC em uma menina brasileira adotada. Estudos in vitro demonstraram que a mutação p.R386P, localizada na cauda carboxiterminal do GPR54, resulta em um atraso na dessensibilização do receptor (60) e, consequentemente, leva à ativação prolongada da via de sinalização intracelular em resposta à kisspeptina, que é sabidamente um potente ativador dos neurônios de GnRH $(61-69)$.

Silveira e cols. (70) identificaram uma nova mutação missense no gene KISS1, p.P74S, em heterozigose, em um menino que desenvolveu PPC idiopática no primeiro ano de vida, e o estudo funcional desta mutação mostrou que esta variante aumenta a resistência da kisspeptina à degradação (70).

No Laboratório de Hormônios e Genética Molecular LIM 42 já foram realizados outros estudos envolvendo o gene que codifica a subunidade alfa do receptor tipo A do ácido gama-amino butírico (GABRA1) e o receptor do NPY (NPYR1 e 5) que não revelaram mutações funcionais ou polimorfismos relacionados ao fenótipo de PPC $(71,72)$.

\subsection{4 - Puberdade precoce central causada por hamartoma hipotalâmico}

O hamartoma hipotalâmico é a causa orgânica mais frequente de PPC em ambos os sexos $(25,73)$, é uma malformação congênita não neoplásica 
rara, localizada no sistema nervoso central, que apresenta em sua constituição tecido hipotalâmico maduro em localização heterotópica $(74-76)$. Os hamartomas hipotalâmicos estão geralmente localizados na base do hipotálamo (túber cinéreo), adjacente a este ou inflitrando-o (74 - 76). Estas lesões nãoneoplásicas são constituídas de elementos neurais, incluindo neurônios produtores de $\mathrm{GnRH}$ presentes em alguns hamartomas hipotalâmicos ou astrócitos que expressam fatores de crescimento de transformação alfa (TGFa) e seu receptor erbB-1, envolvidos na mediação do controle regulatório exercido pelas células da glia na rede neuronal que leva à produção de $\mathrm{GnRH}$ $(76,77)$.

Os hamartomas hipotalâmicos podem ser assintomáticos (18\%) (74) ou apresentar manifestações clínicas endocrinológicas e/ou neurológicas. Puberdade precoce $\mathrm{GnRH}$-dependente, cujo início ocorre geralmente antes dos quatro anos de idade, é a manifestação endócrina presente em $50 \%$ dos casos (78). As manifestações neurológicas incluem epilepsia gelástica (79), caracterizada por crises de riso imotivado, e epilepsias focais e generalizadas. Transtornos cognitivos e de comportamento, como deficit de atenção, hiperatividade, alterações de memória podem estar associados (79) e relacionados à deterioração da condição epilética, uma vez que o tratamento cirúrgico, que resulta na cessação das convulsões, ocasiona a melhora dos aspectos comportamentais e cognitivos (78). Alterações cognitivas subclínicas devem ser avaliadas por exame neurológico e neurocognitivo adequados (80 82). Não está elucidado o mecanismo fisiopatológico pelo qual alguns hamartomas hipotalâmicos causam puberdade precoce sem manifestações neurológicas, ou por que outros hamartomas hipotalâmicos levam a manifestações neurológicas sem puberdade precoce e, finalmente, por que alguns levam às duas manifestações (83). A localização e o tamanho do hamartoma hipotalâmico parecem ter algum papel nessas manifestações clínicas. Hamartomas hipotalâmicos de maior volume e aqueles sésseis estão associados à presença de epilepsia (83). Supõe-se que o próprio hamartoma 
produza substâncias neurotóxicas responsáveis pela neuroexcitabilidade exacerbada. Para causar puberdade precoce é necessário o envolvimento da rede neuronal que atua na ativação do eixo gonadotrófico (83).

O diagnóstico do hamartoma hipotalâmico é confirmado pela ressonância magnética (RM) que indica lesão com isossinal em T1 e sem realce ao gadolíneo geralmente próximo ao túber cinéreo $(74,75)$.

Pouco se conhece sobre os mecanismos moleculares envolvidos na gênese dos hamartomas hipotalâmicos. Uma teoria é a de que os hamartomas hipotalâmicos se desenvolvem devido a defeitos leves do processo normal de desenvolvimento embrionário hipotalâmico. Evidência para esta teoria é a identificação de mutações no gene GL/3 em pacientes com síndrome de Pallister-Hall, cujo fenótipo inclui hamartomas hipotalâmicos associado a outras alterações (hipopituitarismo, polidactilia, unhas displásicas, epiglote bífida e ânus imperfurado) (76, 84 - 86).

Raramente existe indicação cirúrgica, exceto quando as crises convulsivas são intratáveis clinicamente (87). O tratamento da PPC é medicamentoso com análogos de $\mathrm{GnRH}$ e uma boa resposta clínica e laboratorial é relatada em diversos trabalhos $(73,88)$.

\section{3 - Hierarquia gênica que regula a secreção de GnRH}

Diversas vias neuronais e tipos celulares estão envolvidos no controle da puberdade $(3,89$ - 92). Esta complexa rede deve ser coordenada por uma hierarquia de genes regulatórios que atuam conectando bidirecionalmente células neuronais e gliais (93). Neste mecanismo proposto por Ojeda e cols. (94), alguns genes controladores, enhanced at puberty (EAP1) e thyroid transcription factor 1 (TTF-1), chamados de master genes, são hierarquicamente superiores e orquestram genes subordinados que são necessários para a interação neuronal e glial, como GnRH, KiSS1, e preproencefalinas, levando ao início puberal e à manutenção das funções reprodutivas (94). 
Utilizando técnicas de DNA microarray (94) e de expressão de RNA de hipotálamo médio basal (região sabidamente envolvida no controle da puberdade) e córtex cerebral de macacas Rhesus em três diferentes períodos do desenvolvimento (juvenil, puberdade inicial e meio de puberdade), foi constatado aumento da expressão de genes (master genes), dentre eles, C14ORF4 (EAP1) e TTF-1, no hipotálamo médio basal no início da puberdade e no período intermediário. No córtex não houve aumento da expressão destes genes. Estudos realizados em ratas confirmaram este resultado (94).

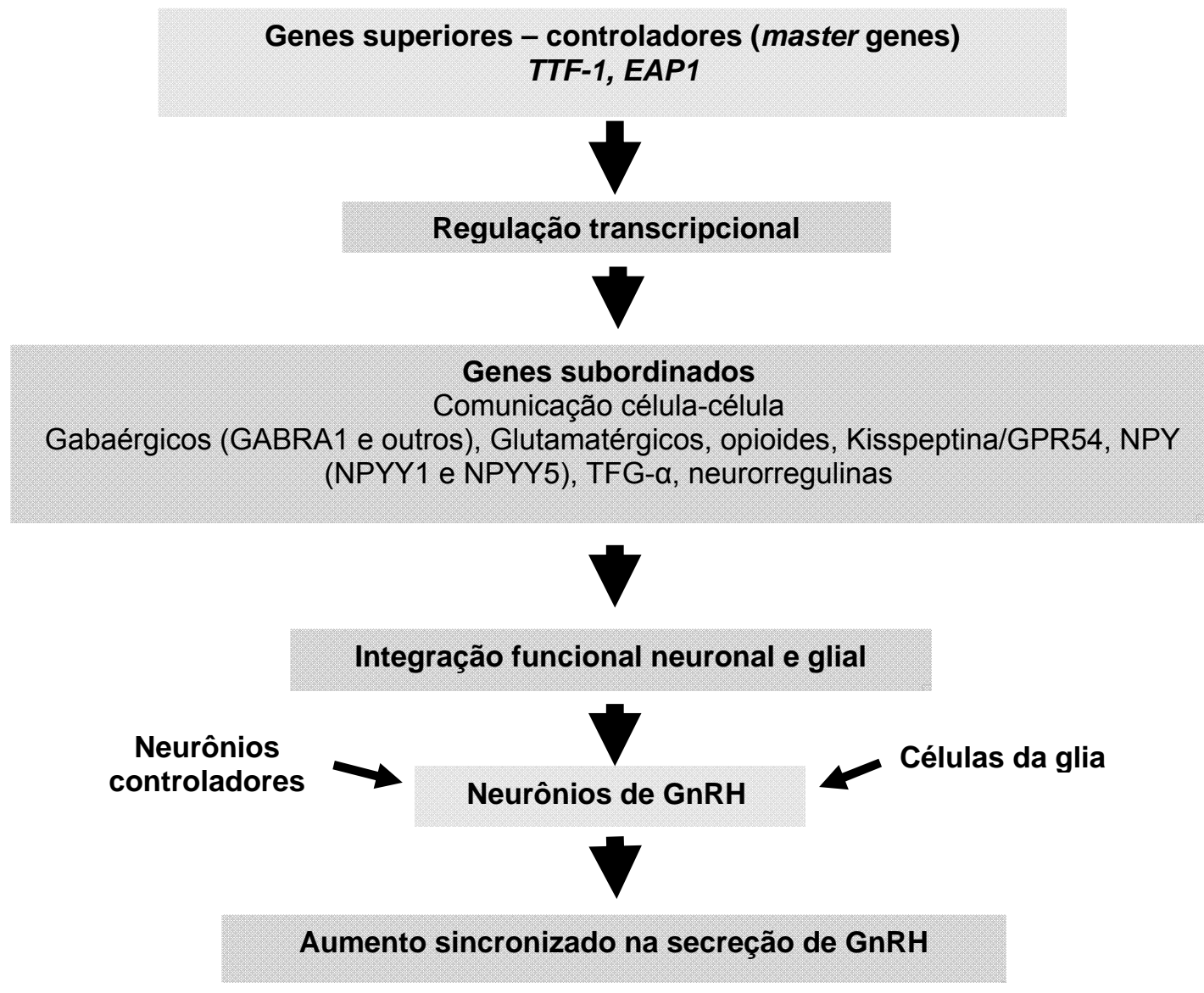

Figura 1. Hierarquia gênica da secreção de GnRH (94)

EAP1 e TTF-1 estão localizados no cromossomo 14 em uma região que pode ser afetada na dissomia uniparental materna deste cromossomo, resultando em uma síndrome com fenótipo complexo caracterizada por retardo 
de crescimento pré e pós-natal, hipotonia, flexibilidade articular, retardo de desenvolvimento, pés e mãos pequenos, obesidade e puberdade precoce ( 95 , 96).

\subsection{1 - TTF-1 e controle da secreção de GnRH}

TTF-1 está localizado no cromossomo 14q13, é composto de três exons e codifica dois transcritos de 2,2 kb e 2,3 kb que resultam em dois fatores de transcrição distintos de 401 e 371 aminoácidos, respectivamente $(97,98)$. O peptídeo mais ativo e abundante é a isoforma de 371 aa. As sequências de aminoácidos humano, de rato e de camundongo são $98 \%$ idênticas, sendo conservados os 60 aminoácidos que compõem a região do homeodomínio (97). A região codificadora é constituída pelos exons 2 e 3 . Uma região localizada no intron 1, localizada a -350 pb do ATG com $98 \%$ de homologia entre camundongo e humano, foi determinada como uma das regiões promotoras deste gene (99).

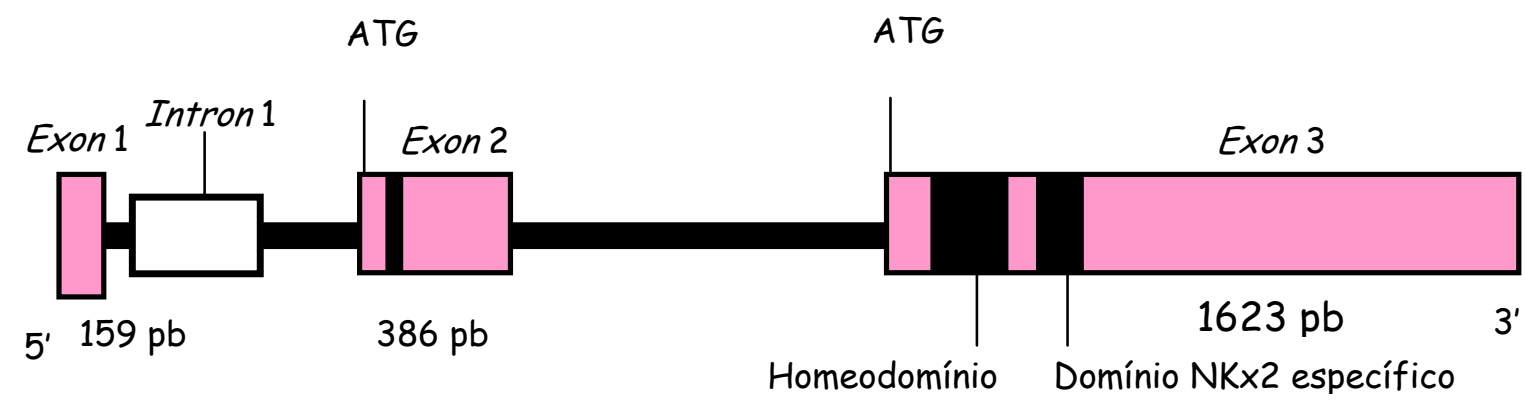

Figura 2. Representação esquemática do gene TTF-1

$3,8 \mathrm{kB}$

O TTF-1 é um fator de transcrição da família homeobox, expresso em tireoide, diencéfalo em desenvolvimento e pulmões. Mais especificamente TTF1 é encontrado em neurônios da área pré-optica que controla o eixo reprodutivo pela liberação de $\mathrm{GnRH}$ (100), em neurônios preproencefalinérgicos do núcleo ventromedial lateral $(100,101)$ que inibem transinapticamente a liberação de 
GnRH (102), em neurônios do núcleo arqueado e em células ependimogliais do terceiro ventrículo e da eminência média.

Recentemente, TTF-1 foi envolvido na regulação do eixo reprodutivo no sexo feminino (103). Um incremento de RNA mensageiro (RNAm) de TTF-1 no hipotálamo foi demonstrado, precedendo o início da puberdade (100). O modelo animal com ablação do TTF-1 é inviável pois é letal (104), porém a deleção hipotalâmica pós-natal do TTF-1 em camundongos, por meio da técnica de CrêloxP, resulta em puberdade atrasada, diminuição da capacidade reprodutiva e ausência de ciclos estrogênicos. Dados moleculares mostraram que estes animais apresentavam aumento de preproencefalinas e diminuição de valores de KiSS1 e GnRH $(100,102,103)$. A diminuição de kisspeptina se faz por ação direta do TTF-1 sobre regiões motif específicas no promotor de KiSS1 (103).

Estudos funcionais com o promotor do TTF-1 demonstraram que o estradiol em doses fisiológicas ou suprafisiológicas não altera a atividade do promotor do TTF-1, sugerindo que o incremento do TTF-1 hipotalâmico no início da puberdade seja um evento primariamente central (103).

Em humanos, foi encontrada a diminuição da expressão do TTF-1 em três pacientes com bócio e hipotireoidismo primário $(105,106)$. Mutações de ponto e deleção do TTF-1 (haploinsuficiência) foram encontradas em seis famílias com coreia familiar benigna, indicando defeitos nos gânglios da base (107 - 111). Deleção e mutações do TTF-1 foram também encontradas em crianças com tireoidopatias neonatais, insuficiência respiratória, hipotonia, coreoatetose e duplicação da haste hipofisária (104, 110 - 116). No entanto, nenhuma informação sobre o desenvolvimento puberal desses pacientes foi descrita.

Além do efeito regulatório do TTF-1 sobre a produção de $\mathrm{GnRH}$, sua participação na morfogênese diencefálica é também confirmada em estudos realizados em modelos animais. Camundongos com deleção do TTF-1 apresentam estruturas diencefálicas pouco desenvolvidas, ausência de 
desenvolvimento de neurônios colinérgicos do diencéfalo, falência de migração de neurônios GABAérgicos do globo pálido para o striatum e córtex cerebral e fusão do terceiro ventrículo $(103,117,118)$. Estas alterações sugerem que a perda do TTF-1 possa resultar em deficiências cognitivas devido à ausência dos neurônios colinérgicos (119) e em alterações comportamentais atribuídas à perda de neurônios GABAérgicos no córtex (120). É sugerido que a formação de hamartomas hipotalâmicos possa ocorrer devido a mutações somáticas esporádicas em genes necessários para a morfogênese, como o TTF-1 (121). Em humanos, nenhum estudo do TTF-1 foi realizado em pacientes com patologias do eixo reprodutivo de origem central, até o momento.

\subsection{2 - EAP1 e controle da secreção de GnRH}

EAP1 (enhanced at puberty), anteriormente conhecido como C14ORF4, é um gene sem intron localizado no cromossomo 14q24.3, que codifica um fator de transcrição que, por atuar no sistema neuroendócrino por meio de redes neuronais ainda não bem estabelecidas, torna-se necessário para o início da puberdade e manutenção da ciclicidade reprodutiva (122).

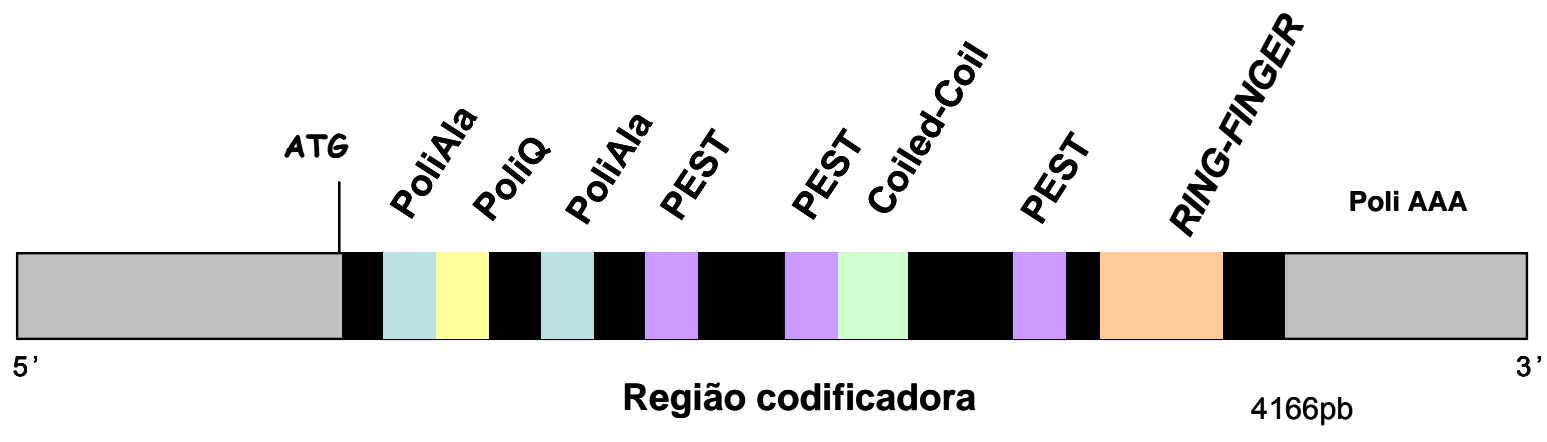

Cromossomo 14q24.3

Figura 3. Representação esquemática do gene EAP-1

Utilizando técnicas de hibridização in situ realizada em macacas Rhesus, elevados níveis de RNAm de EAP1 foram detectados em células dos núcleos 
hipotalâmicos envolvidos no controle da secreção de $\mathrm{GnRH}$ como o núcleo arqueado e a área medial pré-óptica do núcleo ventromedial (94).

Em cérebro de ratas de 28 dias de vida, EAP1 foi também expresso em núcleos de neurônios secretores de $\mathrm{GnRH}$, bem como em neurônios preproencefalinérgicos, primariamente inibitórios da secreção de $\mathrm{GnRH}$ (122). Utilizando microscopia confocal, seguida de deconvolução e reconstrução tridimensional, foi observado que o EAP1 localiza-se em áreas nucleares de cromatina não condensada, que são áreas transcricionalmente ativas, sugerindo envolvimento do EAP1 na regulação da expressão gênica, aumentando a expressão do $\mathrm{GnRH}$ e, concomitantemente, inibindo a de preproencefalina (122).

O EAP1 contém um domínio coiled-coil que indica regulação de expressão gênica e um domínio RING finger $\mathrm{C} 3 \mathrm{CH} 4$, localizado próximo à região $C$ terminal, o que pode sugerir ação do EAP1 na transcrição gênica pela interação com correpressores ou coativadores (figura 3).

Na sua estrutura, o EAP1 possui duas regiões polialanina (poliAla) e uma região intermediária poliglutamina (poliQ) (figura 3). Na sua forma selvagem (wild type), a região poliAla proximal é conservada e constituída de 15 alaninas, a região poliQ tem 25 repetições e a região poliAla subsequente possui 12 alaninas. Rampazzo e cols. (123) avaliaram o número de repetições de glutamina em 50 indivíduos italianos saudáveis e identificaram variação considerável, nesta região, de 20 a 31 repetições (123).

Estudos funcionais demonstraram que o EAP1 transativa o promotor do $\mathrm{GnRH}$, mas reprime o promotor da preproencefalina, indicando que a atividade transcricional do EAP1 ocorre por meio de promotores destes genes (122). Para este efeito é fundamental a conservação da sequência RING finger intacta, uma vez que tanto deleção desta região quanto substituição de um único aminoácido (troca da primeira cisteína por alanina) elimina esta atividade biológica (122).

Usando técnica de silenciamento de RNA e injetando o lentivírus com EAP sh1 na área pré-óptica de ratas, foi demonstrado que estas ratas 
apresentam início puberal atrasado em relação a ratas-controle. Os modelos animais com knock-down do EAP1 também tiveram alteração da ciclicidade estrogênica e episódios prolongados na fase de estrus, além da diminuição dos valores de LH, FSH e estradiol (122), demonstrando efeito fundamental do EAP1 no controle do eixo reprodutivo.

O RNAm de EAP1 hipotalâmico ou a atividade transcricional do gene EAP1 não sofre alteração por esteroides ovarianos, dado comprovado pelo incremento de EAP1 no início da puberdade em ratas ooforectomizadas e pela ausência de elementos responsivos ao estrógeno na região 5' ou 100 kb, próxima ao EAP1. Além disso, estudos funcionais mostraram que estradiol isolado ou associado a progesterona não levam ao aumento na transcrição do EAP1 (124).

Até o momento não há relatos científicos sobre anormalidades germinativas nos genes TTF-1 e EAP1 em humanos com distúrbios puberais centrais. 


\section{2 - Objetivos}




\section{2- OBJETIVOS}

1- Determinar a prevalência de casos familiais de puberdade precoce central e analisar o modo de herança e penetrância.

2- Pesquisar mutações germinativas no gene TTF-1 e em seu promotor em pacientes com distúrbios puberais centrais: puberdade precoce central idiopática e causada por hamartoma hipotalâmico e hipogonadismo hipogonadotrófico isolado normósmico.

3- Pesquisar mutações germinativas no gene EAP1 em pacientes portadores de distúrbios puberais centrais: puberdade precoce central idiopática e causada por hamartoma hipotalâmico e hipogonadismo hipogonadotrófico isolado normósmico.

4- Caracterizar as alterações neurológicas e neurocognitivas de pacientes com puberdade precoce central causada por hamartoma hipotalâmico. 


\section{3 - Pacientes e métodos}




\section{3 - PACIENTES E MÉTODOS}

Este estudo foi aprovado pela Comissão de Ética do Hospital das Clínicas da Faculdade de Medicina da Universidade de São Paulo (HCFMUSP/aprovação nº 983/06) e o consentimento pós-informação formal foi concedido pelos pacientes ou responsáveis.

\section{1 - Casuística}

Foram selecionados 133 pacientes portadores de distúrbios puberais centrais: 71 com PPC idiopática, 15 com PPC devido a hamartoma hipotalâmico e $47 \mathrm{com} \mathrm{HHIn}$. Os pacientes com puberdade precoce foram selecionados no Ambulatório de Endocrinologia do Desenvolvimento do Hospital das Clínicas da Faculdade de Medicina da Universidade de São Paulo (HC-FMUSP), além de alguns casos isolados provenientes de outros serviços (Santa Casa de São Paulo, Governador Valadares, Chile, Argentina, Estados Unidos e Bélgica). Os pacientes hipogonádicos foram selecionados dos Serviços de Endocrinologia do Hospital das Clínicas da Universidade de São Paulo, em São Paulo ou Ribeirão Preto, e do Hospital das Clínicas da Universidade Estadual de Campinas (UNICAMP). Um grupo controle foi composto por 53 indivíduos adultos, de ambos os sexos, que não apresentaram anormalidades no desenvolvimento puberal.

Os critérios clínicos e laboratoriais considerados para inclusão dos pacientes com PPC no presente estudo foram: início dos caracteres sexuais secundários antes dos 8 anos nas meninas e dos 9 anos nos meninos, concentrações de LH puberais em condição basal e/ou após estímulo com GnRH exógeno, ressonância magnética do SNC sem anormalidades na forma idiopática ou com imagem sugestiva de hamartoma hipotalâmico e resposta terapêutica satisfatória ao tratamento com análogos de $\mathrm{GnRH}$ de ação prolongada (depot). Dos 71 pacientes com PPC idiopática, 67 (94\%) eram do sexo feminino e $4(6 \%)$, do sexo masculino. Cinquenta e quatro dos 71 
pacientes apresentavam a forma esporádica e 18 pacientes, pertencentes a 14 famílias, apresentavam a forma familial de PPC, totalizando $25 \%$ de casos familiares. A idade cronológica (IC) média do início do aparecimento dos caracteres sexuais secundários foi 5,4 anos $\pm 1,9$ ano $(0-8,4$ anos), e a IC média da primeira consulta foi 7,3 anos $\pm 2,3$ anos (1,4 ano $-10,25$ anos). 0 estádio de desenvolvimento mamário variou de 2 a 5 e o estádio dos pelos pubianos variou de 1 a 5 , de acordo com os critérios de Marshall \& Tanner (125, 126). Os quatro pacientes do sexo masculino apresentavam testículos maiores que $2,5 \mathrm{~cm}$ ao diagnóstico. A idade óssea (IO) média foi 10 anos $\pm 2,2$ anos (2 anos - 13,5 anos), segundo os critérios de Greulich \& Pyle (127). Os pacientes apresentavam em média um avanço de $\mathrm{IO}$ de 2,7 anos em relação à IC. A tabela 2 resume os achados clínicos dos pacientes com PPC. 
Pacientes e Métodos

\begin{tabular}{|c|c|c|c|c|c|c|c|c|c|c|c|c|c|c|c|c|}
\hline \multirow{2}{*}{ Caso } & \multirow{2}{*}{$\begin{array}{c}\text { IC início } \\
\text { puberdade } \\
\text { (anos) }\end{array}$} & \multirow{2}{*}{ Sexo } & \multirow{2}{*}{$\begin{array}{c}\text { IC início } \\
\text { tratamento } \\
\text { (anos) }\end{array}$} & \multirow{2}{*}{$\underset{(\mathrm{cm})}{\mathrm{E}}$} & \multirow{2}{*}{$\begin{array}{c}\text { DP } \\
\text { alt//C }\end{array}$} & \multirow{2}{*}{ Peso (kg) } & \multirow{2}{*}{$\begin{array}{c}\text { DP } \\
\text { peso/alt }\end{array}$} & \multirow{2}{*}{$\begin{array}{c}10 \\
\text { (anos) }\end{array}$} & \multirow{2}{*}{$\mathrm{EA}(\mathrm{cm})$} & \multirow{2}{*}{ Estádio puberal } & \multicolumn{2}{|c|}{ LH (U/L) } & \multicolumn{2}{|c|}{ FSH (U/L) } & \multirow{2}{*}{$\begin{array}{c}\mathrm{E2} \\
(\mathrm{pg} / \mathrm{mL})\end{array}$} & \multirow{2}{*}{$\stackrel{{ }_{(n g / d L}}{\top}$} \\
\hline & & & & & & & & & & & Basal & Pico & Basal & Pico & & \\
\hline $1 \mathrm{~F} 1 \S$ & 5,8 & $\mathrm{~F}$ & 6,6 & 129,5 & 2,46 & 30 & 0,53 & 11 & 166 & M4PP2 & 1,9 & 31,5 & 6,2 & 12,6 & 53,3 & NA \\
\hline $2 \mathrm{~F} 1 \S$ & 5 & $\mathrm{~F}$ & 8,25 & 140 & 1,9 & 39,2 & 0,7 & 11 & 158,5 & M4PP1 & 1,7 & $34,1 \#$ & 3,9 & ND & 34,6 & NA \\
\hline $3 \mathrm{~F} 1 \S$ & 4,5 & $\mathrm{~F}$ & 6,9 & 129 & 1,97 & 26,3 & $-0,1$ & 7,8 & 158,5 & M3PP1 & $<0,6$ & 11,4 & 1,6 & 12,7 & $<13$ & NA \\
\hline $4 \mathrm{~F} 1 \S$ & 5 & $\mathrm{~F}$ & 6,8 & 127,2 & 1,6 & 28 & 0,34 & 10 & 166,5 & M4PP3 & 1,6 & $23,5 \#$ & 4,7 & ND & 29 & NA \\
\hline $5 \mathrm{~F} 2 \S$ & 6 & $\mathrm{~F}$ & 6,5 & 123,1 & 1,2 & 28 & 0,98 & 7,8 & 158 & M2PP2 & 0,8 & ND & 3,1 & ND & $<20$ & NA \\
\hline $6 \mathrm{~F} 3 \S$ & 7 & $\mathrm{~F}$ & 8 & 135 & 1,7 & 25,5 & $-0,78$ & 11 & 153 & M3PP1 & 0,4 & 9,9 & 3,4 & ND & 38 & NA \\
\hline $7 \mathrm{~F} 4 \S$ & 7,75 & $\mathrm{~F}$ & 8,25 & 133,2 & 1,08 & 28,6 & $-0,11$ & 11 & 167 & M3PP3 & $<0,6$ & $17,6 \#$ & 4,2 & ND & 31 & NA \\
\hline $8 \mathrm{~F} 5 \S$ & 5,5 & $\mathrm{~F}$ & 8,2 & 132 & 1,21 & 28,2 & $-0,1$ & 11 & 160,5 & M3PP4 & 1 & $8,8 \#$ & 1,9 & $\mathrm{ND}$ & 17,4 & NA \\
\hline $9 \mathrm{~F} 6 \S$ & 5,75 & $\mathrm{~F}$ & 5,75 & 116 & 0,94 & 22 & 0,16 & 6 & 149 & M2PP3 & $<0,6$ & 37,37 & 1,13 & 17,92 & 11,01 & NA \\
\hline $10 \mathrm{~F} 7 \S$ & 6,2 & $\mathrm{~F}$ & 6,5 & 127 & 1,9 & $\mathrm{ND}$ & $\mathrm{ND}$ & 7,1 & 165,4 & M2PP1 & $<0,6$ & 7,3 & 7 & 19,2 & 6,2 & NA \\
\hline $11 \mathrm{~F} 8 \S$ & 4,5 & $\mathrm{~F}$ & 10,25 & 131,7 & $-0,1$ & 37 & 1,62 & 11 & 153 & M4PP5 & 4,2 & ND & 2,6 & ND & 98,8 & NA \\
\hline $12 \mathrm{~F} 8 \S$ & 6,8 & $\mathrm{~F}$ & 9,8 & 141,4 & 0,7 & 34,8 & 0,03 & 11 & 153 & M3PP4 & 2,2 & $\mathrm{ND}$ & 4,6 & ND & $<13$ & NA \\
\hline $13 \mathrm{~F} 9 \S$ & 7,3 & $F$ & 8 & 148,5 & 4 & 42,2 & 0,28 & 11 & 171,5 & M3PP3 & 1,5 & $45,8 \#$ & 2,7 & ND & $<13$ & NA \\
\hline $14 \mathrm{~F} 10 \S$ & 6,75 & $\mathrm{~F}$ & 7,3 & 133,2 & 2,18 & 33,8 & 0,77 & 8,8 & 155,6 & M4PP2 & 0,6 & 16,91 & 3,7 & ND & 20,9 & NA \\
\hline $15 \mathrm{~F} 11 \S$ & 6 & $M$ & 8,1 & 131 & 0,83 & 30,5 & 1 & 8,9 & 167 & G2PP1 & 1,18 & $14,1 \#$ & 1,53 & ND & NA & 116 \\
\hline $16 \mathrm{~F} 12 \S$ & 5,5 & $\mathrm{~F}$ & 7,6 & 131,8 & 1,7 & 28 & 0 & 7,8 & 169,5 & M3PP1 & $<0,6$ & $\mathrm{ND}$ & 1,5 & ND & $<13$ & NA \\
\hline $17 \mathrm{~F} 13 \S$ & 6,9 & $\mathrm{~F}$ & 6,9 & 125,2 & 1,27 & 26,8 & 0,45 & 7,9 & ND & M3PP1 & 3,5 & 35 & 5,2 & 22 & $<13$ & NA \\
\hline $18 \mathrm{~F} 14 \S$ & 3 & $\mathrm{~F}$ & 6,5 & 136 & 3,96 & 30,4 & $-0,1$ & 8,8 & 169,5 & M4PP3 & $<0,6$ & $9,8 \#$ & 3,7 & 10,5 & $<13$ & NA \\
\hline 19 & 6 & $\mathrm{~F}$ & 7,3 & 129,5 & 1,3 & 38,2 & 2,17 & 9 & 158 & M3PP3 & $<0,6$ & 8,1 & ND & 13 & $<13$ & NA \\
\hline 20 & 4 & $\mathrm{~F}$ & 5,25 & 116,5 & 1,25 & 19,6 & $-0,6$ & 6,8 & 158,5 & M3PP1 & $<0,6$ & 16,9 & 2 & 20,4 & $<13$ & NA \\
\hline 21 & 6,2 & $\mathrm{~F}$ & 8,7 & 141,5 & 2,1 & 33,2 & $-0,1$ & 12 & 154 & M4PP4 & 1,2 & $\mathrm{ND}$ & $\mathrm{ND}$ & ND & 19,8 & NA \\
\hline 22 & 0 & $\mathrm{~F}$ & 2,66 & 100,5 & 2,8 & 18,3 & 1 & 6,8 & 168,75 & M3PP1 & 3 & 41 & 4,4 & ND & $\mathrm{ND}$ & NA \\
\hline 23 & 0,75 & $\mathrm{~F}$ & 1,66 & 83 & 0 & 12,4 & 0,5 & 2 & 144,5 & M4PP3 & 1,1 & 21 & 4,3 & ND & 60,4 & NA \\
\hline 24 & 3,2 & $\mathrm{~F}$ & 3,4 & 106 & 2,26 & 19,1 & 0,5 & 7,5 & 149 & M4PP1 & 5 & 89,7 & 9,8 & $\mathrm{ND}$ & $<13$ & NA \\
\hline
\end{tabular}

F: família; IC: idade cronológica; E: estatura; IO: idade óssea; DP: desvio-padrão de estatura e do peso; G: genitália (estádio, segundo critérios de Tanner); PP: pelos pubianos (estádio, segundo critérios de Tanner); EA: estatura alvo; E2: estradiol, T: testosterona, M: mamas (estádio, segundo critérios de Tanner); ND: não disponível; NA: não aplicável; Exames realizados por IFMA; \# LH 2 horas pós acetato de leuprolide depot; § casos familiares 
Pacientes e Métodos

\begin{tabular}{|c|c|c|c|c|c|c|c|c|c|c|c|c|c|c|c|c|}
\hline \multirow{2}{*}{ Caso } & \multirow{2}{*}{$\begin{array}{l}\text { IC início } \\
\text { puberdade } \\
\text { (anos) }\end{array}$} & \multirow{2}{*}{ Sexo } & \multirow{2}{*}{$\begin{array}{c}\text { IC início } \\
\text { tratamento } \\
\text { (anos) }\end{array}$} & \multirow{2}{*}{$\begin{array}{c}E \\
(\mathbf{c m})\end{array}$} & \multirow{2}{*}{$\begin{array}{l}\text { DP } \\
\text { alt/IC }\end{array}$} & \multirow{2}{*}{ Peso (kg) } & \multirow{2}{*}{$\begin{array}{c}\text { DP } \\
\text { pesolalt }\end{array}$} & \multirow{2}{*}{$\begin{array}{c}10 \\
\text { (anos) }\end{array}$} & \multirow{2}{*}{$\mathrm{EA}(\mathrm{cm})$} & \multirow{2}{*}{ Estádio puberal } & \multicolumn{2}{|c|}{ LH (U/L) } & \multicolumn{2}{|c|}{ FSH (U/L) } & \multirow{2}{*}{$\begin{array}{c}E 2 \\
(p g / m L)\end{array}$} & \multirow{2}{*}{$\begin{array}{c}\mathrm{T} \\
\text { (ng/dL) }\end{array}$} \\
\hline & & & & & & & & & & & Basal & Pico & Basal & Pico & & \\
\hline 25 & 6,2 & $\mathrm{~F}$ & 6,6 & 124 & 1,2 & 25,7 & 0,25 & 10 & ND & M2PP1 & 0,7 & 7,5 & ND & ND & 45 & NA \\
\hline 26 & 4 & $\mathrm{~F}$ & 7,25 & 136,4 & 3,13 & 37,7 & 0,99 & 11 & 155,5 & M3PP2 & 0,9 & ND & ND & ND & $<13$ & NA \\
\hline 27 & 2 & $\mathrm{~F}$ & 4,75 & 118,8 & 3,3 & 24,7 & 0,76 & 8,8 & 160 & M4PP1 & 0,7 & 18,8 & 1,5 & 10,1 & 19,1 & NA \\
\hline 28 & 6,16 & $\mathrm{~F}$ & 7,9 & 133,5 & 1,47 & 30,6 & 0,22 & 9 & adotada & M2PP2 & $<0,6$ & 9,5 & 5,5 & 24 & 7 & NA \\
\hline 29 & 5 & $\mathrm{~F}$ & 9,8 & 135 & 0,25 & 39,3 & 1,38 & 12 & 153,5 & M4PP3 & $<0,6$ & 13,2 & 1,7 & ND & $<13$ & NA \\
\hline 30 & 6 & $\mathrm{~F}$ & 8 & 142,9 & 3 & 34,3 & $-0,1$ & 10 & 161,5 & M4PP4 & 1 & 12 & 5,9 & 18 & 15 & NA \\
\hline 31 & 6,8 & $\mathrm{~F}$ & 7,66 & 128,4 & 0,9 & 38,8 & 2,4 & 7,8 & 156,5 & M3PP2 & 1,4 & 20 & 2 & 7,5 & $<13$ & NA \\
\hline 32 & 6,8 & $\mathrm{~F}$ & 7,8 & 125,5 & 0,24 & 27,9 & 2,4 & 8,8 & 153,5 & M3PP3 & $2,8^{*}$ & $41^{*}$ & $4,5^{*}$ & ND & $<13$ & NA \\
\hline 33 & 4 & $\mathrm{~F}$ & 6,8 & 136 & 3,22 & 31,3 & 0,03 & 9,5 & 153 & M4PP3 & 6,1 & ND & 4,7 & ND & 62 & NA \\
\hline 34 & 2 & $\mathrm{~F}$ & 7,58 & 140,3 & 3,23 & 34,4 & 0,09 & 12 & 161,5 & M2PP3 & 2,6 & 9,8 & 6 & 11 & 21 & NA \\
\hline 35 & 2 & $\mathrm{~F}$ & 4,8 & 115 & 2,4 & 23,3 & 0,7 & 8 & ND & M3PP1 & $3,8^{*}$ & $28,8^{*}$ & $16,3^{*}$ & ND & $23^{*}$ & NA \\
\hline 36 & 4 & $\mathrm{~F}$ & 8,58 & 131,5 & 0,63 & 26,7 & $-0,2$ & 11 & adotada & M4PP2 & 0,6 & 6,4 & 1 & 16,9 & 22 & NA \\
\hline 37 & 2 & $\mathrm{M}$ & 5,1 & 129 & 4,36 & 27,9 & 0,66 & 13 & 178,5 & G2PP4 & 1,1 & $17,7 \#$ & 1,1 & ND & NA & 92 \\
\hline 38 & 1 & $M$ & 1,4 & 85 & 0,5 & 14,3 & 1,55 & 2,6 & 165 & G2PP2 & $11,5^{*}$ & $47,2^{*}$ & $8,3^{*}$ & $4,1^{*}$ & NA & 600 \\
\hline 39 & 7 & $\mathrm{~F}$ & 8,4 & 133 & 0,88 & 30,5 & 0,2 & 11 & 157 & M3PP2 & 0,7 & $2,3 \#$ & $<1,0$ & ND & 13 & NA \\
\hline 40 & 4 & $\mathrm{~F}$ & 7,1 & 128,7 & 1,78 & 31,3 & 0,93 & 11 & 155,5 & M3PP2 & $<0,6$ & $4,2 \#$ & $<1,0$ & ND & $<13$ & NA \\
\hline 41 & 6 & $\mathrm{~F}$ & 8,75 & 157,2 & 1,86 & 39,7 & $-0,81$ & 12 & 157,2 & M5PP4 & 1,5 & 13,5 & 5,9 & 10,7 & 62,2 & NA \\
\hline 42 & 6 & $\mathrm{~F}$ & 8 & ND & ND & ND & ND & 11 & 162,6 & M2PP2 & 1 & ND & 1,3 & ND & 20 & NA \\
\hline 43 & 6 & $\mathrm{~F}$ & 8,25 & 128,6 & 0,14 & 30,7 & 0,8 & 12 & 152,25 & M3PP2 & $<0,6$ & $5,3 \#$ & 2,7 & ND & 13,4 & NA \\
\hline 44 & 4,9 & $\mathrm{~F}$ & 5 & 115,2 & 1,7 & 20,7 & $-0,13$ & 6 & 161,8 & M2PP1 & $<0,6$ & 7,8 & 2,1 & 13 & $<13$ & NA \\
\hline 45 & 7 & $\mathrm{~F}$ & 8 & 136 & 2 & 35 & 0,58 & 12 & 157,5 & M4PP3 & 1,2 & $50,4 \#$ & 4,1 & ND & 20,5 & NA \\
\hline 46 & 7 & $\mathrm{~F}$ & 8,75 & 135,4 & 0,95 & 32,6 & 0,32 & 11 & 154,5 & M3PP3 & 1,2 & 19 & 1,8 & 5,4 & 13,1 & NA \\
\hline 47 & 7 & $\mathrm{~F}$ & 8,9 & 135,3 & 0,78 & 29 & $-0,2$ & 11 & 155,5 & M3PP4 & $<0,6$ & 8 & 2 & ND & 40 & NA \\
\hline 48 & 2,8 & $\mathrm{~F}$ & 4,25 & 106,6 & 1,16 & 19,5 & 0,7 & 6,8 & 158 & M4PP1 & 0,6 & 13,5 & 4,2 & ND & 18,2 & NA \\
\hline
\end{tabular}

IC: idade cronológica; E: estatura; IO: idade óssea; DP: desvio-padrão de estatura e do peso; G: genitália (estádio, segundo critérios de Tanner); PP: pelos pubianos (estádio, segundo critérios de Tanner); EA: estatura alvo; E2: estradiol, T: testosterona, M: mamas (estádio, segundo critérios de Tanner); ND: não disponível; NA: não aplicável; *Exames realizados por radioimunoensaio (RIE). Os demais exames foram realizados por IFMA; \# LH 2 horas pós acetato de leuprolide depot

Continua.... 
Pacientes e Métodos

\section{Tabela 2 (continuação) - Dados clínicos e hormonais dos pacientes com PPC idiopática}

\begin{tabular}{|c|c|c|c|c|c|c|c|c|c|c|c|c|c|c|c|c|}
\hline \multirow{2}{*}{$\begin{array}{c}\text { Cas } \\
\text { o }\end{array}$} & \multirow{2}{*}{$\begin{array}{c}\text { IC início } \\
\text { puberdade } \\
\text { (anos) }\end{array}$} & \multirow{2}{*}{$\begin{array}{c}\text { Sex } \\
\text { o }\end{array}$} & \multirow{2}{*}{$\begin{array}{c}\text { IC início } \\
\text { tratament } \\
\text { o } \\
\text { (anos) } \\
\end{array}$} & \multirow{2}{*}{$\begin{array}{c}E \\
(\mathbf{c m})\end{array}$} & \multirow{2}{*}{$\begin{array}{c}\text { DP } \\
\text { alt/IC }\end{array}$} & \multirow{2}{*}{ Peso (kg) } & \multirow{2}{*}{$\begin{array}{c}\text { DP } \\
\text { pesolalt }\end{array}$} & \multirow{2}{*}{$\begin{array}{c}10 \\
\text { (anos) }\end{array}$} & \multirow{2}{*}{$\mathrm{EA}(\mathrm{cm})$} & \multirow{2}{*}{$\begin{array}{l}\text { Estádio } \\
\text { puberal }\end{array}$} & \multicolumn{2}{|c|}{ LH (U/L) } & \multicolumn{2}{|c|}{ FSH (U/L) } & \multirow{2}{*}{$\begin{array}{c}E 2 \\
(p g / m L)\end{array}$} & \multirow{2}{*}{$\begin{array}{c}\mathrm{T} \\
\text { (ng/dL) }\end{array}$} \\
\hline & & & & & & & & & & & Basal & Pico & Basal & Pico & & \\
\hline 49 & 6 & $\mathrm{~F}$ & 9,8 & 129 & -1 & 27 & 0,04 & 11 & 147 & M4PP3 & 0,8 & ND & 3,5 & ND & 22,2 & NA \\
\hline 50 & 7,5 & $\mathrm{~F}$ & 8,5 & 141,8 & 2,38 & 42 & 0,93 & 12 & Adotada & М3РP3 & 1,1 & 10,3 & 5,6 & ND & 35 & NA \\
\hline 51 & 6,8 & $\mathrm{~F}$ & 8,25 & 139 & 2,26 & 38,3 & 0,7 & 11,5 & 158,5 & M4PP3 & 1,5 & ND & 5,6 & ND & 46,3 & NA \\
\hline 52 & 6,8 & $\mathrm{~F}$ & 7,5 & 129,5 & 1,3 & 30,8 & 0,7 & 8,8 & 157,3 & М3РP1 & 1,2 & 27,6 & 3,9 & ND & 15 & NA \\
\hline 53 & 5 & $\mathrm{~F}$ & 7,66 & 135,1 & 2,1 & 27 & $-0,54$ & 11,5 & 148,5 & M4PP1 & 1,6 & 29,4 & 2,8 & ND & 26,8 & NA \\
\hline 54 & 6 & $\mathrm{~F}$ & 7,8 & 143,5 & 3,4 & 31,1 & $-0,57$ & 11 & 168 & М3РP3 & $<0,6$ & 6,9 & 1,2 & ND & $<13$ & NA \\
\hline 55 & 8 & $\mathrm{M}$ & 8 & 150 & 4,3 & 43,2 & 0,19 & 13,5 & 166 & G2PP4 & 1,7 & ND & 1,8 & ND & NA & 312 \\
\hline 56 & 6 & $\mathrm{~F}$ & 6,75 & 120,9 & 0,5 & 27,1 & 1,17 & 7,8 & 156,5 & М3РP2 & 1,6 & ND & 4,6 & ND & ND & NA \\
\hline 57 & 7 & $\mathrm{~F}$ & 9,75 & 135 & 0 & 28,9 & $-0,25$ & 11 & 160 & M4PP3 & 3,7 & ND & 3,6 & ND & 16 & NA \\
\hline 58 & 6 & $\mathrm{~F}$ & 8,25 & 142,6 & 2,69 & 36,5 & 0,15 & 11 & 174,5 & M3РP3 & $<0,6$ & 2,1 & 1,2 & ND & $<13$ & NA \\
\hline 59 & 5 & $\mathrm{~F}$ & 9,1 & 143,2 & 1,92 & 39,6 & 0,42 & 12 & 170,5 & M3PP3 & 0,9 & $27,8 \#$ & 4,1 & ND & 22 & NA \\
\hline 60 & 6 & $\mathrm{~F}$ & 8,5 & 141 & 10,8 & 30 & $-0,56$ & 10 & 158,2 & M4PP3 & $<0,6$ & 24 & 3 & ND & $<15$ & NA \\
\hline 61 & 6 & $\mathrm{~F}$ & 7,58 & 130 & 1 & 30,7 & 0,58 & 11 & 149 & M3PP2 & $<0,6$ & 3,1 & $<1,0$ & ND & 14,4 & NA \\
\hline 62 & 7,6 & $\mathrm{~F}$ & 7,75 & 132,2 & 1,42 & 33,6 & 0,85 & 8,8 & 163,5 & M3PP2 & 1 & ND & 5,3 & ND & 69,9 & NA \\
\hline 63 & 3 & $\mathrm{~F}$ & 7,5 & 133,3 & 2 & 33,3 & 0,68 & 11,5 & 160,5 & M2PP1 & $<0,6$ & $8,6 \#$ & 1,4 & ND & $<13$ & NA \\
\hline 64 & 8 & $\mathrm{~F}$ & 9,4 & 131,6 & $-0,7$ & 30 & 0,33 & 11 & 149,2 & M3РP1 & $<0,6$ & $16,3 \#$ & 2,1 & ND & $<13$ & NA \\
\hline 65 & 7 & $\mathrm{~F}$ & 9,1 & 142,5 & 1,8 & 43,6 & 1 & 11 & 163,2 & M4PP3 & 0,7 & $9,7 \#$ & 3,6 & ND & 30 & NA \\
\hline 66 & 3 & $\mathrm{~F}$ & 3,3 & 106 & 2,9 & 21,2 & 1,47 & ND & 148 & М3РP1 & 3,5 & ND & 7,4 & ND & 25 & NA \\
\hline 67 & 8,4 & $\mathrm{~F}$ & 9,4 & 146,7 & 2,1 & 51,5 & 1,4 & 12 & 155,5 & M4PP5 & 5,4 & ND & 4,4 & ND & 53,4 & NA \\
\hline 68 & 7,5 & $\mathrm{~F}$ & 8,2 & 137,5 & 2,17 & 34,5 & 5 & 12 & 159 & М3РP3 & 0,7 & 7,5 & 3,5 & 5,2 & 45 & NA \\
\hline 69 & 7,3 & $\mathrm{~F}$ & 7,9 & 142 & 3,14 & 31,6 & $-0,4$ & 11 & 167,5 & М3РP3 & 2 & ND & 6,8 & ND & 13 & NA \\
\hline 70 & 6 & $\mathrm{~F}$ & 8,3 & 140,3 & 2,29 & 28 & $-0,7$ & 11 & 161 & M2PP3 & $<0.6$ & 11,3 & 1,4 & ND & $<13$ & NA \\
\hline 71 & 7 & $\mathrm{~F}$ & 7,8 & 138,5 & 2,52 & 41,1 & 1,25 & 11 & 166,5 & М3РP3 & 1,2 & $17,9 \#$ & 3,4 & ND & 35,2 & NA \\
\hline
\end{tabular}

IC: idade cronológica; E: estatura; IO: idade óssea; DP: desvio-padrão de estatura e do peso; G: genitália (estádio, segundo critérios de Tanner); PP: pelos pubianos

(estádio, segundo critérios de Tanner); EA: estatura alvo; E2: estradiol, T: testosterona, M: mamas (estádio, segundo critérios de Tanner); ND: não disponível; NA:

não aplicável; Exames realizados por IFMA; \# LH 2 horas pós acetato de leuprolide depot 
Dos 15 pacientes com PPC devido a hamartoma hipotalâmico, 7 eram do sexo feminino e 8 , do sexo masculino. A idade cronológica (IC) média do início do aparecimento dos caracteres sexuais secundários foi 1,6 ano $\pm 1,8$ ano $(0,4$ ano - 7 anos), e a IC média da primeira consulta foi 3,1 anos $\pm 2,6$ anos $(0,75$ ano - 8,25 anos). O estádio de desenvolvimento mamário variou de 2 a 5 e o estádio dos pelos pubianos variou de 1 a 5 , de acordo com os critérios de Marshall \& Tanner $(125,126)$. Todos os meninos apresentavam genitália estádio 2 a 4 . A idade óssea (IO) média foi 5,6 anos $\pm 4,1$ anos $(0,75$ ano -14 anos), segundo os critérios de Greulich \& Pyle (127). Os pacientes apresentavam em média um avanço de IO de 2,4 anos em relação à IC. Estes dados estão na tabela 3. 
Tabela 3 - Dados clínicos e hormonais dos pacientes com PPC devido a hamartoma hipotalâmico

\begin{tabular}{|c|c|c|c|c|c|c|c|c|c|c|c|c|c|c|c|c|}
\hline Caso & $\begin{array}{l}\text { IC início } \\
\text { puberdade } \\
\text { (anos) }\end{array}$ & Sexo & $\begin{array}{l}\text { IC início } \\
\text { tratamento } \\
\text { (anos) }\end{array}$ & $\begin{array}{c}E \\
(\mathrm{~cm})\end{array}$ & $\begin{array}{c}\text { DP } \\
\text { Alt/IC }\end{array}$ & Peso (kg) & $\begin{array}{c}\text { DP } \\
\text { pesolalt }\end{array}$ & $\begin{array}{c}10 \\
\text { (anos) }\end{array}$ & $\mathrm{EA}(\mathrm{cm})$ & Estádio puberal & $\begin{array}{l}\text { LH } \\
\text { Basal }\end{array}$ & /L) & $\begin{array}{r}\text { FS } \\
\text { Basal }\end{array}$ & L) & $\begin{array}{c}E 2 \\
(\mathrm{pg} / \mathrm{mL})\end{array}$ & $\begin{array}{c}\mathrm{T} \\
\text { (ng/dL) }\end{array}$ \\
\hline 1 & 0,41 & $\mathrm{~F}$ & 0,91 & 77 & 0,7 & 10,7 & 0,25 & 1 & 157 & M1PP1 & 0,6 & 52 * & 0,8 & ND & $<10$ & NA \\
\hline 2 & 0,75 & $\mathrm{~F}$ & 1,83 & 95,5 & 3,21 & 16,8 & 1,1 & 6,8 & 164 & M4PP3 & 1,7 & 23,4 & 2,4 & 8 & 15 & NA \\
\hline 3 & 0,41 & $\mathrm{~F}$ & 1,08 & 77 & 0,7 & 10,5 & 0 & 2 & 156,7 & M2PP1 & 1,4 & 23,3 & 5,5 & 12,7 & 11 & NA \\
\hline 4 & 0,5 & $\mathrm{~F}$ & 3 & 106 & 3,39 & 22,1 & 1,87 & 8,8 & ND & M4PP1 & 9,5 & 25,4 & 6,6 & 25,4 & $<13$ & NA \\
\hline 6 & 0,5 & $\mathrm{~F}$ & 2,6 & 106 & 4,7 & 21,2 & 1,4 & 6 & 156 & M3PP2 & $12^{*}$ & $59^{*}$ & $8^{*}$ & $16^{*}$ & 40 & NA \\
\hline 7 & 7 & $\mathrm{~F}$ & 8,1 & 138 & 2,43 & 44 & 1,6 & 11 & 158,5 & M3PP3 & 4,3 & 15 & 8,3 & 10,3 & 59,8 & NA \\
\hline 8 & 2 & M & 3 & 95 & 0,27 & 13,7 & $-0,3$ & 2,6 & 175 & G2PP2 & $<0,6$ & 13 & $<1,0$ & 3,8 & NA & 34 \\
\hline 9 & 0,6 & $M$ & 2,8 & 107,8 & 3,34 & 21 & 1,6 & 2 & 174 & G2PP2 & $<0,6$ & 13 & $<1,0$ & 2,3 & NA & 241 \\
\hline 10 & 1,9 & $M$ & 1,8 & 97,5 & 2,55 & 17 & 1,25 & 5 & 159 & G2PP3 & 3 & 77,3 & 7,5 & 22,3 & NA & 283 \\
\hline 12 & 2 & $\mathrm{M}$ & 6,83 & 151 & 5,6 & 46,8 & 0,9 & 14 & 169,9 & G4PP4 & 4,5 & 23 & 7,6 & 11 & NA & 565 \\
\hline 13 & 0,66 & $\mathrm{M}$ & 0,75 & 76 & 1,3 & 10,3 & 1 & 0,75 & 169 & G4PP1 & 1,4 & $30,8 \#$ & 1,3 & ND & NA & 138 \\
\hline 14 & 5 & $M$ & 8,25 & 142,6 & 2,93 & 35,5 & 0,4 & 12 & 177,5 & G3PP3 & 1,1 & ND & 1,6 & ND & NA & 473 \\
\hline 15 & 2 & $M$ & 2 & 98 & 3,6 & 16,3 & 0,87 & 4 & 175 & G2PP3 & 0,6 & $19,1 \#$ & $<1,0$ & ND & NA & 98 \\
\hline
\end{tabular}

IC: idade cronológica; E: estatura; IO: idade óssea; DP: desvio-padrão de estatura e peso; G: genitália (estádio, segundo critérios de Tanner); PP: pelos pubianos (estádio, segundo critérios de Tanner); EA: estatura alvo; E2: estradiol, T: testosterona, M: mamas (estádio, segundo critérios de Tanner); ND: não disponível; NA: não aplicável; *Exames realizados por radioimunoensaio (RIE). Os demais exames foram realizados por IFMA; \# LH 2 horas pós acetato de leuprolide depot 
No grupo de 47 pacientes com HHIn, 34 (72\%) indivíduos eram do sexo masculino e 13 (28\%), do sexo feminino. Os critérios clínicos e laboratoriais utilizados para a inclusão dos pacientes com HHIn foram: a falta de aparecimento ou desenvolvimento incompleto de caracteres sexuais secundários após os 18 anos em ambos os sexos, concentrações baixas de esteroides sexuais (testosterona ou estradiol) para o sexo e idade, associados a concentrações séricas de LH baixas ou inapropriadamente normais em condição basal e/ou após teste de estímulo com GnRH exógeno, olfato normal e RM do SNC sem evidências de anormalidade. Trinta e seis dos 47 pacientes (77\%) apresentavam a forma esporádica de HHIn e 11 (23\%) apresentavam a forma familial. Todos os pacientes do sexo masculino apresentavam volume testicular reduzido, estádios 1 e 2 . Criptorquidia uni ou bilateral esteve presente em $17,5 \%$ dos casos. Ginecomastia foi observada em $23 \%$ dos pacientes. A média de idade cronológica da primeira consulta foi 24 anos \pm 9,3 anos e variou de 14 anos a 54 anos. LH e FSH basais pré-púberes foram encontrados em $62 \%$ e $42 \%$ dos pacientes, respectivamente, e apresentavam valores intrapúberes no restante dos casos. Os achados clínicos dos pacientes com HHIn estão resumidos na tabela 4 . 
Pacientes e Métodos

Tabela 4 - Dados clínicos e hormonais de pacientes com hipogonadismo hipogonadotrófico isolado normósmico

\begin{tabular}{|c|c|c|c|c|c|c|c|c|c|c|c|c|c|c|c|}
\hline Caso & Sexo & IC $1^{\mathrm{a}}$ & $E$ & DP & Peso (kg) & DP & IO & Estádio puberal & Criptorquidia & $\begin{array}{r}\text { LH } \\
\end{array}$ & & $\begin{array}{r}\text { FSt } \\
\text { Basal }\end{array}$ & & $\begin{array}{c}\mathrm{E} 2 \\
(\mathrm{pg} / \mathrm{mL})\end{array}$ & $\begin{array}{c}T \\
(\mathrm{ng} / \mathrm{dL})\end{array}$ \\
\hline 1 & $M$ & 17 & 160,1 & $-2,16$ & ND & ND & 13,5 & G1PP3 & Sim (direita) & 1,7 & 6,5 & 3,5 & 6,3 & NA & 28,3 \\
\hline 2 & M & 19 & 170,2 & $-0,7$ & ND & ND & 15 & G2PP3 & Não & 0,7 & 9,8 & 1,4 & 2,7 & NA & 47 \\
\hline 3 & M & 16 & 153,5 & $-2,6$ & ND & ND & 13,5 & G2PP3 & Não & 9,7 & 22,4 & 5,9 & 13,9 & NA & 31 \\
\hline 4 & M & 18 & 180 & 0,9 & ND & ND & ND & G2PP2 & Não & $<0,6$ & ND & $<1,0$ & ND & NA & ND \\
\hline 5 & M & 29 & 166 & $-1,3$ & ND & ND & 17 & G2PP3 & Não & $<0,6$ & 6,6 & $<1,0$ & 1,7 & NA & 54 \\
\hline 6 & $M$ & 19 & 167,6 & $-1,1$ & ND & ND & 18 & G1PP3 & Não & $<0,6$ & 7 & $<1,0$ & 2,6 & NA & 24 \\
\hline 7 & M & 22 & 178,6 & 0,5 & ND & ND & 14,6 & G1PP4 & Não & $<0,6$ & 2,7 & 1 & 1,3 & NA & $<14$ \\
\hline 8 & M & 26 & ND & ND & ND & ND & ND & ND & ND & $<0,6$ & 3,1 & $<1,0$ & 3,6 & NA & $<14$ \\
\hline 9 & M & 30 & 167,4 & $-1,1$ & 56,5 & 0,47 & 17 & G1PP3 & Não & $<0,6$ & 0,8 & $<1,0$ & 3,5 & NA & 35 \\
\hline 10 & M & 25 & 152 & $-3,41$ & 93 & 5 & 18 & G1PP4 & Sim (esquerda) & $<0,6$ & $<0,6$ & $<1,0$ & $<1,0$ & NA & 43 \\
\hline 11 & M & 19 & 176,4 & 0,2 & 56 & $-0,8$ & 15 & G1PP3 & Não & $<0,6$ & 2,3 & $<1,0$ & 1,7 & NA & $<14$ \\
\hline 12 & M & 33 & 189 & 2,15 & 80 & 0 & ND & G1ND & Sim (direita) & $<0,6$ & ND & $<1,0$ & ND & NA & 126 \\
\hline 13 & $M$ & 20 & 167,2 & $-1,12$ & ND & ND & 13 & G1PP3 & Sim (direita) & $<0,6$ & 1 & 1 & 2,8 & NA & 34 \\
\hline 14 & $M$ & 22 & 169,6 & $-0,7$ & 80,4 & 2,9 & 15 & G1PP4 & Não & $<0,6$ & 1,7 & $<1,0$ & 1,9 & NA & 26 \\
\hline 15 & $M$ & 49 & 182,5 & 1,17 & 102 & 1 & ND & G1PP3 & Não & 0,6 & ND & $<1,0$ & ND & NA & 94,6 \\
\hline 16 & M & 34 & ND & ND & 58,2 & ND & ND & G1ND & Sim (bilateral) & $<0,6$ & 2 & 1 & 2,6 & NA & 70 \\
\hline 17 & M & 19 & 164 & $-1,6$ & 45,6 & $-0,3$ & 16 & G1PP2 & Não & 1,1 & 11 & 2,1 & 4,9 & NA & 38 \\
\hline 18 & M & 24 & 164 & $-1,6$ & 62 & 1,3 & ND & G1PP1 & Sim (bilateral) & $<0,6$ & 4,4 & 2,3 & 6,4 & NA & 239 \\
\hline 19 & M & 24 & ND & ND & ND & ND & 16 & G1ND & Não & $<0,6$ & ND & $<1,0$ & ND & NA & $<14$ \\
\hline 20 & M & 28 & 180 & 0,8 & ND & ND & ND & G2ND & Não & 1,5 & 44,5 & 2,9 & 11 & NA & 44 \\
\hline 21 & M & 25 & ND & ND & ND & ND & 16 & G2ND & Sim (direita) & $<0,6$ & ND & $<1,0$ & ND & NA & $<14$ \\
\hline 22 & M & 27 & ND & ND & ND & ND & ND & G2ND & Não & 12,5 & 33 & 2,2 & ND & NA & 267 \\
\hline 23 & M & 24 & ND & ND & ND & ND & ND & G2ND & Sim (direita) & 1,2 & ND & 1,2 & ND & NA & 228,5 \\
\hline
\end{tabular}

IC: idade cronológica; E: estatura; IO: idade óssea; DP: desvio-padrão de estatura e peso; G: genitália (estádio, segundo critérios de Tanner); PP: pelos pubianos (estádio, segundo critérios de Tanner); EA: estatura alvo; E2: estradiol, T: testosterona, M: mamas (estádio, segundo critérios de Tanner); ND: não disponível; NA: não aplicável.

Continua... 
Tabela 4 (continuação) - Dados clínicos e hormonais de pacientes com hipogonadismo hipogonadotrófico isolado normósmico

\begin{tabular}{|c|c|c|c|c|c|c|c|c|c|c|c|c|c|c|c|}
\hline & Sexo & $\begin{array}{c}\text { IC } 1^{\mathrm{a}} \\
\text { consulta }\end{array}$ & $\begin{array}{c}E \\
(\mathrm{~cm})\end{array}$ & DP & Peso (kg) & $\begin{array}{c}\text { DP } \\
\text { peso }\end{array}$ & $\begin{array}{c}10 \\
\text { (anos) }\end{array}$ & Estádio puberal & Criptorquidia & $\begin{array}{r}\text { LH } \\
\text { Basal } \\
\end{array}$ & $\begin{array}{l}\text { L) } \\
\text { Pico }\end{array}$ & $\begin{array}{r}\mathrm{FSF} \\
\text { Basal }\end{array}$ & $\begin{array}{l}\text { IL) } \\
\text { Pico }\end{array}$ & $\begin{array}{c}E 2 \\
(\mathrm{pg} / \mathrm{mL})\end{array}$ & $\begin{array}{c}\mathrm{T} \\
\text { (ng/dL) }\end{array}$ \\
\hline 24 & $\mathrm{M}$ & 27 & ND & ND & ND & ND & 16 & G1ND & Não & $<0,6$ & ND & 1,2 & ND & NA & 45,9 \\
\hline 25 & $\mathrm{M}$ & 31 & 171 & $-0,55$ & 64,8 & 1,05 & 16 & G1PP3 & Não & $<0,6$ & 7,51 & 1,39 & 4,53 & NA & $<20$ \\
\hline 26 & $\mathrm{M}$ & 22 & 169 & $-0,85$ & 71,7 & 1,9 & ND & G1PP3 & Não & $<0,6$ & 9,51 & 1,63 & 6,14 & NA & 31 \\
\hline 27 & $\mathrm{M}$ & 18 & 174,5 & 0 & 64,8 & 0,3 & ND & NAND & Sim (bilateral) & $<0,6$ & ND & $<1,0$ & ND & NA & 140 \\
\hline 28 & $\mathrm{M}$ & 20 & 163 & $-1,75$ & 63 & 1,5 & ND & G2PP3 & Não & 5 & ND & 9 & ND & NA & 67 \\
\hline 29 & M & 33 & 167 & $-1,15$ & 53,5 & 0,16 & ND & NAND & Sim (bilateral) & 2,3 & 4,5 & 1,8 & 3,8 & NA & 106 \\
\hline 30 & $\mathrm{M}$ & 24 & 188 & 2 & 87,9 & 0,2 & ND & G1PP1 & Não & $<0,6$ & ND & 1,4 & ND & NA & 60 \\
\hline 31 & $\mathrm{M}$ & 34 & 164 & $-1,6$ & 58 & 0,9 & ND & NDPP2 & ND & 9,28 & 2,02 & 1,08 & 2,34 & NA & 20 \\
\hline 32 & $\mathrm{M}$ & 14,7 & 168,5 & 0,4 & 47,1 & $-0,6$ & 13,5 & G1PP2 & Sim (bilateral) & 0,9 & ND & 1,5 & ND & NA & 30 \\
\hline 33 & M & 16,3 & 170 & $-0,4$ & 64,8 & 1,15 & 14,5 & G2PP4 & Não & $<0,6$ & 1,6 & $<1,0$ & 2,6 & NA & 125 \\
\hline 34 & $\mathrm{~F}$ & 17 & 160,2 & $-0,3$ & ND & ND & 15 & G1ND & Não & $<0,6$ & 3,8 & $<1,0$ & 2,8 & $<13$ & NA \\
\hline 35 & $\mathrm{~F}$ & 22 & 158,5 & $-0,6$ & 42,4 & $-0,7$ & 11 & M1PP2 & NA & $<0,6$ & 2,34 & $<1,0$ & 6,16 & $<13$ & NA \\
\hline 36 & $\mathrm{~F}$ & 21 & 146 & $-2,7$ & ND & ND & ND & M1PP4 & NA & $<0,6$ & 1,5 & $<1,0$ & 2,8 & 15 & NA \\
\hline 37 & $\mathrm{~F}$ & 20 & 159,8 & $-0,4$ & ND & ND & 14 & M1PP3 & NA & $<0,6$ & 5,1 & 1,5 & 5,5 & $<13$ & NA \\
\hline 38 & $\mathrm{~F}$ & 16 & 157 & $-0,8$ & 40,8 & $-0,7$ & 10 & M1PP5 & NA & $<0,6$ & 4,7 & $<1,0$ & 5,2 & $<13$ & NA \\
\hline 39 & $\mathrm{~F}$ & 30 & 170,5 & 1,4 & ND & ND & ND & M5PP5 & NA & 1,7 & 12 & 3 & 6,4 & $<13$ & NA \\
\hline 40 & $\mathrm{~F}$ & 19 & 154,9 & $-1,2$ & ND & ND & 11 & M2PP2 & NA & $<0,6$ & 1,4 & $<1,0$ & 1,7 & $<13$ & NA \\
\hline 41 & $\mathrm{~F}$ & 14 & 144,3 & $-2,4$ & ND & ND & 11 & M1PP1 & NA & $<0,6$ & 1,7 & $<1,0$ & 2,4 & $<13$ & NA \\
\hline 42 & $\mathrm{~F}$ & 28 & 159 & $-0,5$ & ND & ND & ND & M4PP4 & NA & $<0,6$ & 0,9 & $<1,0$ & 1,9 & $<13$ & NA \\
\hline 43 & $\mathrm{~F}$ & 17 & 160,2 & $-0,3$ & ND & ND & 15 & M3PP3 & NA & $<0,6$ & 3,8 & $<1,0$ & 3,6 & $<13$ & NA \\
\hline 44 & $\mathrm{~F}$ & 19 & 161 & $-0,2$ & ND & ND & 13 & M1PP2 & NA & $<0,6$ & 6 & 3,8 & 10,6 & $<13$ & NA \\
\hline 45 & $\mathrm{~F}$ & 32 & 165,5 & 0,55 & 110 & 6,8 & ND & M1PP1 & NA & 1 & 11,5 & 1,7 & 4,8 & $<13$ & NA \\
\hline 46 & $\mathrm{~F}$ & 54 & ND & ND & ND & ND & ND & M5 ND & NA & $<0,6$ & ND & $<1,0$ & ND & $<14$ & NA \\
\hline 47 & $\mathrm{~F}$ & 18 & ND & ND & ND & ND & ND & M1PP2 & NA & 3,6 & 5,1 & 2,6 & 2,9 & $<13$ & NA \\
\hline
\end{tabular}

IC: idade cronológica; E: estatura; IO: idade óssea; DP: desvio-padrão de estatura e peso; G: genitália (estádio, segundo critérios de Tanner); PP: pelos pubianos (estádio, segundo critérios de Tanner); EA: estatura alvo; E2: estradiol, T: testosterona, M: mamas (estádio, segundo critérios de Tanner); ND: não disponível; NA: não aplicável. 


\section{2 - Avaliação hormonal}

O diagnóstico laboratorial dos distúrbios do desenvolvimento puberal foi baseado nas dosagens das gonadotrofinas (LH e FSH) e dos esteroides sexuais (estradiol e testosterona). Gonadotrofinas hipofisárias e esteroides sexuais foram dosados por radioimunoensaio (RIE) com duplo anticorpo policlonal (Wallac, Turku, Finlândia) até 1991; após este período o ensaio utilizado foi imunofluorométrico (IFMA) (Perkin Elmer, Wallac, Finlândia), mais sensível e específico, utilizando anticorpos monoclonais.

O teste de estímulo com $\mathrm{GnRH}$ de ação curta foi realizado pela administração de $100 \mu \mathrm{g}$ de gonadorelina intravenosa no tempo zero e coleta de sangue nos tempos -15, 0, 15, 30, 45 e 60 minutos. Os valores de esteroides sexuais e de LH e FSH basais e após estímulo com $\mathrm{GnRH}$, considerados normais, estão descritos nas tabelas 5 e 6.

Tabela 5 - Valores normais de testosterona e LH no sexo masculino, obtidos nos ensaios IFMA e RIE em pré-púberes e adultos

\begin{tabular}{ccccc}
\hline & $\begin{array}{c}\text { Testosterona } \\
\mathbf{n g} / \mathbf{d L}\end{array}$ & $\begin{array}{c}\text { LH basal } \\
\text { U/L }\end{array}$ & $\begin{array}{c}\text { LH pico* } \\
\text { U/L }\end{array}$ & Ensaio \\
\hline Pré-púberes & $<14$ & $\leq 0,6$ & $<9,6$ & IFMA \\
Adultos & $300-950$ & $1,4-9,2$ & $12-29,7$ & \\
& & & \\
Pré-púberes & $<30$ & & $\Delta \geq 15$ & RIE \\
Adultos & $350-1090$ & & &
\end{tabular}


Tabela 6 - Valores normais de estradiol e LH no sexo feminino, obtidos nos ensaios de IFMA e RIE em pré-púberes e adultos

\begin{tabular}{ccccc}
\hline & $\begin{array}{c}\text { Estradiol } \\
\mathbf{p g} / \mathbf{m L}\end{array}$ & $\begin{array}{c}\text { LH basal } \\
\text { U/L }\end{array}$ & $\begin{array}{c}\text { LH pico* } \\
\text { U/L }\end{array}$ & Ensaio \\
\hline Pré-púberes & $<13$ & $\leq 0,6$ & $<6,9$ & IFMA \\
Adultas fase folicular & $30-94$ & $1,0-8,4$ & $7,6-31,7$ & \\
& & & & \\
Pré-púberes & $<10$ & & $\Delta<15$ & RIE \\
Adultas fase folicular & $10-80$ & & $\Delta \geq 15$ & \\
\hline
\end{tabular}

* após $100 \mu g$ de gonadorelina i.v.; $\Delta$ : delta

No diagnóstico de PPC, consideram-se concentrações puberais no sexo feminino: $\mathrm{LH}$ basal > 0,6 U/L ou após estímulo com $\mathrm{GnRH}>6,9 \mathrm{U} / \mathrm{L}$ para o IFMA (128); $\Delta \mathrm{LH}$ após estímulo com $\mathrm{GnRH}>15 \mathrm{U} / \mathrm{L}$ para o RIE (129). No sexo masculino, consideram-se concentrações puberais: $\mathrm{LH}$ basal $>0,6 \mathrm{U} / \mathrm{L}$ ou após estímulo com $\mathrm{GnRH}>$ 9,6 U/L e testosterona > $14 \mathrm{ng} / \mathrm{dL}$ para o IFMA (128); $\Delta \mathrm{LH}$ após estímulo com $\mathrm{GnRH}>25 \mathrm{U} / \mathrm{L}$ e testosterona $>30 \mathrm{ng} / \mathrm{dL}$ para o RIE (129). Adicionalmente, $\mathrm{LH}>10 \mathrm{U} / \mathrm{L}$, dosado 2 horas após administração da primeira ampola de acetato de leuprolida $3,75 \mathrm{mg}$ via subcutânea, também foi considerado como resposta puberal para ambos os sexos (130).

Valores de esteroides sexuais abaixo do limite normal associados a concentrações inapropriadamente normais ou baixas de $\mathrm{LH}$ e $\mathrm{FSH}$, basais ou após estímulo com $\mathrm{GnRH}$ (tabelas 5 e 6), na ausência de deficiências combinadas dos hormônios hipofisários, foram os critérios hormonais adotados para a determinação do diagnóstico de HHIn (131).

\section{3 - Modo de herança e taxa de penetrância dos pacientes com PPC idiopática}

O critério de classificação como forma familial foi a presença de mais de um caso de precocidade sexual na prole ou no heredograma. O valor da taxa de penetrância $(K)$ de puberdade precoce central em famílias com mais de um membro afetado foi estimado a partir de um programa desenvolvido no 
Departamento de Genética do Instituto de Biociências da Universidade de São Paulo (132). Os indivíduos com idade pré-puberal foram excluídos para esta análise, bem como os familiares sem dados da história pregressa de precocidade sexual. Neste cálculo admitiu-se que a PPC tem mecanismo autossômico dominante com penetrância incompleta, como previamente demonstrado por de Vries e cols. (19).

Para a estimativa da taxa de penetrância $(K)$, levando em consideração as informações contidas nas 14 genealogias, utilizou-se a expressão: $P=K^{41}$ (1$K)^{10}(2-K)^{26}\left[4+(1-K)(2-K)^{2}\right]\left[8+(1-K)(2-K)^{3}\right]$ e para o cálculo da estimativa de máxima verossimilhança de $\mathrm{K}: \mathrm{dL} / \mathrm{dK}=0$, em que $\mathrm{L}=\log (P)$. Foi calculado também o intervalo de confiança de $95 \%$.

\section{4 - Estudo molecular}

\subsection{1 - Extração do DNA genômico de leucócitos periféricos}

DNA genômico foi extraído de $15 \mathrm{~mL}$ de sangue periférico colhido em tubo com EDTA. O material foi incubado em solução para lise de glóbulos vermelhos (114 mM cloreto de amônia; $1 \mathrm{mM}$ carbonato de amônia) durante 30 minutos a $4^{\circ} \mathrm{C}$. Após este período, a amostra foi centrifugada a $3.000 \mathrm{rpm}$ durante 15 minutos a $4^{\circ} \mathrm{C}$. O sobrenadante foi descartado, o botão de células foi ressuspenso em solução tampão constituída de $100 \mathrm{mM} \mathrm{NaCl} ; 10 \mathrm{mM}$ Tris- $\mathrm{HCl}$ $\mathrm{pH} 8 ; 0 ; 1 \mathrm{mM}$ EDTA pH 8,0 contendo $1 \%$ SDS e $0,2 \mathrm{mg} / \mathrm{mL}$ proteinase $\mathrm{K}$ e mantido durante a noite a $37^{\circ} \mathrm{C}$. No dia seguinte, a amostra foi submetida a duas extrações com fenol: clorofórmio: álcool isoamílico (25:24:1) e a uma extração com clorofórmio e álcool isoamílico (24:1). O DNA foi precipitado com acetato de sódio 0,3 M em pH 7,0 e com dois volumes de etanol absoluto gelado. Posteriormente, o DNA foi lavado em etanol $70 \%$ por 5 minutos e ressuspenso em TE (10 mM Tris-HCl pH 8,0; 0,1 mM EDTA pH 8,0).

A concentração do DNA foi estimada a partir da leitura da densidade óptica por espectrofotometria com luz ultravioleta (Ultrospec III - Pharmacia Biotech, EUA); o grau de pureza foi avaliado pela relação A260/280. A 
integridade do material foi verificada com eletroforese em gel de agarose $1 \%$ e visualização por transiluminação com luz ultravioleta após coloração com solução de brometo de etídio. As amostras foram armazenadas a $4^{\circ} \mathrm{C}$ até sua utilização.

\subsection{2 - Amplificação de DNA genômico por reação em cadeia da polimerase (PCR)}

O DNA genômico obtido foi utilizado como substrato para a amplificação dos três exons e do intron 1 onde está localizada a região promotora do gene TTF-1 e do único exon do gene EAP1, por meio da reação em cadeia da polimerase (PCR), utilizando-se pares de oligonucleotídeos específicos (tabelas 7 e 8$)$.

Tabela 7 - Oligonucleotídeos usados para amplificação do gene TTF-1

\begin{tabular}{|c|c|c|c|l|}
\hline $\begin{array}{c}\text { Região } \\
\text { amplificada }\end{array}$ & $\begin{array}{c}\text { Temperatura de } \\
\text { anelamento (C) }\end{array}$ & $\begin{array}{c}\text { Tamanho do } \\
\text { fragmento (bp) }\end{array}$ & Oligo & \multicolumn{1}{|c|}{ Sequência de oligonucleotídeos (5'- 3') } \\
\hline Exon 1 & 56 & 298 & $F$ & ACAGACTGACAGACACGTAGACCA \\
& 61 & 501 & $F$ & GCTTCGCCTTCCCCCTCTCCCTTTT \\
& & & $R$ & GACGGCTCTCGCCGCACCTCCTGAG \\
\hline Exon 2 & 51 & 809 & $F$ & GGGGCTGTGAGCGCTCCAGTACAGCC \\
& 54 & & $R$ & CCTGGCTGGTGGCCCGGGTGTGCGCCAA \\
\hline Exon 3B & 459 & $F$ & TGGCGGTGCCGGTCCTGGTGAAAGA \\
& 55 & 1309 & $F$ & CCAGGTTGTTAAGAAAAGTCG \\
\hline Intron1 & & & $R$ & GACGGCTCTCGCCGCACCTCCTGAG \\
& & & $S$ & AAAGCACACGACTCCGTTCT \\
\hline
\end{tabular}

F: forward; R: reverse; S: oligo utilizado apenas para sequenciamento 
Tabela 8 - Oligonucleotídeos usados para amplificação do gene EAP1

\begin{tabular}{|c|c|c|c|c|}
\hline $\begin{array}{c}\text { Região } \\
\text { amplificada }\end{array}$ & $\begin{array}{l}\text { Temperatura de } \\
\text { anelamento (C) }\end{array}$ & $\begin{array}{c}\text { Tamanho do } \\
\text { fragmento (bp) }\end{array}$ & Oligo & Sequência de oligonucleotídeos (5'- 3') \\
\hline Fragmento 1 & 54 & 831 & $\begin{array}{l}F \\
R\end{array}$ & $\begin{array}{l}\text { AGACTCGCGTTCCCTCCAG } \\
\text { CCGACGCCGCCGCTGAAGAAGAAT }\end{array}$ \\
\hline Fragmento $2 / 1$ & 55 & 695 & $\begin{array}{l}F \\
R\end{array}$ & $\begin{array}{l}\text { GGAACCCGTATGCCGCG } \\
\text { TAAGCAGCGTCTGCGGTAG }\end{array}$ \\
\hline Fragmento $2 / 2$ & 56 & 682 & $\begin{array}{l}F \\
R\end{array}$ & $\begin{array}{l}\text { AGCCCCAATTCTTCTTCAGC } \\
\text { ACATCTGCTTGGCCACACC }\end{array}$ \\
\hline Fragmento 3 & 56 & 1894 & $\begin{array}{l}F \\
R\end{array}$ & $\begin{array}{l}\text { CGTCTCCAAGCCCGGCATG } \\
\text { CCGTGCATCAATAAAGCAAAAACA }\end{array}$ \\
\hline & & & $\begin{array}{l}S \\
S \\
S\end{array}$ & $\begin{array}{l}\text { CAAGAGAAAGGCCTCTCCG } \\
\text { TAACGGGGACCTGAATTTACA } \\
\text { АCCAGСTCСTСTCСААTCCT }\end{array}$ \\
\hline
\end{tabular}

F: forward; R: reverse; S: utilizado somente para sequenciamento

As reações para amplificação do gene TTF-1 foram realizadas em um volume final de $50 \mu \mathrm{L}$. Para cada reação foram utilizados $100 \mathrm{ng}$ a $200 \mathrm{ng}$ de DNA genômico, $200 \mu \mathrm{M}$ de cada desoxinucleotídeo (dNTP), 15 pmol de cada oligonucleotídeo, 2,5 U de enzima GoTaq polimerase (Promega, Madison, WI, EUA), $10 \mu \mathrm{l}$ 5X GoTaq Reaction Buffer (Promega, Madison, WI, EUA) e $5 \mu \mathrm{l}$ $\mathrm{DMSO}_{4}$ 10\%. Para a amplificação do exon 3 foram utilizados $1 \mathrm{U}$ da enzima Platinum $^{\circledR}$ Taq PCRx DNA polimerase (Invitrogen, Carlsbad, CA, EUA), específica para amplificação de regiões ricas em GC e $5 \mu \mathrm{L}$ do tampão $10 X$ PCRx Amplification Buffer (Promega, Madison, WI, EUA). A reação de amplificação foi realizada em um termociclador MJ Research PTC-200 (GMI, Inc., Ramsey, Minessota, EUA) e consistiu das seguintes etapas: desnaturação inicial a $95^{\circ} \mathrm{C}$ por 5 minutos, seguida por 35 ciclos de desnaturação a $94^{\circ} \mathrm{C}$ por 30 segundos, anelamento, variando de $51^{\circ} \mathrm{C}$ a $61^{\circ} \mathrm{C}$ por 30 segundos, extensão a $72^{\circ} \mathrm{C}$ por 45 segundos a 1 minuto e extensão final a $72^{\circ} \mathrm{C}$ por 15 minutos, após o último ciclo.

As reações para amplificação do gene EAP1 foram realizadas em um volume final de $50 \mu \mathrm{L}$. Para cada reação foram utilizados $100 \mathrm{ng}$ a $200 \mathrm{ng}$ de 
DNA genômico, $200 \mu \mathrm{M}$ de cada desoxinucleotídeo (dNTP) e 15 pmol de cada oligonucleotídeo, 2,5 U de enzima GoTaq polimerase (Promega, Madison, WI, EUA), $10 \mu \mathrm{l}$ XX GoTaq Reaction Buffer (Promega, Madison, WI, EUA) e $5 \mu \mathrm{l}$ $\mathrm{DMSO}_{4} 10 \%$. As reações de amplificação foram realizadas em um termociclador MJ Research PTC-200 (GMI, Inc., Ramsey, Minessota, EUA) e consistiram das seguintes etapas: desnaturação inicial a $94^{\circ} \mathrm{C}$ por 5 minutos, seguida por 35 ciclos de desnaturação a $94^{\circ} \mathrm{C}$ por 30 segundos, anelamento variando de $54{ }^{\circ} \mathrm{C}$ a $56^{\circ} \mathrm{C}$ por 30 segundos a 45 segundos, extensão a $72^{\circ} \mathrm{C}$ por 60 segundos a 90 segundos e extensão final a $72^{\circ} \mathrm{C}$ por 15 minutos, após o último ciclo.

Os produtos de PCR foram submetidos à eletroforese em gel de agarose a $1 \%$, corados com brometo de etídio $(0,5 \mu \mathrm{g} / \mathrm{mL})$ e visualizados por transiluminação em luz ultravioleta.

\subsection{3 - Sequenciamento automático}

A concentração de DNA dos produtos gerados pela PCR foi determinada a partir da comparação da intensidade de sinal emitido pelos fragmentos de um marcador de peso molecular de concentração conhecida em gel de agarose. Posteriormente, os produtos de amplificação foram submetidos à prépurificação enzimática, utilizando-se o produto comercial EXO-SAP que contém as enzimas Shrimp Alkaline Phosphatase.e exonuclease I (Amersham Science, USB, Cleveland, Ohio, EUA). A reação de sequenciamento foi realizada, utilizando o produto comercial $A B I$ Prism $^{T M}$ BigDye Terminator (Perkin Elmer, Foster City, CA, EUA). Os produtos desta reação foram submetidos à eletroforese em sequenciador automático ABI Prism Genetic Analyzer 3100 automatic DNA sequencer (Perkin Elmer, Foster City, CA, EUA). As sequências obtidas foram comparadas com as sequências depositadas na base de dados do National Center for Biotechnology and Information (NCBI). 


\subsection{4 - Estudo das regiões de poliglutamina (poliQ) e polialanina (poliAla) do EAP1}

Analisamos o tamanho dos fragmentos amplificados para as regiões poliQ e poliAla pelo programa GeneScan (Applyed Biosystems, Foster City, CA, EUA). A região do EAP1 que codifica a região poliQ foi estudada, utilizando um par de nucleotídeos iniciadores, sendo o oligonucleotídeo sense marcado com fluorescência FAM na extremidade 5' CGTCGGGGTCAAGACAGT e o oligo antisense GTAGCGCTCCAGGCCAGA. A região do EAP1 que codifica a segunda região poliAla foi também estudada utilizando um par de nucleotídeos iniciadores, sendo o oligonucleotídeo sense marcado com fluorescência FAM na extremidade 5' AACCACGTTGATGGTTCCAG e o oligo antisense CCTCCTCTGGTGTTGGTTTG.

Em um volume final de $50 \mu \mathrm{l}$, foram adicionados $100 \mathrm{ng}$ de DNA genômico, $200 \mu \mathrm{M}$ de cada desoxinucleotídeo (dNTP), $15 \mathrm{pmol}$ de cada oligonucleotídeo iniciador, 2,5 U de enzima GoTaq polimerase (Promega, Madison, WI, EUA), $10 \mu \mathrm{l}$ 5X GoTaq Reaction Buffer (Promega, Madison, WI, EUA) e $5 \mu \mathrm{IMSO}_{4}$ 10\%. A reação de amplificação foi realizada em um termociclador MJ Research PTC-200 (GMI, Inc., Ramsey, Minessota, EUA) e consistiu das seguintes etapas: desnaturação inicial a $94^{\circ} \mathrm{C}$ por 5 minutos, seguida por 35 ciclos de desnaturação a $94^{\circ} \mathrm{C}$ por 30 segundos, anelamento a $56^{\circ} \mathrm{C}$ por 30 segundos, extensão a $72^{\circ} \mathrm{C}$ por 30 segundos e extensão final a $72^{\circ} \mathrm{C}$ por 15 minutos, após o último ciclo. $\mathrm{O}$ produto resultante destas reações foi submetido a eletroforese capilar em sequenciador automático $A B I$ Prism Genetic Analyzer 3100 automatic DNA sequencer (Perkin Elmer, Foster City, CA, EUA).

Uma amostra controle, de tamanho conhecido previamente, foi incluída em todas as eletroforeses, a fim de corrigir possíveis variações na análise do tamanho dos fragmentos. Com o objetivo de correlacionar o tamanho do fragmento ao número de repetições de CAA e CAG, na região poliglutamina, e GCT e GCC, na região polialanina, uma amostra de indivíduo homozigoto, 
identificado pela presença de um único sinal na representação gráfica fornecida pelo GeneScan, teve a região dessas repetições analisada por sequenciamento automático.

\section{5 - Avaliação neurológica e neurocognitiva dos pacientes com PPC devido a hamartoma hipotalâmico}

Os pacientes com PPC devido a hamartoma hipotalâmico foram submetidos a avaliação neurológica e neurocognitiva realizadas no Serviço de Neurologia do Hospital das Clínicas da Faculdade de Medicina da Universidade de São Paulo, sob a coordenação do Dr. Luiz Henrique Castro Martins. A avaliação neurológica incluiu exame neurológico completo, com ênfase nas etapas de aquisição de desenvolvimento neuromotor e cognitivo, status cognitivo no momento da avaliação e ocorrência de convulsões isoladas ou recorrentes. Quando presentes, as convulsões foram classificadas em gelásticas ou dacrísticas, de início como crise parcial ou primariamente generalizada (tônico-clônica, tônica ou atônica). Eletroencefalograma (EEG) digital durante sono e vigília após deprivação de sono com procedimentos de ativação padrão (fotoestímulo e hiperventilação) também foi realizado.

Para a avaliação neurocognitiva foram investigados os quoeficientes de inteligência total (QIT), de inteligência verbal (QIV) e de execução (QIE). O QIV inclui raciocínio abstrato sobre material verbal, formação de conceitos, conhecimento de regras sociais, memória imediata e capacidade de cálculo. $\mathrm{O}$ QIE engloba habilidade construtiva, raciocínio sobre material visual, funcionamento visoperceptivo, raciocínio sequencial lógico, resistência à distração, rapidez grafomotora e planejamento. Esta avaliação foi realizada em duas sessões de aproximadamente 60 minutos cada. As respostas de cada paciente foram comparadas com normas para crianças de mesma idade e, assim, calculados os quoeficientes de inteligência verbal (QIV), de execução (QIE) e o quoeficiente de inteligência total (QIT). Para esta análise, a escala de inteligência de Wechsler para crianças (WISC-III) foi utilizada para os pacientes 
entre 6 anos e 16 anos; dois pacientes com idade superior a 16 anos foram avaliados pela escala de inteligência de Wechsler para adultos (WAIS-III) e uma criança com menos de 6 anos foi avaliada pela escala de inteligência de Wechsler para pré-escolares revisada (WPPSI-R) $(80$ - 82). Os dados foram classificados, segundo a escala, como limítrofe, médio baixo, médio, médio alto, alto e muito alto. QIV, QIE e QIT foram comparados entre os pacientes com e sem epilepsia.

Todos os pacientes com PPC devido a hamartoma hipotalâmico realizaram pelo menos uma ressonância magnética cerebral em T1 nos planos sagital e coronal e sequências T2 pelo menos no plano coronal com cortes de 3 $\mathrm{mm}$. Outra sequência T1 foi realizada após injeção de contraste paramagnético intravenoso (Gd-DTPA). Hamartoma hipotalâmico foi confirmado pelo achado de massa de sinal isointenso em T1 e sem realce pelo contraste, e com sinal iso ou levemente hiperintenso em T2 na RM, localizada próxima ao túber cinéreo. Os hamartomas hipotalâmicos foram classificados de acordo com suas características morfológicas (tamanho e forma). Quanto à forma, o hamartoma foi classificado como pedunculado, quando conectado por estreita ligação ao túber cinéreo ou ao ângulo entre o túber cinéreo e os corpos mamilares, ou séssil, quando apresentasse ampla base de ligação à base do terceiro ventrículo e corpos mamilares $(133,134)$. A classificação quanto a forma e tamanho do hamartoma foi realizada no serviço de Radiologia, com auxílio da Dra. Cláudia da Costa Leite.

\section{6 - Análise estatística}

Os dados numéricos foram apresentados em média e DP para as variáveis com distribuição normal determinada pelo teste de KolmogorovSmirnov, ou mediana e intervalo, para aquelas com distribuição não-normal. Para comparação da média ou da mediana das variáveis numéricas entre 2 grupos foi utilizado o teste $\mathrm{t}$ de Student ou teste de Mann-Whitney, respectivamente. Correlação de Pearson foi utilizada para variáveis numéricas. 
As variáveis categóricas foram analisadas em tabela de contingência $2 X 2$ pelo teste exato de Fisher ou qui-quadrado, ou por regressão logística. Para comparações múltiplas diminuímos o limiar de significância estatística utilizando a correção de Bonferroni. Foi utilizado o software SigmaStat Versão 3.5 para Windows, Systat, Inc., 2006. Significância estatística foi considerada quando $p$ $<0,05$ 
4 - Resultados 


\section{4 - RESULTADOS}

\section{1- Puberdade precoce central forma familial}

Modo de herança e taxa de penetrância: a investigação sistemática dos pacientes permitiu a detecção de 18 pacientes com história familiar de precocidade sexual pertencentes a 14 famílias, representando $25 \%$ da casuística. Os heredogramas destas famílias estão representados na figura 4. Com exceção das famílias 1, 7, 8, 9, 13 e 14, os demais heredogramas sugerem herança autossômica dominante. A taxa de penetrância foi 67,5\% [K (constante de penetrância) $=0,675(\mathrm{Cl}$ 95\% [0,55 - 0,79])].

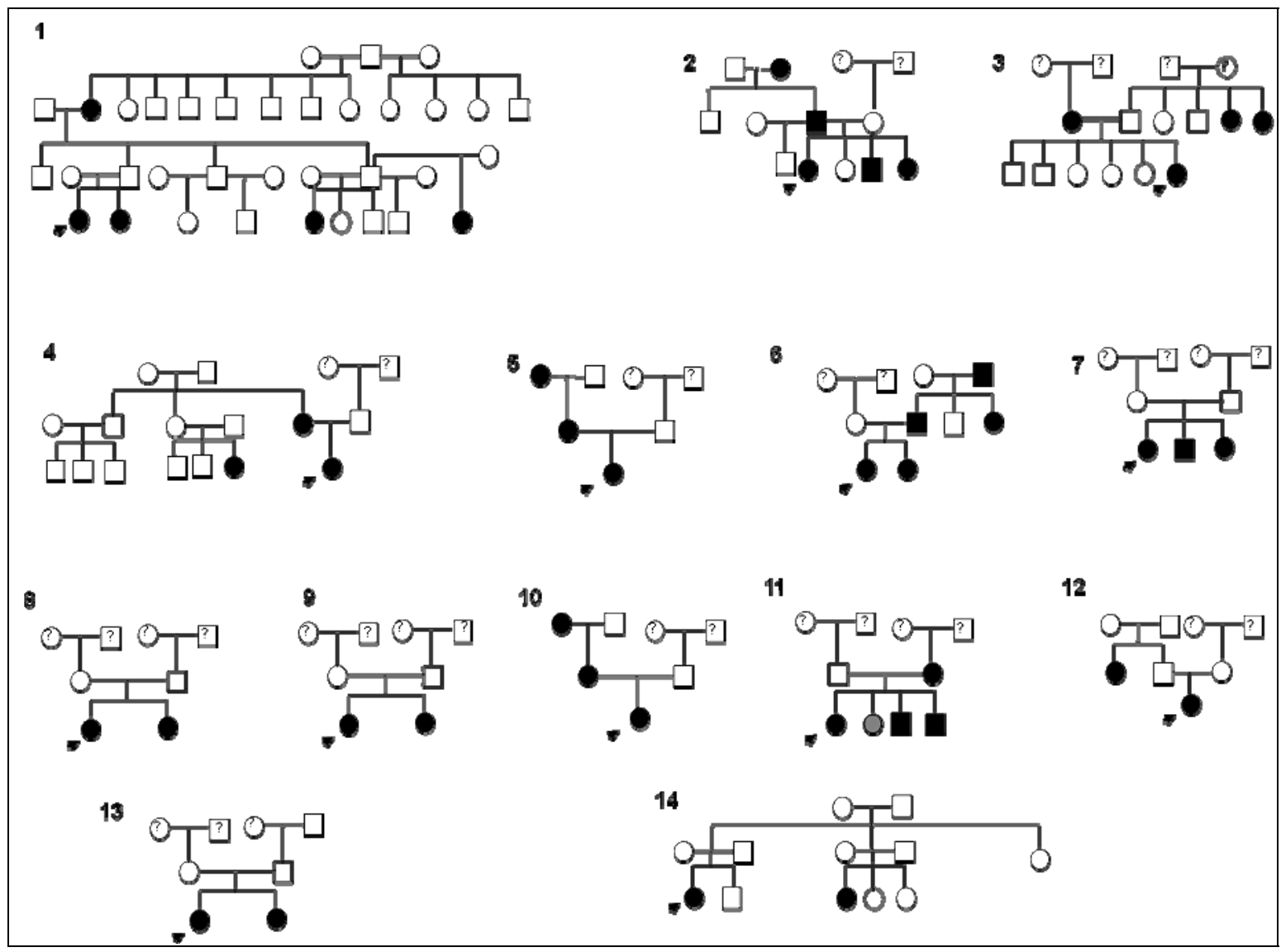

Figura 4. Heredogramas de 14 famílias de pacientes com PPC idiopática. A seta indica o caso índice. 


\section{2 - Estudo molecular}

\subsection{1 - TTF-1}

A amplificação e o sequenciamento dos exons e regiões intrônicas adjacentes às regiões codificadora e promotora do TTF-1 foram realizados com sucesso em toda a casuística e não foi encontrada nenhuma variante alélica nos pacientes com PPC idiopática, PPC devido a hamartoma hipotalâmico e HHIn.

\subsection{2 - EAP1}

A amplificação e o sequenciamento da região codificadora do EAP1 foram realizados com sucesso nos pacientes com PPC (idiopática e devido a hamartoma hipotalâmico, $n=86)$ e nos pacientes com HHIn $(n=47)$.

Quatro variantes alélicas sinônimas do EAP1 foram identificadas, sendo três já descritas no banco de dados (www.ncbi.nlm.nih.gov): p.E87E (rs 71428775), p. A163A (rs 61991619) e p.Y415Y (rs879027); e uma nova variante alélica sinônima p.C758C (localizada na região RING finger). O estudo em controles foi realizado para avaliar a ocorrência da nova variante p.C758C. A distribuição das frequências alélicas e genotípicas das variantes alélicas sinônimas do EAP1 está apresentada na tabela 9. 


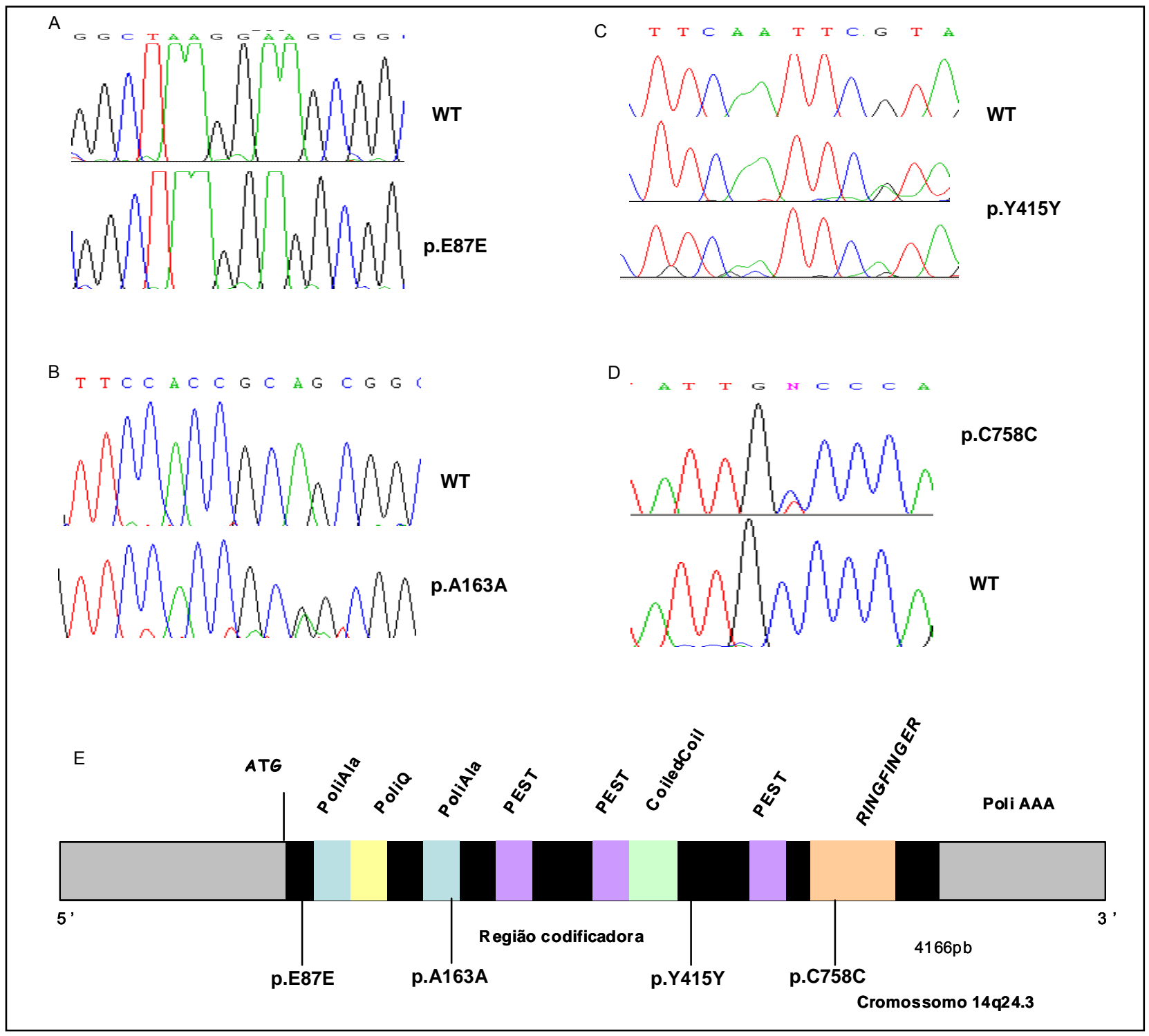

Figura 5. Eletroferograma das variantes alélicas identificadas no EAP1. A p.E87E; B - p.A163A; C - p.Y415Y; D - p.C758C e E - representação esquemática desses polimorfismos no EAP1 
Tabela 9 - Frequência alélica e genotípica das variantes alélicas sinônimas do EAP1

\begin{tabular}{|c|c|c|c|}
\hline & $\begin{array}{c}\text { PPC } \\
(n=86)\end{array}$ & $\begin{array}{c}\text { HHIn } \\
(n=47)\end{array}$ & $P$ \\
\hline \multicolumn{4}{|c|}{ p.E87E (rs 71428775) } \\
\hline A & $132(76,7 \%)$ & $57(60,6 \%)$ & \multirow[b]{2}{*}{0,009} \\
\hline G & $40(23,3 \%)$ & $37(39,4 \%)$ & \\
\hline AA & $56(65,1 \%)$ & $23(49 \%)$ & \multirow{3}{*}{$\begin{array}{c}0,1 \\
0,03\end{array}$} \\
\hline GA & $20(23,2 \%)$ & $11(23,4 \%)$ & \\
\hline GG & $10(11,7 \%)$ & $13(27,6 \%)$ & \\
\hline \multicolumn{4}{|c|}{ p. A163A (rs 61991619) } \\
\hline $\mathrm{T}$ & $135(78,5 \%)$ & $77(82 \%)$ & \multirow{2}{*}{0,6} \\
\hline $\mathrm{C}$ & $37(21,5 \%)$ & $17(18 \%)$ & \\
\hline TT & $56(65,1 \%)$ & $31(66 \%)$ & \multirow{3}{*}{$\begin{array}{l}0,9 \\
0,3\end{array}$} \\
\hline CT & $23(26,7 \%)$ & $15(31,9 \%)$ & \\
\hline $\mathrm{CC}$ & $7(8,2 \%)$ & $1(2,1 \%)$ & \\
\hline \multicolumn{4}{|c|}{ p.Y415Y (rs879027) } \\
\hline C & $106(61,6 \%)$ & $53(56,4 \%)$ & \multirow{2}{*}{0,5} \\
\hline$T$ & $66(38,4 \%)$ & $41(43,6 \%)$ & \\
\hline $\mathrm{CC}$ & $38(44,2 \%)$ & $18(38,3 \%)$ & \multirow{3}{*}{$\begin{array}{l}0,6 \\
0,7\end{array}$} \\
\hline TC & $30(34,8 \%)$ & $17(36,1 \%)$ & \\
\hline TT & $18(21 \%)$ & $12(25,6 \%)$ & \\
\hline \multicolumn{4}{|c|}{ p.C758C* } \\
\hline $\mathrm{C}$ & $171(99,3 \%)$ & $93(98,9 \%)$ & \multirow{2}{*}{0,7} \\
\hline$T$ & $1(0,7 \%)$ & $1(1,1 \%)$ & \\
\hline $\mathrm{CC}$ & $85(98,8 \%)$ & $46(97,8 \%)$ & \multirow{3}{*}{0,7} \\
\hline CT & $1(1,2 \%)$ & $1(2,2 \%)$ & \\
\hline TT & 0 & 0 & \\
\hline
\end{tabular}

Não houve diferença estatisticamente significativa das frequências alélica e genotípica dos polimorfismos do EAP1 entre os grupos de PPC e HHIn, exceto da frequência alélica e genotípica da variante p.E87E ( $p=0,009$ e 0,03). No entanto, após a correção do valor de $p$ para múltiplos testes (Bonferroni), com $p$ corrigido de 0,004 , este resultado não permaneceu estatisticamente significante.

O sequenciamento do fragmento 2 do EAP1, contendo as regiões poliQ e poliAla revelou dificuldade de leitura em alguns pacientes, sugerindo uma possível variação em heterozigose no número de repetições trinucleotídeas. 
Para avaliar esta hipótese, optamos por analisar esta região pelo software de análise de tamanho de fragmento GeneScan.

O estudo da região poliQ e poliAla 5' distal revelou variação no número de repetições glutamina (CAA e CAG) e alanina (GCT e GCC).

Pela análise de tamanho de fragmento e sequenciamento de uma amostra homozigota, foi estabelecido que o fragmento de $229 \mathrm{pb}$ correspondeu a 25 repetições de glutamina (figura 6 ). Desta forma, o número de repetições de glutamina estudada nos pacientes com distúrbios puberais variou de 22 a 25 no grupo com PPC, sendo que apenas 2 pacientes com PPC idiopática relacionadas ( $\mathrm{P} 1$ e $\mathrm{P} 2$ ) apresentaram 22 repetições de glutamina em um alelo e 25 repetições no outro alelo. No grupo com HHIn foram detectados somente homozigotos portando 25 repetições de glutamina.

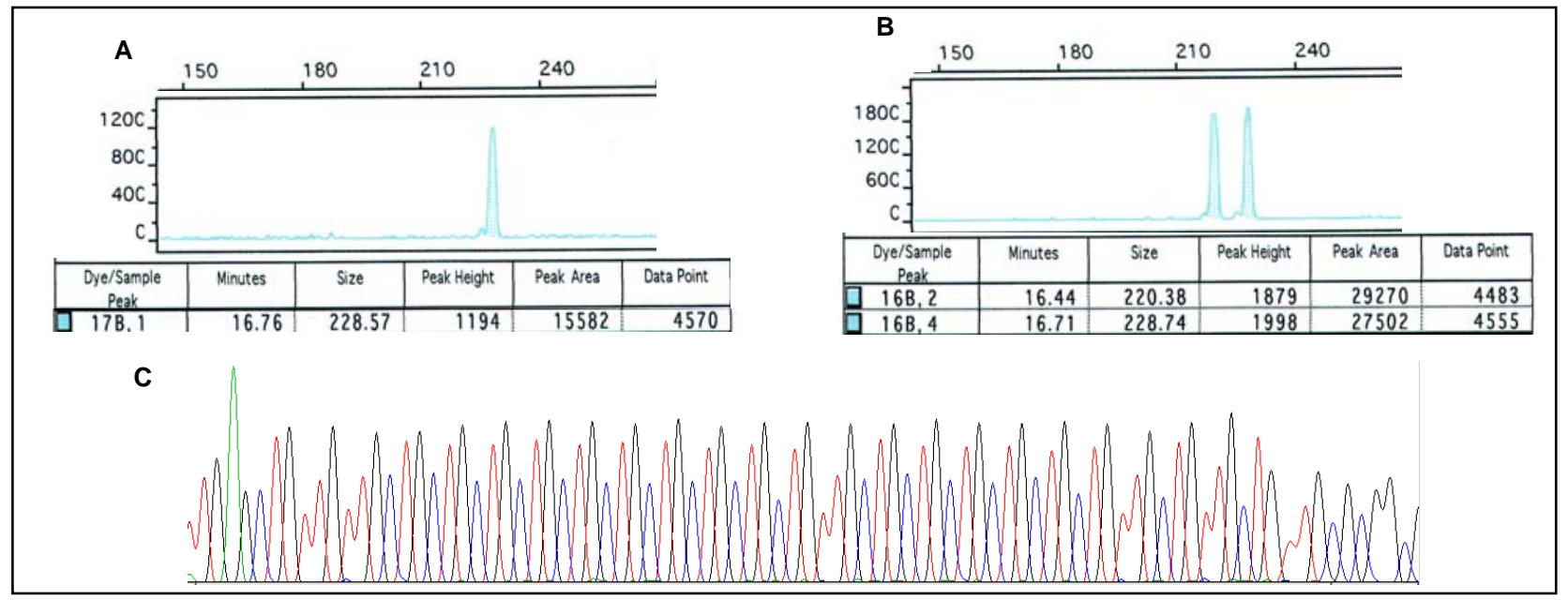

Figura 6. Estudo do número de repetições glutaminas (região poliglutamina) do $E A P 1$. Resultados obtidos pelo programa GeneScan (A e B) e pelo sequenciamento automático (C). A - fragmento de $229 \mathrm{pb}$ em homozigose; B fragmentos de 229 e 220 pb em heterozigose; C - sequenciamento automático do fragmento de $229 \mathrm{pb}$ estabelecendo a sua correspondência com 25 repetições de glutaminas.

Da mesma forma, estabelecemos que o fragmento de $230 \mathrm{pb}$ corresponde a 12 repetições de alanina (figura 7). Dos 172 alelos estudados, 
pertencentes a 86 pacientes com PPC, 168 apresentaram 12 alaninas (Ala 12) $^{2}$; 2 alelos com 11 repetições alaninas $\left(\mathrm{Ala}_{11}\right)$ e 2 alelos com 9 repetições alaninas (Alag). Desta forma, 4 pacientes com PPC idiopática apresentaram o genótipo com variação em heterozigose no número de alaninas: 2 pacientes não relacionados com um alelo com 12 alaninas e o outro alelo com 11 alaninas $\left(\mathrm{Ala}_{12} / \mathrm{Ala}_{11}\right)$ e 2 pacientes da mesma família (pacientes 1 e 2 ) com 12 repetições de alaninas em um alelo e 9 repetições no outro alelo $\left(\mathrm{Ala}_{12} / \mathrm{Ala}_{9}\right)$. No grupo com HHIn todos os alelos apresentaram 12 repetições de alanina $\left(A l a_{12}\right)$. O estudo desta variante no grupo controle $(n=53,106$ alelos) detectou 104 alelos com 12 repetições de alanina $\left(\mathrm{Ala}_{12}\right), 1$ alelo com 11 repetições de alanina $\left(\mathrm{Ala}_{11}\right)$ e outro com 16 repetições de alanina $\left(\mathrm{Ala}_{16}\right)$ (tabela 11$)$.

Não houve diferença significativa da frequência alélica em relação ao número de repetições alaninas entre os grupos PPC e controle $(p>0,05)$.

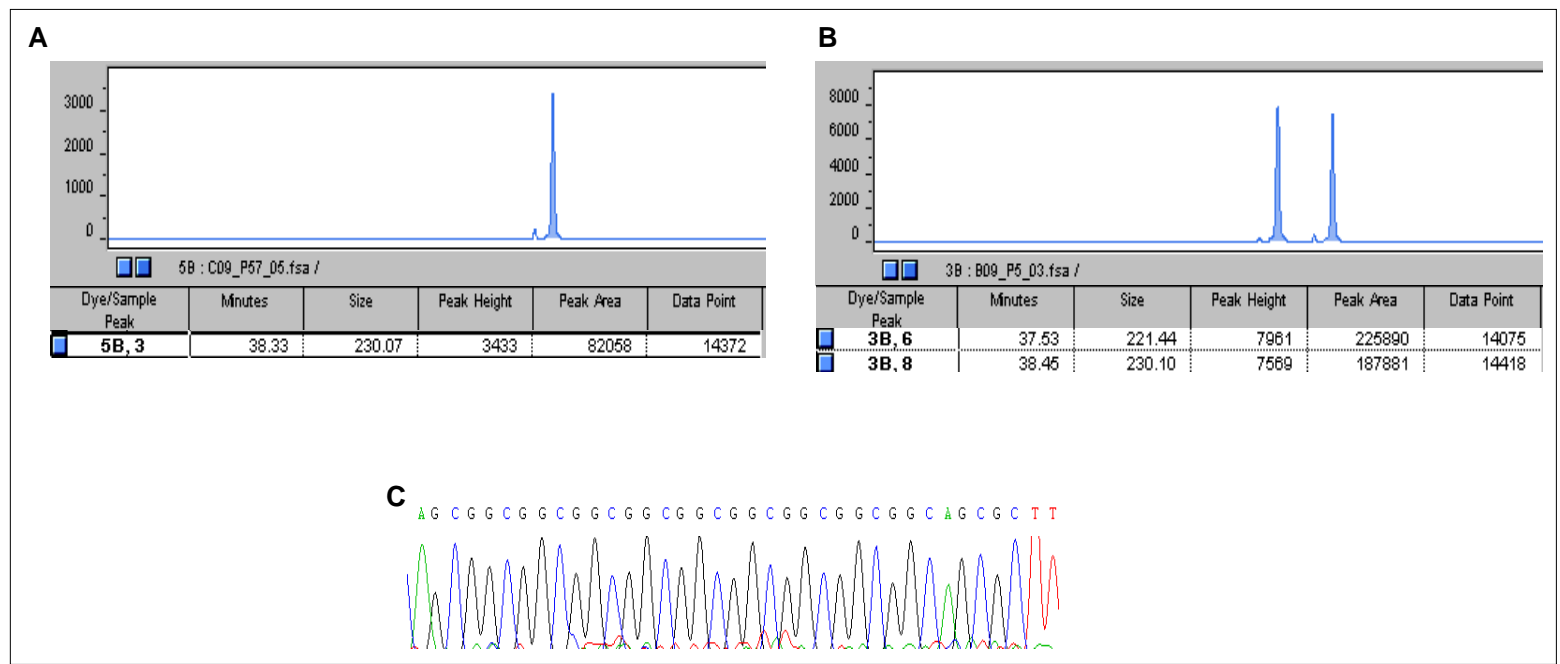

Figura 7. Estudo do número de repetições alaninas (região polialanina 5' distal) no EAP1. Resultados obtidos pelo programa GeneScan (A e B) e pelo sequenciamento automático (C). A - fragmento de $230 \mathrm{pb}$ em homozigose; B fragmentos de 230 e $221 \mathrm{pb}$ em heterozigose; C - sequenciamento automático do fragmento de $230 \mathrm{pb}$ estabelecendo a sua correspondência com 12 repetições de alaninas 
Tabela 10 - Distribuição alélica das variantes da região poliAla 5' distal nos distúrbios puberais centrais

\begin{tabular}{|l|c|c|c|c|}
\hline Ala $_{(\mathbf{n})^{*}}$ & $\mathbf{( A l a}_{\mathbf{1 6}}$ & $\mathbf{( A l a}_{\mathbf{1 2}}$ & $\mathbf{( A l a}_{\mathbf{1 1}}$ & $\mathbf{( A l a}_{\mathbf{9}}$ \\
\hline PPC (n=172) & 0 & 168 & 2 & 2 \\
\hline HHIn (n=94) & 0 & 94 & 0 & 0 \\
\hline Controles (n=106) & 1 & 104 & 1 & 0 \\
\hline
\end{tabular}

*número de repetições de alanina; $p=0,85$ (PPC vs. controles); $p=0,33$ (PPC vs HHIn); $p=0,53$ (HHIn vs controles)

\section{3 - Avaliação neurológica e neurocognitiva dos pacientes com PPC devido a hamartoma hipotalâmico}

Uma avaliação neurológica foi realizada nos 15 pacientes com PPC devido a hamartoma hipotalâmico. A mediana da idade cronológica na avaliação neurológica foi 13,2 anos, variando de 4 anos a 24 anos. Nestes pacientes a PPC manifestou-se na idade mediana de 0,9 ano (5 meses a 7 anos). A história perinatal destes pacientes não apresentava fatos relevantes e o desenvolvimento neuropsicomotor foi normal.

Dez dos 15 pacientes estudados (67\%) tiveram avaliação neurológica e cognitiva normal. Nesse grupo de pacientes todos tiveram bom desempenho escolar e nenhum apresentava relato de alterações comportamentais ou psiquiátricas. Não apresentavam história de epilepsia nem convulsões isoladas. Nove pacientes realizaram traçado eletroencefalográfico em sono e vigília o qual não evidenciou anormalidades.

Anormalidades neurológicas foram evidenciadas em 5 dos 15 pacientes $(33 \%)$. Dois $(12,5 \%)$ (pacientes 13 e 15$)$ tiveram um evento de convulsão isolada não provocada: um paciente (paciente 13) teve evento rápido de ausência, com duração de aproximadamente um minuto, aos 20 meses, durante o qual o paciente permaneceu arresponsivo, sem qualquer movimento ou automatismo. Este evento ocorreu uma única vez e na ausência de febre. Hoje o paciente tem 17 anos e não apresenta qualquer comprometimento social ou acadêmico. O outro paciente (paciente 15), hoje com 6 anos, apresentou 
convulsão generalizada afebril que foi precedida por espasmo das pernas na idade de 9 meses. O evento ocorreu logo após vacinação e não recorreu. Este paciente não apresenta alterações neurológicas ou comportamentais. O EEG de ambos os pacientes é normal.

Três pacientes apresentavam epilepsia: (1) paciente 11, idade atual de 19 anos, apresenta crises gelásticas desde os 8 meses de vida que não alteram a consciência, duram de 15 segundos a 40 segundos e são precedidas por uma sensação peculiar na cabeça e abdome. Aos 12 anos apresentou duas convulsões tônico-clônicas que ocorreram durante o sono, mas que cessaram após a introdução de medicação anticonvulsivante; no entanto, as crises gelásticas ainda ocorrem diariamente. O paciente terminou a oitava série, mas parou de frequentar a escola ou trabalho; apresenta isolamento social importante e raramente sai de casa, seu EEG mostra atividade epileptiforme no hemisfério cerebral posterior esquerdo. (2) Paciente 8, 14 anos, apresentou três eventos de epilepsia generalizada tônico-clônica que foram precedidos por uma sensação vaga não específica; o tratamento com medicação anticonvulsivante (carbamazepina) foi introduzido após esta avaliação neurológica. Seu EEG interictal é normal. O paciente apresenta, também, dificuldade escolar: ele frequenta a sexta-série, após ter repetido duas vezes o ano. (3) Paciente 7, 15 anos, apresenta crises gelásticas desde os 3 meses de idade e, a partir dos 3 anos, crises parciais complexas com generalização. Seu EEG mostra atividade epileptiforme no lobo esquerdo com projeção para a região centro-anterior.

Dois pacientes sem epilepsia (5 e 6) e um paciente com um evento convulsivo isolado (13) têm parentes de primeiro ou segundo grau com epilepsia. Nenhum paciente com epilepsia tem história familiar de epilepsia. Além disso, nenhum paciente tem história ou exame neurológico compatível com coreoatetose.

A análise da RM da região hipotálamo-hipofisária revelou que os hamartomas hipotalâmicos variaram de $4 \mathrm{~mm}$ a $30 \mathrm{~mm}$, com mediana de 10 $\mathrm{mm}$. A mediana do maior diâmetro dos hamartomas dos pacientes com PPC e 
manifestações neurológicas foi $13 \mathrm{~mm}$, variando de $10 \mathrm{~mm}$ a $20 \mathrm{~mm}$ e o daqueles sem manifestação neurológica foi $10 \mathrm{~mm}$, variando de $4 \mathrm{~mm}$ a $30 \mathrm{~mm}$ $(p=0,039)$. Quanto à forma e localização, 10 hamartomas foram classificados como sésseis e 5, como pedunculados. No grupo com manifestações neurológicas, todos eram sésseis e, no grupo sem manifestações neurológicas, havia 5 hamartomas hipotalâmicos sésseis e 5 pedunculados. Houve influência da forma do hamartoma sobre a ocorrência de epilepsia neste estudo ( $p=$ $0,02)$.

Onze pacientes $(73 \%)$ foram submetidos a avaliação neurocognitiva. Nove dos onze pacientes apresentam QI que variou de médio baixo a muito alto. Quatro dos cinco pacientes com convulsão realizaram avaliação neurocognitiva e o QI de dois dos três pacientes com epilepsia foi limítrofe, os outros dois pacientes com eventos convulsivos isolados tinham QI médio alto e muito alto. O QI verbal dos pacientes com PPC sem epilepsia foi $107 \pm 14,3$ e $79,5 \pm 2,1$ para aqueles com epilepsia $(p<0,05)$. O QI de execução médio dos pacientes com PPC sem epilepsia foi 110,5 \pm 16 e $82 \pm 11,3$ para aqueles com epilepsia $(p=0,06)$. O QI total médio dos pacientes com PPC sem epilepsia foi $109,5 \pm 14,6$ e $78,5 \pm 4,9$ para aqueles com epilepsia $(p<0,05)$. Para esta análise, os 2 pacientes com evento convulsivo isolado foram inseridos no grupo sem epilepsia. Estes dados estão representados na figura 8.

Não houve correlação significativa entre tamanho do hamartoma hipotalâmico e QIV, QIE e QIT ( $r=-0,07, p=0,8$ ) ou diferença na média dos quoeficientes entre os pacientes com hamartoma hipotalâmico pedunculado e séssil $(p>0,05)$.

Os dados clínicos, radiológicos e neurológicos dos pacientes estão resumidos na tabela 11 . 


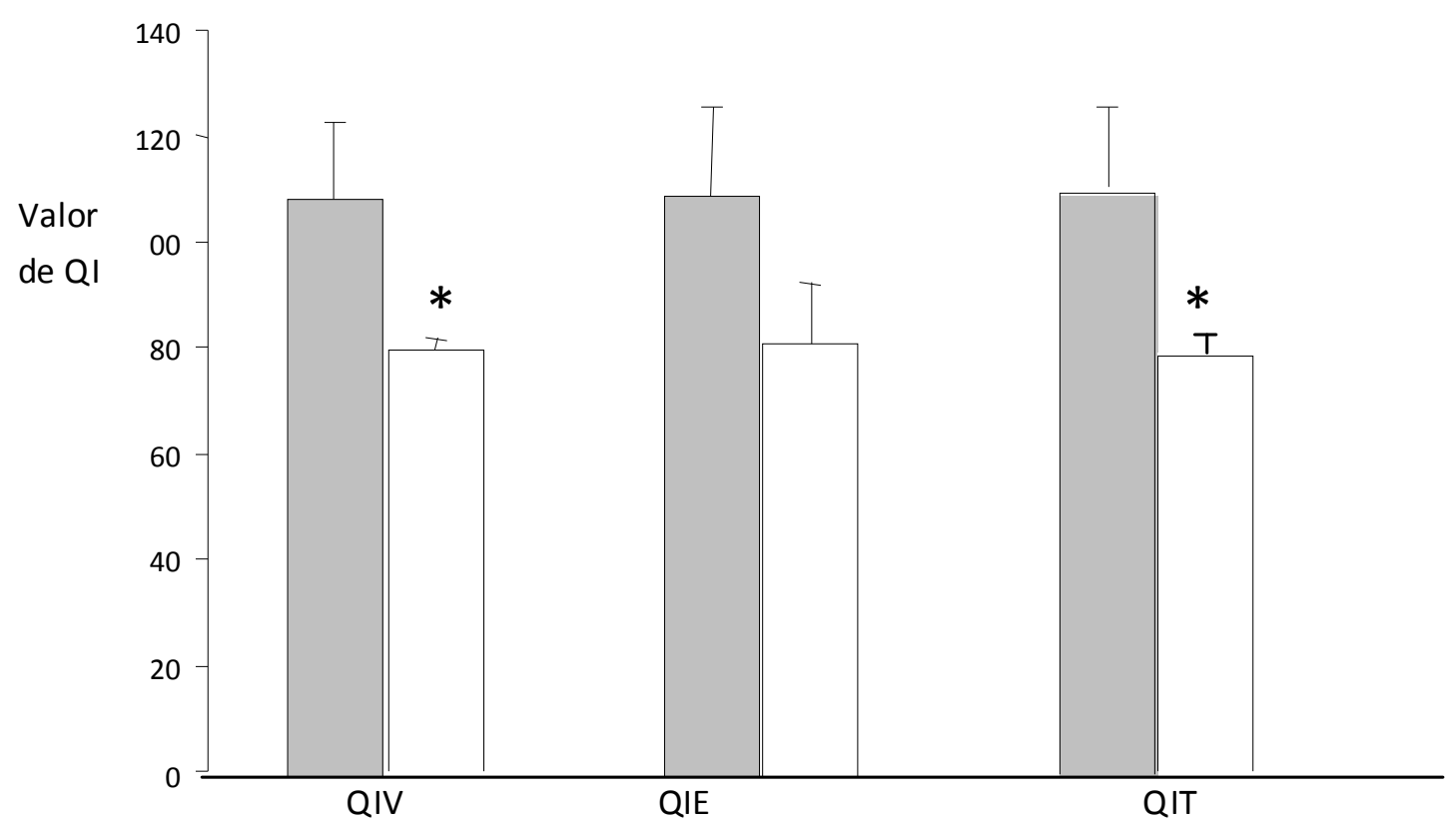

Figura 8. Quoeficiente de inteligência nos pacientes com hamartoma hipotalâmico com e sem epilepsia. Quoeficiente de inteligência avaliado por quoeficiente de inteligência verbal (QIV), quoeficiente de inteligência de execução (QIE) e quoeficiente de inteligência total (QIT) no grupo de pacientes com PCC devido a hamartoma hipotalâmico sem epilepsia (barra cinza; $n=9$ ) e com epilepsia (barra branca; $\mathrm{n}=2$ ). * $p<0,05$ 
Tabela 11 - Dados neurológicos e neurocognitivos dos pacientes com PPC devido a hamartoma hipotalâmico

\begin{tabular}{|c|c|c|c|c|c|c|}
\hline Caso & Sexo & & & $\begin{array}{c}\text { Característica da } \\
\text { epilepsia se presente }\end{array}$ & EEG interictal & $\begin{array}{c}\text { Classificação } \\
\text { de Ql }\end{array}$ \\
\hline & & $\begin{array}{l}\text { Tamanho } \\
(\mathrm{mm})\end{array}$ & Forma & & & \\
\hline 1 & $\mathrm{~F}$ & 8 & $P$ & $\mathrm{~N}$ & Normal & Média $^{\$}$ \\
\hline 2 & $\mathrm{~F}$ & 7 & $P$ & $\mathrm{~N}$ & Normal & Médio \\
\hline 3 & $\mathrm{~F}$ & 4 & P & $\mathrm{N}$ & Normal & $\begin{array}{l}\text { Médio } \\
\text { superior }\end{array}$ \\
\hline 4 & $\mathrm{~F}$ & 11 & $S$ & $\mathrm{~N}$ & Normal & ND \\
\hline 5 & $\mathrm{~F}$ & 10 & $S$ & $\mathrm{~N}$ & Normal & Média* \\
\hline 6 & $\mathrm{~F}$ & 13 & $S$ & $\mathrm{~N}$ & Normal & ND \\
\hline 7 & $\mathrm{~F}$ & 13 & $S$ & $\mathrm{Gel} \rightarrow \mathrm{CPC} \rightarrow \mathrm{TC}$ & $\begin{array}{l}\text { Paroxismos em hemisfério } \\
\text { esquerdo com projeção para } \\
\text { região frontocentral }\end{array}$ & Limítrofe \\
\hline 8 & M & 10 & $\mathrm{~S}$ & $\mathrm{CPS} \rightarrow \mathrm{CPC} \rightarrow \mathrm{TC}$ & Normal & Limítrofe \\
\hline 9 & $\mathrm{M}$ & 11 & $\mathrm{P}$ & $\mathrm{N}$ & Normal & Superior \\
\hline 10 & $\mathrm{M}$ & 6 & S & $\mathrm{N}$ & Normal & $\begin{array}{l}\text { Médio } \\
\text { inferior }\end{array}$ \\
\hline 11 & M & 20 & S & Gel e TC & $\begin{array}{l}\text { Paroxismos em hemisfério } \\
\text { posterior esquerdo durante } \\
\text { sono }\end{array}$ & ND \\
\hline 12 & $\mathrm{M}$ & 10 & $\mathrm{~S}$ & $\mathrm{~N}$ & ND & ND \\
\hline 13 & M & 19 & $S$ & CPS isolada & Normal & $\begin{array}{l}\text { Muito } \\
\text { Superior }\end{array}$ \\
\hline 14 & M & 30 & $S$ & $\mathrm{~N}$ & Normal & $\begin{array}{c}\text { Médio } \\
\text { inferior }^{\$}\end{array}$ \\
\hline 15 & M & 5 & P & CPS isolada & Normal & $\begin{array}{l}\text { Médio } \\
\text { superior }\end{array}$ \\
\hline
\end{tabular}

P: pedunculado; S: séssil; CPS: convulsão parcial simples; CPC: convulsão parcial complexa; TC: convulsão tônico-clônica; Gel: convulsão gelástica; ND: não disponível; N: normal; ${ }^{\$}$ avaliada pela escala de Wechsler de inteligência para adultos - $3^{\text {a }}$ edição (WAIS-III); *avaliada pela escala Wechsler Preschool and Primary Scale of Intelligence-Revised (WPPSI-R) 


\section{5 - Discussão}




\section{5 - DISCUSSÃO}

A elucidação dos mecanismos responsáveis pelo desencadeamento da puberdade humana é um dos grandes desafios de nosso século. A rápida evolução no conhecimento dos mecanismos genéticos que determinam o início da puberdade humana, principalmente a contribuição de pesquisas em modelos animais e os avanços em metodologias de biologia molecular, permitiu a identificação de potenciais genes candidatos envolvidos no desenvolvimento puberal, na espécie humana.

O amplo espectro dos distúrbios puberais, variando de telarca precoce isolada a puberdade precoce completa e de atraso puberal a hipogonadismo hipogonadotrófico, sugere uma modulação multifatorial (ambiental, nutricional, metabólica, psicossocial e genética) complexa. Atualmente, não há dúvidas de que os fatores genéticos influenciam o início da puberdade $(16-19)$. Até o presente momento apenas de Vries e cols. (19) documentaram, em uma casuística de 156 pacientes com puberdade precoce central, a forma familial em $27,5 \%$ dos casos (19). No presente estudo, pela pesquisa sistemática de casos familiais, identificamos $25 \%$ de casos familiares, prevalência semelhante àquela descrita na literatura; no entanto, este valor pode estar subestimado devido à dificuldade de acessarmos dados dos ancestrais, principalmente quanto ao início da puberdade no sexo masculino uma vez que, no sexo feminino, a ocorrência da menarca constitui um evento marcante. O padrão de herança autossômica dominante na maioria dos heredogramas analisados, bem como uma taxa de penetrância reduzida $(67,5 \%)$, estão em congruência com o estudo anterior de de Vries e cols. (19).

A teoria da hierarquia gênica no controle da secreção de $\mathrm{GnRH}$ proposta por Ojeda e cols. (94) demonstra uma interação entre substratos neuronais e gliais, bem como categoriza os genes em escalões hierárquicos de acordo com a sequência de eventos primários até a produção e a secreção do $\mathrm{GnRH}$. Embora isto auxilie a compreensão desses mecanismos, é importante 
considerar que a simultaneidade, a pluralidade e a heterogeneidade temporal e espacial dos eventos moleculares, em termos de localização no sistema nervoso central, dificultam a identificação de um único gene ou fator responsável pelo comprometimento da regulação da secreção pulsátil de $\mathrm{GnRH}$.

Neste estudo, nenhuma mutação ou polimorfismo foi identificado no TTF1. A grande heterogeneidade fenotípica dos pacientes portadores de mutações neste gene, descritos na literatura, está de acordo com a variável expressão do TTF-1 nos diferentes tecidos (tireoide, pulmão e diencéfalo) (106 - 117). São descritas mutações no TTF-1 em pacientes com fenótipo de bócio e hipotireoidismo $(106,107)$; coreia familiar benigna (99 - 111); tireoidopatias neonatais, insuficiência respiratória, hipotonia e coreoatetose (106, 111 - 117); no entanto, os dados sobre o desenvolvimento puberal, bem como a história de fertilidade, não são relatados nestas descrições. Uma vez que a associação do TTF-1 com o eixo reprodutivo foi reportada recentemente, é admissível a possibilidade de ampliação do espectro fenotípico decorrente de anormalidades genéticas no TTF-1. Além disso, nenhum paciente estudado em nossa casuística apresentava anormalidades tireoidianas ou pulmonares. Do ponto de vista neurológico, embora somente os pacientes com hamartoma hipotalâmico tenham sido avaliados sistematicamente, os demais não apresentavam manifestações neurológicas evidentes. Em particular, o diagnóstico de coreia e coreoatetose não pode ser excluído definitivamente nesses pacientes, uma vez que formas subclínicas somente podem ser identificadas com exames mais refinados. Por outro lado, o alto grau de conservação do TTF-1 e a falta de evidências de mutações germinativas em nossa casuística não excluem anormalidades em sua expressão hipotalâmica ou defeitos somáticos, que poderiam estar envolvidos tanto na etiologia dos distúrbios puberais, até então considerados idiopáticos, como na base molecular dos hamartomas hipotalâmicos esporádicos e não sindrômicos que cursam com PPC. A grande 
limitação para estudos de expressão e pesquisa de mutações somáticas é a indisponibilidade do tecido hipotalâmico.

Assim como o TTF-1, EAP1 também parece ser um fator primordial no processo, pois o aumento de sua expressão hipotalâmica ocorre antes do aumento dos níveis de esteroides sexuais (124). Em nossa casuística, embora tenham sido identificadas quatro variantes alélicas sinônimas no EAP1 (p.E87E, p.A163A, p.Y415Y e p.C758C), em pacientes com PPC e HHIn, a ausência de associação com o fenótipo afasta um possível efeito funcional destas variantes na fisiopatologia dos distúrbios puberais centrais.

Estudamos também os tratos poliglutamina e polialanina no gene EAP1. Sabe-se que a expansão no número de trinucleotídeos é causa comum de doenças, em sua maioria, neurológicas (atrofia dentatorubropalidoluisiana, doença de Huntington, atrofia muscular espinobulbar e ataxia espinocerebelar tipos 1, 2, 3, 6, 7 e 17). As repetições CAG ou CAACAG, que formam na síntese proteica o trato poliQ são as mais frequentes (135). Outras repetições trinucletídeas, como alanina, também podem causar doenças. Pelo menos nove genes com expansão da região polialanina foram descritos, dos quais oito são fatores de transcrição, como causadores de doenças (sindactilia blefarofimoseptose-epicanto inverso, holoprosencefalia, hipoventilação congênita central, síndrome de West, retardo mental com deficiência de hormônio de crescimento, displasia cleidocranial, sindrome cabeça-pé-genital e simpolidactilia) (136). Os estudos in vitro sugerem que a expansão destas regiões altera a estrutura da proteína, levando a maior agregação e subsequente degradação (136). São doenças de caráter autossômico dominante que apresentam fenômeno de antecipação, cujo número maior de repetições está associado a maior precocidade ou maior agressividade da manifestação (135). No nosso estudo, é notável que o número de repetições $Q$ na região poliQ e de Ala na região poliAla apresentou pequena variabilidade nos grupos com distúrbios puberais, contrastando com os achados de Rampazzo e cols. na população italiana (123). A falta de associação significativa do número de repetições de glutamina e 
alanina com o fenótipo PPC ou HHIn também pode afastar um potencial papel funcional da variabilidade no número de repetições trinucleotídeas do EAP1 na gênese dos distúrbios puberais.

$E A P-1$ é um gene de difícil amplificação e sequenciamento, devido à sua riqueza em nucleotídeos guanina-citosina (GC), à presença de repetição de várias sequências com mono, di ou trinucleotídeos e ao grande número de polimorfismos nesta região poliQ, exigindo fragmentar, utilizar enzimas DNApolimerase específicas e confeccionar vários oligonucleotídeos para sequenciamento, bem como a utilização de metodologia para análise de tamanho de fragmento. Além disso, EAP1 é um gene polimórfico e, até o momento, cerca de 70 variantes alélicas foram depositadas no banco de dados (www.ncbi.nlm.nih.gov).

A falta de associação entre variantes alélicas germinativas no EAP1 e distúrbios puberais centrais, como ocorre no TTF-1, não exclui o papel deste gene na patogênese dos distúrbios puberais centrais, uma vez que alterações de expressão e/ou mutações somáticas hipotalâmicas não puderam ser avaliadas no presente estudo pela falta de tecido de hipotálamo disponível.

Os genes TTF-1 e EAP1 foram também estudados nos pacientes portadores de hamartoma hipotalâmico e, da mesma forma que nos pacientes com PPC idiopática, somente polimorfismos no EAP1 foram identificados. Em relação à base molecular dos hamartomas hipotalâmicos, pouco ainda é conhecido. A síndrome de Pallister-Hall determinada por mutações no GL/3, um regulador da via morfogênica controlada por proteínas sonic-hedgehog que controlam em parte o desenvolvimento hipotalâmico por meio da ativação transcricional de genes da família homeodomínio como o TTF-1 (137), é o modelo clássico de atuação de um fator de transcrição na gênese de hamartomas. Anormalidades cromossômicas na região do GL/3 já foram identificadas em tecidos de hamartoma hipotalâmico esporádico e não sindrômico (138), no entanto, a maioria dos casos esporádicos de hamartoma hipotalâmico não é decorrente de mutações somáticas no $G L / 3$, e outros 
mecanismos, como mutações em outros genes ou regiões, devem estar envolvidos (137). Outros genes têm sido responsabilizados na patogênese de hamartomas hipotalâmicos associados a outras anormalidades de desenvolvimento. Mutações inativadoras no SOX2, um fator de transcrição da família SOX que utiliza o domínio de ligação ao DNA HMG-box, foram associadas com anomalias do desenvolvimento, como malformações oculares, hipoplasia hipofisária anterior e defeitos cerebrais de linha média. Um trabalho recente demonstrou a associação de mutações germinativas no SOX2 em 25\% dos casos de pacientes com hamartoma hipotalâmico sem epilepsia (139). No entanto, não é possível afastar mutações somáticas no SOX2 em casos esporádicos, não sindrômicos de hamartoma hipotalâmico. Finalmente, foi identificado outro locus susceptível para hamartomas hipotalâmicos em uma região que inclui o gene $F O X C 1$, fator de transcrição da família forkhead, que também pode representar um gene candidato na patogênese dos hamartomas hipotalâmicos (140). Além disso, estudos comparando a expressão gênica em tecidos de hamartomas de pacientes com e sem PPC identificaram a expressão diferencial de dez genes cuja expressão foi aumentada em hamartomas hipotalâmicos associados a PPC que codificam proteínas envolvidas em três processos celulares chave: regulação transcricional, sinalização célula-célula e adesividade celular, incluindo IA-1 e MEF2A, dois fatores de transcrição necessários para o desenvolvimento neuronal; mGluR1 e VILIP-1 que codificam proteínas envolvidas na comunicação neuronal; e TSG6 que codifica proteína envolvida na adesividade celular (141).

Outro aspecto investigado em nosso estudo foi a caracterização neurológica e neurocognitiva dos pacientes com PPC devido a hamartoma hipotalâmico, causa orgânica mais frequente de PPC $(25,73)$. Quando a primeira manifestação clínica destes pacientes portadores de hamartoma hipotalâmico é a puberdade precoce central, eles são encaminhados para o endocrinologista pediátrico, enquanto as manifestações neurológicas, quando presentes, direcionam 0 paciente para o neurologista. No subgrupo de 
pacientes com PPC, os sintomas neurológicos podem estar pouco evidentes, a menos que uma sintomatologia típica seja relatada.

Além disso, uma alta prevalência de distúrbios cognitivos e psiquiátricos (dificuldades cognitivas leves, deficit de atenção e hiperatividade) é demonstrada nos pacientes com epilepsia devido ao hamartoma hipotalâmico (142). Nenhum estudo de avaliação neurocognitiva de pacientes com PPC devido hamartoma hipotalâmico com e sem epilepsia está disponível até o momento.

O hamartoma hipotalâmico é responsável por diferentes formas de epilepsia, incluindo a epilepsia gelástica, um tipo característico e sugestivo de hamartoma. Uma extensa análise de 277 pacientes com hamartoma hipotalâmico demonstrou que $63 \%$ destes manifestaram PPC, $61 \%$ apresentaram epilepsia e a associação entre PPC e epilepsia foi encontrada em apenas $27 \%$ neste grupo $(78,143)$. Em nosso estudo, epilepsia foi diagnosticada em 3/15 (20\%) pacientes e 2/15 (13\%) apresentaram apenas um evento convulsivo isolado que não pode ser atribuído exclusivamente ao hamartoma hipotalâmico. De fato, nós não podemos desconsiderar o fato de nossa amostra ser constituída de pacientes atendidos pela manifestação inicial de puberdade precoce.

Epilepsia gelástica é amplamente associada ao hamartoma hipotalâmico, embora não seja patognomônica, e é causada por uma lesão subcortical. Das outras formas de epilepsia, apenas dois subtipos foram encontrados em nossa casuística: crises convulsivas parciais complexas e crises tônico-clônicas generalizadas. Neste estudo, dois dos três pacientes apresentaram inicialmente epilepsia gelástica e progrediram para crises parciais complexas e/ou tônicoclônicas, em concordância com outros relatos $(144,145)$. A fisiopatologia da epilepsia devido ao hamartoma hipotalâmico é complexa e controversa. Várias hipóteses são sugeridas, dentre elas a disgenesia cortical e a compressão mecânica do hipotálamo e dos corpos mamilares (142). Descargas ictais 
recorrentes que se propagam por redes neuronais até o córtex cerebral estão envolvidas nas alterações da alça tálamo-cortical e originam as alterações na atividade eletroencefalográfica (ondas e espículas lentas) (146). A forma do hamartoma hipotalâmico (pedunculado ou séssil) parece ser um fator relevante na gênese das convulsões (147). A frequência e intensidade das crises convulsivas estão associadas a um declínio na função cognitiva e comportamental (148). As descargas excitatórias recorrentes causadas pela dispersão da atividade convulsiva originada no hamartoma hipotalâmico pela via mamilo-talâmica e área cerebral associada poderia ser responsável pela deterioração cognitiva $(144,145,149)$.

Neste estudo, ficou evidente que o subgrupo de pacientes com PPC e epilepsia apresentou QIT, QIV e QIE significativamente menor do que os pacientes com PPC sem epilepsia, reforçando a teoria de que os distúrbios cognitivos possam estar associados à severidade da encefalopatia epilética (142). Os pacientes sem epilepsia apresentaram QIT dentro do intervalo de normalidade ou acima deste. A limitação principal do nosso estudo consiste no pequeno número de pacientes, porém considerando que a incidência e a prevalência de hamartoma hipotalâmico é relativamente baixa $(<0,001 \%)$, nossos dados correspondem a uma série representativa de pacientes com hamartoma hipotalâmico que manifestaram inicialmente PPC. Limitamos a análise à escala de QI, uma vez que qualquer distúrbio comportamental que pudesse potencialmente ser detectado por outras ferramentas poderia também ser atribuído à própria ocorrência de puberdade precoce.

Quanto à forma do hamartoma hipotalâmico, é sugerido que os sésseis, ao contrário dos pedunculados, poderiam causar diversos distúrbios das funções integrativas cerebrais e, consequentemente, a função cognitiva pior (83, 134, 143, 150). Em nossa análise, a avaliação cognitiva baseada nas médias dos quoeficientes não apresentou diferença entre os pacientes com hamartomas sésseis comparados com os pedunculados. Além disso, houve influência da forma do hamartoma sobre a ocorrência de epilepsia neste estudo 
( $p=0,02)$ : todos os pacientes com PPC e epilepsia apresentavam hamartoma séssil, no entanto os pacientes com PPC sem epilepsia apresentaram hamartomas sésseis $(n=5)$ e pedunculados $(n=5)$, confirmando que a forma pedunculada está menos associada a manifestações neurológicas (134, 143, 150, 151).

Finalmente, novas metodologias têm sido utilizadas para elucidar o papel genético no controle da secreção de $\mathrm{GnRH}$ e, consequentemente, dos distúrbios puberais. Estudos de genome-wide association (GWAS) têm sido uma estratégia de investigação genética em evidência, abrindo perspectivas para novas descobertas. Estudos de associação de idade de menarca e/ou menopausa, utilizando GWAS, identificaram um locus no cromossomo $6 q 21$, onde se localiza o gene LIN28B (152). LIN28B é um gene que medeia a regulação de um precursor do microRNA let-7, criando um novo mecanismo que envolve os microRNAs, uma classe de RNAs endógenos, de aproximadamente 22 nucleotídeos; estes atuam como silenciadores póstranscricionais e inibem a tradução de RNAs mensageiros-alvo. Desta forma microRNAs podem estar envolvidos no controle da secreção de $\mathrm{GnRH}$ e, consequentemente, no desenvolvimento puberal.

Concluindo, o nosso estudo adicionou a investigação de dois genes candidatos (TTF-1 e EAP1) para elucidar a base genética dos distúrbios puberais centrais, embora mutações germinativas nestes genes não tenham sido associadas ao fenótipo dos distúrbios puberais centrais. 


\section{6- Conclusões}




\section{6- CONCLUSÕES}

1. A forma familiar de PPC foi identificada em $25 \%$ da nossa casuística com modo de herança autossômica dominante e penetrância incompleta, reforçando o papel de fatores genéticos na etiologia da PPC.

2. Variantes alélicas germinativas no gene TTF-1 e em seu promotor não foram identificadas em pacientes com distúrbios puberais centrais idiopáticos nem em pacientes com PPC devido a hamartoma hipotalâmico. TTF-1 é um gene altamente conservado e não está envolvido na etiologia dos distúrbios puberais centrais.

3. EAP-1 é um gene polimórfico, porém as variantes alélicas germinativas identificadas não foram associadas aos distúrbios puberais centrais idiopáticos nem em pacientes com PPC devido a hamartoma hipotalâmico.

4. Anormalidades neurológicas foram diagnosticadas em $20 \%$ dos pacientes com PPC devido a hamartoma hipotalâmico, caracterizadas principalmente por epilepsia gelástica e epilepsia focal e generalizada. Avaliação neurológica deve ser realizada em todos os pacientes com PPC devido a hamartoma hipotalâmico.

5. Pacientes com PPC devido a hamartoma hipotalâmico e sem epilepsia apresentaram desenvolvimento neurocognitivo normal, enquanto aqueles com epilepsia revelaram função neurocognitiva prejudicada, sugerindo que o efeito das crises convulsivas sobre as estruturas cerebrais seja deletério. Recomendamos que a avaliação neurocognitiva seja realizada em pacientes com PPC devido a hamartoma hipotalâmico com epilepsia. 


\section{7- Referências bibliográficas}




\section{7- REFERÊNCIAS BIBLIOGRÁFICAS}

1. Palmert MR, Boepple PA. Variation in the timing of puberty: clinical spectrum and genetic investigation. J Clin Endocrinol Metab. 2001;86:2364-8.

2. Seminara SB, Crowley WF Jr. Perspective: the importance of genetic defects in humans in elucidating the complexities of the hypothalamic-pituitarygonadal axis. Endocrinology. 2001;142:2173-7.

3. Terasawa E, Fernandez DL. Neurobiological mechanisms of the onset of puberty in primates. Endocr Rev. 2001;22:111-51.

4. Grumbach MM. The neuroendocrinology of human puberty revisited. Horm Res. 2002;57(Suppl 2):2-14.

5. Plant TM. Neurophysiology of puberty. J Adolesc Health. 2002;31:185-91.

6. Dhillo WS, Chaudhri OB, Patterson M, Thompson EL, Murphy KG, Badman MK, McGowan BM, Amber V, Patel S, Ghatei MA, Bloom SR. Kisspeptin-54 stimulates the hypothalamic-pituitary gonadal axis in human males. J Clin Endocrinol Metab. 2005;90:6609-15.

7. El Majdoubi M, Sahu A, Ramaswamy S, Plant TM. Neuropeptide Y: A hypothalamic brake restraining the onset of puberty in primates. Proc Natl Acad Sci U S A. 2000;97:6179-84.

8. Plant TM. Leptin, growth hormone, and the onset of primate puberty. $J$ Clin Endocrinol Metab. 2001;86:458-60.

9. Moore CR, Price D. Gonadal hormone functions and the reciprocal influence between gonads and hypophysis, with its bearing on sex hormone antagonism. Am J Anat. 1932;50:1371.

10. Partsch CJ, Sippell WG. Pathogenesis and epidemiology of precocious puberty. Effects of exogenous oestrogens. Human Reprod Update. 2001;7:292302. 
11. Karsch FJ, Bowen JM, Caraty A, Evans NP, Moenter SM. Gonadotropin releasing hormone requirements for ovulation. Biol Reprod. 1997;56:303-9.

12. Mitamura R, Yano K, Suzuki N, Ito $\mathrm{Y}$, Okuno A. Diurnal rhythms of luteinizing hormone, folliclestimulating hormone, and testosterone secretion before the onset of male puberty. J Clin Endocrinol Metab. 1999;84:29-37.

13. Mitamura R, Yano K, Suzuki N, Ito Y, Makita Y, Okuno A. Diurnal rhythms of luteinizing hormone, folliclestimulating hormone, testosterone, and estradiol secretion before the onset of female puberty in short children. J Clin Endocrinol Metab. 2000;85:1074-80.

14. Grumbach MM, Styne DM. Pubery: Ontogeny, Neuroendocrinology, Physiology, and Disorders. In: Williams Textbook of Endocrinology. 10th ed, Philadelphia: Saunders; 2003.

15. Conte FA, Grumbach MM, Kaplan SL, Reiter EO. Correlation of luteinizing hormone releasing factor induced luteinizing hormone and follicle stimulating hormone release from infancy to 19 years with the changing pattern of gonadotropin secretion in agonadal patients: relation to the restraint of puberty. J Clin Endocrinol Metab. 1980;50:163-8.

16. Wu T, Mendola P, Buck GM. Ethnic differences in the presence of secondary sex characteristics and menarche among US girls: the Third National Health and Nutrition Examination Survey, 1988-1994. Pediatrics. 2002;110:7527.

17. Anderson SE, Must A. Interpreting the continued decline in the average age at menarche: results from two nationally representative surveys of U.S. girls studied 10 years apart. J Pediatr. 2005;147:753-60.

18. Sedlmeyer IL, Palmert MR. Delayed puberty: analysis of a large case series from an academic center. J Clin Endocrinol Metab. 2002;87:1613-20. 
19. de Vries L, Kauschansky A, Shohat M, Phillip M. Familial central precocious puberty suggests autosomal dominant inheritance. J Clin Endocrinol Metab. 2004;89:1794-800.

20. Palmert MR, Hirschhorn JN. Genetic approaches to stature, pubertal timing, and other complex traits. Mol Genet Metab. 2003;80:1-10.

21. Banerjee I, Clayton P. The genetic basis for the timing of human puberty. J Neuroendocrinol. 2007;19:831-8.

22. Achermann JC, Ozisik G, Meeks JJ, Jameson JL. Genetic causes of human reproductive disease. J Clin Endocrinol Metab. 2002;87:2447-54.

23. Kalantaridou SN, Chrousos GP. Clinical review 148: Monogenic disorders of puberty. J Clin Endocrinol Metab. 2002;87:2481-94.

24. Lin L, Conway GS, Hill NR, Dattani MT, Hindmarsh PC, Achermann JC. A homozygous $\mathrm{R} 262 \mathrm{Q}$ mutation in the gonadotropin-releasing hormone receptor presenting as constitutional delay of growth and puberty with subsequent borderline oligospermia. J Clin Endocrinol Metab. 2006;91:5117-21.

25. Brito VN, Latronico AC, Arnhold IJ, Mendonca BB. Update on the etiology, diagnosis and therapeutic management of sexual precocity. Arq Bras Endocrinol Metabol. 2008;52:18-31.

26. Carel JC, Léger J. Precocious puberty. N Engl J Med. 2008;358:2366-77.

27. Parent AS, Teilmann G, Juul A, Skakkebaek NE, Toppari J, Bourguignon JP. The timing of normal puberty and the age limits of sexual precocity: variations around the world, secular trends, and changes after migration. Endocr Rev. 2003;24:668-93.

28. Teilmann G, Pedersen CB, Jensen TK, Skakkebaek NE, Juul A. Prevalence and incidence of precocious pubertal development in Denmark: an epidemiologic study based on national registries. Pediatrics. 2005;116:1323-8. 
29. Kakarla N, Bradshaw KD. Disorders of pubertal development: precocious puberty. Semin Reprod Med. 2003;21:339-51.

30. Grumbach M M. Puberty: ontogeny, neuroendocrinology, physiology and disorders. In: Williams Textbook of Endocrinology. 11th ed, Philadelphia: Saunders; 2008.

31. Bierich JR, Nolte K, Drews K, Brugmann G. Constitutional delay of growth and adolescence. Results of short-term and long-term treatment with $\mathrm{GH}$. Acta Endocrinol. 1992;127:392-6.

32. Clayton PE, Shalet SM, Price DA. Endocrine manipulation of constitutional delay in growth and puberty. J Endocrinol. 1988;116:321-3.

33. Raivio T, Falardeau J, Dwyer A, Quinton R, Hayes FJ, Hughes VA, Cole LW, Pearce SH, Lee H, Boepple P, Crowley WF Jr, Pitteloud N. Reversal of idiopathic hypogonadotropic hypogonadism. N Engl J Med. 2007;357:863.

34. Ribeiro RS, Vieira TC, Abucham J. Reversible Kallmann syndrome: report of the first case with a KAL1 mutation and literature review. Eur J Endocrinol 2007;156:285-90. Erratum in: Eur J Endocrinol. 2007;156:703

35. Sinisi AA, Asci R, Bellastella G, Maione L, Esposito D, Elefante A, De Bellis A, Bellastella A, Iolascon A. Homozygous mutation in the prokineticinreceptor2 gene (Val274Asp) presenting as reversible Kallmann syndrome and persistent oligozoospermia: case report. Hum Reprod. 2008;23:2380-4.

36. Pitteloud N, Acierno JS Jr, Meysing AU, Dwyer AA, Hayes FJ, Crowley WF Jr. Reversible kallmann syndrome, delayed puberty, and isolated anosmia occurring in a single family with a mutation in the fibroblast growth factor receptor 1 gene. J Clin Endocrinol Metab. 2005;90:1317-22.

37. Franco B, Guioli S, Pragliola A, Incerti B, Bardoni B, Tonlorenzi R, Carrozzo R, Maestrini E, Pieretti M, Taillon-Miller P, Brown CJ, Willard HF, Lawrence C, Graziella Pérsico M, Camerino G, Ballabio A. A gene deleted in 
Kallmann's syndrome shares homology with neural cell adhesion and axonal path-finding molecules. Nature. 1991;353:529-36.

38. Legouis R, Hardelin JP, Levilliers J, Claverie JM, Compain S, Wunderle V, Milasseau P, Le Pasilier D, Cohen D, Caterina D, et al. The candidate gene for the X-linked Kallmann syndrome encodes a protein related to adhesion molecules. Cell. 1991;67:423-35.

39. Dode C, Levilliers J, Dupont JM, De Paepe A, Le Dû N, SoussiYanicostas N, Coimbra RS, Delmaghani S, Compain-Nouaille S, Baverel F, Pêcheux C, Le Tessier D, Cruaud C, Delpech M, Speleman F, Vermeulen S, Amalfitano A, Bachelot Y, Bouchard P, Cabrol S, Carel JC, Delemarre-van de Waal H, Goulet-Salmon B, Kottler ML, Richard O, Sanchez-Franco F, Saura R, Young J, Petit C, Hardelin JP. Loss-of-function mutations in FGFR1 cause autosomal dominant Kallmann syndrome. Nat Genet. 2003;33:463-5.

40. Dode C, Teixeira L, Levilliers J, Fouveaut C, Bouchard P, Kottler ML, Lespinasse J, Lienhardt-Roussie A, Mathieu M, Moerman A, Morgan G, Murat A, Toublanc JE, Wolczynski S, Delpech M, Petit C, Young J, Hardelin JP. Kallmann syndrome: mutations in the genes encoding prokineticin-2 and prokineticin receptor-2. PLoS Genetics. 2006;2:e175.

41. Pitteloud N, Zhang C, Pignatelli D, Li JD, Raivio T, Cole LW, Plummer L, JacobsonDickman EE, Mellon PL, Zhou QY, Crowley Jr WF. Lossoffunction mutation in the prokineticin 2 gene causes Kallmann syndrome and normosmic idiopathic hypogonadotropic hypogonadism. Proc Natl Acad Sci U S A. 2007b;104:17447-52.

42. Abreu AP, Trabach EB, de Castro M, Costa EMF, Versiani B, Baptista MTM, Garmes HM, Mendonca BB, Latronico AC. Lossoffunction mutations in the genes encoding Prokineticin2 or Prokineticin receptor2 cause autosomal recessive Kallmann syndrome. J Clin Endocrinol Metab. 2008;93:4113-8. 
43. Falardeau J, Chung WCJ, Beenken A, Raivio T, Plummer L, Sidis $\mathrm{Y}$, JacobsonDickman EE, Eliseenkova AV, Ma J, Dwyer A, Quinton R, na S, Hall JE, Huot C, Alois N, Pearce SHS, Cole LW, Hughes V, Mohammadi M, Tsai P, Pitteloud N. Decreased FGF8 signaling causes deficiency of gonadotropinreleasing hormone in humans and mice. J Clin Invest. 2008;118:2822-31.

44. Kim HG, Kurth I, Lan F, Meliciani I, Wenzel W, Eom SH, Kang GB, Rosenberger G, Tekin M, Ozata M, Bick DP, Sherins RJ, Walker SL, Shi Y, Gusella JF, Layman LC. Mutations in CHD7, encoding a chromatinremodeling protein, cause idiopathic hypogonadotropic hypogonadism and Kallmann syndrome. Am J Hum Genet. 2008;83:511-9.

45. Gajdos ZKZ, Butler JL, de Lellis Henderson K, He C, Supelak PJ, Egyud M, Price A, Reich D, Clayton PE, le Marchand L, Hunter DJ, Henderson BE, Palmert MR and Hirschhorn J. Association studies of common variants in ten hypogonadotropic hypogonadism genes with age at menarche. J Clin Endocrinol Metab. 2008;93:4290-8.

46. de Roux N, Young J, Misrahi M, Schaison G, Milgrom E. Loss of function mutations of the $\mathrm{GnRH}$ receptor: a new cause of hypogonadotropic hypogonadism. J Pediatr Endocrinol Metab. 1999;12:267-75.

47. de Roux N, Genin E, Carel JC, Matsuda F, Chaussain JL, Milgrom E. Hypogonadotropic hypogonadism due to loss of function of the KiSS1-derived peptide receptor GPR54. Proc Natl Acad Sci U S A. 2003;100:10972-6.

48. Seminara SB, Messager S, Chatzidaki EE, et al. The GPR54 gene as a regulator of puberty. N Engl J Med. 2003;349:1614-27.

49. Lanfranco F, Gromoll J, von Eckardstein S, Herding EM, Nieschlag E, Simoni M. Role of sequence variations of the $\mathrm{GnRH}$ receptor and $\mathrm{G}$ proteincoupled receptor 54 gene in male idiopathic hypogonadotropic hypogonadism. Eur J Endocrinol. 2005;153:845-52. 
50. Semple RK, Achermann JC, Ellery J, Farooqi IS, Karet FE, Stanhope RG, O'rahilly S, Aparicio SA. Two novel missense mutations in g protein-coupled receptor 54 in a patient with hypogonadotropic hypogonadism. J Clin Endocrinol Metab. 2005;90:1849-55.

51. Bouligand J, Guiochon-Mantel A, Young J. GNRH1 mutation in familial hypogonadotropic hypogonadism. Med Sci. 2009;25:791-3.

52. Pitteloud N, Acierno JS Jr, Meysing A, Eliseenkova AV, Ma J< Ibrahimi OA, Metzger DL, Hayes FJ, Dwyer AA, Hughes VA, Yialamas M, Hall JE, Grant E, Mohammadi M, Crowley WL Jr.. Mutations in fibroblast growth factor receptor 1 cause both Kallmann syndrome and normosmic idiopathic hypogonadotropic hypogonadism. Proc Natl Acad Sci U S A. 2006;103:6281-6.

53. Matthews $\mathrm{CH}$, Borgato $\mathrm{S}$, Beck-Peccoz $\mathrm{P}$, Adams $\mathrm{M}$, Tone $\mathrm{Y}$, Gambino G, Casagrande S, Tedeschini G, Benedetti A, Chatterjee VK. Primary amenorrhoea and infertility due to a mutation in the beta-subunit of folliclestimulating hormone. Nat Genet. 1993;5:83-6.

54. Weiss J, Axelrod L, Whitcomb RW, Harris PE, Crowley WF, Jameson JL. Hypogonadism caused by a single amino acid substitution in the beta subunit of luteinizing hormone. N Engl J Med. 1992;326:179-83.

55. Topaloglu AK, Reimann F, Guclu M, Yalin AS, Kotan LD, Porter KM, Serin A, Mungan NO, Cook JR, Ozbek MN, Imamoglu S, Akalin NS, Yuksel B, O'Rahilly S, Semple RK. TAC3 and TACR3 mutations in familial hypogonadotropic hypogonadism reveal a key role for Neurokinin B in the central control of reproduction.Nat Genet. 2009;4:354-8.

56. Latronico AC. The neurokinin B pathway in human reproduction. Nat Genet. 2009;41:269-70.

57. Silveira LF, MacColl GS, Bouloux PM. Hypogonadotropic hypogonadism. Semin Reprod Med. 2002;20:327-38. 
58. Sedlmeyer IL, Pearce CL, Trueman JA, Butler JL, Bersaglieri T, Read AP, Clayton PE, Kolonel LN, Henderson BE, Hirschhorn JN, Palmert MR. Determination of sequence variation and haplotype structure for the gonadotropinreleasing hormone $(\mathrm{GnRH})$ and $\mathrm{GnRH}$ receptor genes: investigation of role in pubertal timing. J Clin Endocrinol Metab. 2005;90:1091-9.

59. Nanao K, Hasegawa Y. Polymorphisms at the $5^{\prime}$ end of the human gonadotropinreleasing hormone receptor gene are not associated with the timing of menarche in Japanese girls. Eur J Endocrinol. 2000;143:555-6.

60. Teles MG, Bianco SD, Brito VN, Trarbach EB, Kuohung W, XuS, Seminara SB, Mendonca BB, Kaiser UB, Latronico AC. A GPR54-activating mutation in a patient with central precocious puberty. $N$ Engl $\mathrm{J}$ Med. 2008;358:709-15.

61. Gottsch ML, Cunningham MJ, Smith JT, Popa SM, Acohido BV, Crowley WF, Seminara S, Clifton DK, Steiner RA. A role for kisspeptins in the regulation of gonadotropin secretion in the mouse. Endocrinology. 2004;145:4073-7.

62. Irwig MS, Fraley GS, Smith JT, Acohido BV, Popa SM, Cunningham MJ, Gottsch ML, Clifton DK, Steiner RA. Kisspeptin activation of gonadotropin releasing hormone neurons and regulation of Kiss1 mRNA in the male rat. Neuroendocrinology. 2004;80:264-72.

63. Navarro VM, Fernández-Fernández R, Castellano JM, Roa J, Mayen A, Barreiro ML, Gaytan F, Aguilar E, Pinilla L, Dieguez C, Tena-Sempere M. Advanced vaginal opening and precocious activation of the reproductive axis by KiSS-1 peptide, the endogenous ligand of GPR54. J Physiol. 2004;561:379-86.

64. Navarro VM, Castellano JM, Fernández-Fernández R, Barreiro ML, Roa J, Sanchez-Criado JE, Aguilar E, Dieguez C, Pinilla L, Tena-Sempere M. Developmental and hormonally regulated messenger ribonucleic acid expression of KiSS-1 and its putative receptor, GPR54, in rat hypothalamus and 
potent luteinizing hormone-releasing activity of KiSS-1 peptide. Endocrinology. 2004;145:4565-74.

65. Navarro VM, Castellano JM, Fernández-Fernández R, Tovar S, Roa J, Mayen A, Nogueiras R, Vazquez MJ, Barreiro ML, Magni P, Aguilar E, Dieguez $C$, Pinilla $L$ and TenaSempere $M$. Characterization of the potent luteinizing hormonereleasing activity of KiSS1 peptide, the natural ligand of GPR54. Endocrinology. 2005;146:156-63.

66. Messager S, Chatzidaki EE, Ma D, Hendrick AG, Zahn D, Dixon J, Thresher RR, Malinge I, Lomet D, Carlton MBL, Colledge WH, Caraty A, Aparicio SAJR. Kisspeptin directly stimulates gonadotropinreleasing hormone release via $G$ proteincoupled receptor 54. Proc Natl Acad Sci U $S$ A. 2005;102:1761-6.

67. Shahab M, Mastronardi C, Seminara SB, Crowley WF, Ojeda SR, Plant TM. Increased hypothalamic GPR54 signaling: a potential mechanism for initiation of puberty in primates. Proc Natl Acad Sci U S A. 2005;102:2129-34.

68. Castellano JM, Navarro VM, Fernández-Fernández R, Castaño JP, Malagón MM, Aguilar E, Dieguez C, Magni P, Pinilla L, Tena-Sempere M. Ontogeny and mechanisms of action for the stimulatory effect of kisspeptin on gonadotropinreleasing hormone system of the rat. Mol Cell Endocrinol. 2006;26:257-8:75-83.

69. Plant TM, Ramaswamy S, Dipietro MJ. Repetitive activation of hypothalamic G protein-coupled receptor 54 with intravenous pulses of kisspeptin in the juvenile monkey (Macaca mulatta) elicits a sustained train of gonadotropin-releasing hormone discharges. Endocrinology. 2006;147:1007-13.

70. Silveira LG, Noel SD, Silveira-Neto AP, Abreu AP, Brito VN, Santos MG, Bianco SD, Kuohung W, Xu S, Gryngarten M, Escobar ME, Arnhold IJ, Mendonca BB, Kaiser UB, Latronico AC. Mutations of the KISS1 gene in disorders of puberty. Clin Endocrinol Metab. 2010;95:2276-80. 
71. Brito VN, Mendonca BB, Guilhoto LM, Freitas KC, Arnhold IJ, Latronico AC. Allelic variants of the gamma-aminobutyric acid-A receptor alpha1-subunit gene (GABRA1) are not associated with idiopathic gonadotropin-dependent precocious puberty in girls with and without electroencephalographic abnormalities. J Clin Endocrinol Metab. 2006;91:2432-6.

72. Freitas KC, Ryan G, Brito VN, Tao YX, Costa EM, Mendonca BB, Segaloff D, Latronico AC. Molecular analysis of the neuropeptide Y1 receptor gene in human idiopathic gonadotropin-dependent precocious puberty and isolated hypogonadotropic hypogonadism. Fertil Steril. 2007;87:627-34.

73. Arita K, Kurisu K, Kiura Y, lida K, Otsubo H. Hypothalamic hamartoma. Neurol Med Chir (Tokyo). 2005;45:221-31

74. Zuniga OF, Tanner SM, Wild WO, Mosier HD Jr. Hamartoma of CNS associated with precocious puberty. Am J Dis Child. 1983;137:127-133.

75. Richter RB. True hamartoma of the hypothalamus associated with pubertas praecox. J Neuropathol Exp Neurol. 1951;10:368-83.

76. Freeman JL. The anatomy and embryology of the hypothalamus in relation to hypothalamic hamartomas. Epileptic Disord. 2003;5:177-86.

77. Burger PC, Scheithauer BW, Vogel FS. Surgical Pathology of the Nervous System and its Coverings. New York: Churcill-Livingstone; 1991.

78. Nguyen D, Singh S, Zaatreh M, Novotny E, Levy S, Testa F, Spencer SS. Hypothalamic hamartomas: seven cases and review of the literature. Epilepsy Behav. 2003;4:246-58.

79. Bedwell SF, Lindenberg R. A hypothalamic hamartoma with dendritic proliferation and other neuronal changes associated with "blastomatoid" reaction of astrocytes. J Neuropathol Exp Neurol. 1961;20:219-36.

80. Wechsler D. Wechsler Intelligence Scale for Children. 3rd ed. San Antonio, TX: Psychological Corporation;1991. 
81. Wechsler D. Wechsler Preschool and Primary Scale of IntelligenceRevised. San Antonio, TX: Psychological Corporation;1989.

82. Wechsler D. Wechsler Adult Intelligence Scale. 3rd ed. San Antonio, TX: Psychological Corporation;1997.

83. Jung $H$, Neumaier Probst E, Hauffa BP, Partsch CJ, Dammann O. Association of morphological characteristics with precocious puberty and/or gelastic seizures in hypothalamic hamartoma. J Clin Endocrinol Metab. 2003;88:4590-5.

84. Killoran CE, Abbott M, McKusick VA, Biesecker LG. Overlap of PIV syndrome, VACTERL and Pallister-Hall syndrome: clinical and molecular analysis. Clin Genet. 2000;58:28-30.

85. Biesecker LG, Abbott M, Allen J, Clericuzio C, Feuillan P, Graham JM Jr, Hall J, Kang S, Olney AH, Lefton D, Neri G, Peters K, Verloes A. Report from the workshop on Pallister-Hall syndrome and related phenotypes. Am J Med Genet. 1996;65:76-81.

86. Biesecker LG, Ondrey F. Pallister-Hall syndrome. Otolaryngol Head Neck Surg. 1998;119:556.

87. Freeman JL, Zacharin M, Rosenfeld JV, Harvey AS. The endocrinology of hypothalamic hamartoma surgery for intractable epilepsy. Epileptic Disord. 2003;5:239-47.

88. de Brito VN, Latronico AC, Arnhold IJ, Lo LS, Domenice S, Albano MC, Fragoso MC, Mendonca BB. Treatment of gonadotropin dependent precocious puberty due to hypothalamic hamartoma with gonadotropin releasing hormone agonist depot. Arch Dis Child. 1999;80:231-4.

89. Plant TM, Witchel SF. Puberty in nonhuman primates and humans. In The physiology of reproduction. 3rd ed, San Diego: Elsevier; 2006. 
90. Kordon C, Drouva SV, Martínez de la Escalera G, Weiner RI. Role of classic and peptide neuromediators in the neuroendocrine regulation of luteinizing hormone and prolactin. The physiology of reproduction. 2nd ed, New York: Raven Press;1994.

91. Ojeda SR, Terasawa E. Neuroendocrine regulation of puberty. In Hormones, brain and behavior. Volume 4, New York: Elsevier;2002.

92. Ojeda SR, Prevot V, Heger S, Lomniczi A, Dziedzic B, Mungenast A. Glia-to-neuron signaling and the neuroendocrine control of female puberty. Ann Med. 2003.;35:244-55.

93. Ojeda SR. The mystery of mammalian puberty: how much more do we know? Perspect Biol Med. 1991;34:365-83.

94. Ojeda SR, Lomniczi A, Mastronardi C, Heger S, Roth C, Parent AS, Matagne $V$, Mungenast $A E$. Minireview: the neuroendocrine regulation of puberty: is the time ripe for a systems biology approach? Endocrinology. 2006;147:1166-74.

95. Sutton, VR, Shaffer, LG. Search for imprinted regions on chromosome 14: comparison of maternal and paternal UPD cases with cases of chromosome 14 deletion. Am J Med Genet. 2000;93:381-7.

96. Martin, RA, Sabol, DW, Rogan, PK. Maternal uniparental disomy of chromosome 14 confined to an interstitial segment (14q23-14q24.2). J Med Genet. 1999;36:633-6.

97. Bingle CD. Thyroid Transcription Factor-1. Int J Biochem Cell Biol. 1997;1471-3.

98. Ikeda K, Clark JC, Shaw-White JR, Stahlman MT, Boutell CJ, Whitsett JA Gene structure and expression of human thyroid transcription factor-1 in respiratory epithelial cells. J Biol Chem. 1995;8108-14. 
99. Lonigro R, De Felice M, Biffali E, Macchia PE, Damante G, Asteria C, Di Lauro R. Expression of thyroid transcription factor 1 gene can be regulated at the transcriptional and posttranscriptional levels. Cell Growth Differ. 1996;7:25161.

100. Lee BJ, Cho GJ, Norgren RB Jr, Junier MP, Hill DF, Tapia V, Costa ME, Ojeda SR 2001 TTF-1, a homeodomain gene required for diencephalic morphogenesis, is postnatally expressed in the neuroendocrine brain in a developmentally regulated and cell-specific fashion. Mol Cell Neurosci. 17:107126.

101. Davis AM, Seney ML, Stallings NR, Zhao L, Parker KL, Tobet SA. Loss of steroidogenic factor 1 alters cellular topography in the mouse ventromedial nucleus of the hypothalamus. J Neurobiol. 2004;60:424-36.

102. Ojeda SR, Skinner MK. Puberty in the rat. In: The physiology of reproduction, 3rd ed. San Diego: Academic/Elsevier; 2006.

103. Mastronardi C, Smiley GG, Raber J, Kusakabe T, Kawaguchi A, Matagne V, Dietzel A, Heger S, Mungenast AE, Cabrera R, Kimura S, Ojeda SR. Deletion of the Ttf1 gene in differentiated neurons disrupts female reproduction without impairing basal ganglia function. J Neurosci. 2006;26:13167-79.

104. Kimura S, Hara Y, Pineau T, Fernandez-Salguero P, Fox CH, Ward JM, Gonzalez FJ. The T/ebp null mouse: thyroid-specific enhancer-binding protein is essential for the organogenesis of the thyroid, lung, ventral forebrain, and pituitary. Genes Dev. 1996;10:60-9.

105. Krude H, Schutz B, Biebermann H, von Moers A, Schnabel D, Neitzel H, Tonnies H, Weise D, Lafferty A, Schwarz S, DeFelice M, von Deimling A, van Landeghem F, DiLauro R, Gruters A Choreoathetosis, hypothyroidism, and pulmonary alterations due to human NKX2-1 haploinsufficiency. J Clin Invest. 2002;109:475-80. 
106. Acebrón A, Aza-Blanc P, Rossi DL, Lamas L, Santisteban P. Congenital human thyroglobulin defect due to low expression of the thyroid-specific transcription factor TTF-1. J Clin Invest. 1995;96:781-5.

107. Breedveld GJ, van Dongen JWF, Danesino C, Guala A, Percy AK, Dure LS, Harper P, Lazarou LP, van der Linde H, Joosse M, Gruters A, MacDonald ME, de Vries BBA, Arts WFM, Oostra BA, Krude H, Heutink P. Mutations in TITF-1 are associated with benign hereditary chorea. Hum Molec Genet. 2002;11:971-9.

108. Breedveld GJ, Percy AK, MacDonald ME, de Vries BBA, Yapijakis C, Dure LS, Ippel EF, Sandkuijl LA, Heutink P, Arts WFM. Clinical and genetic heterogeneity in benign hereditary chorea. Neurology. 2002;59:579-84.

109. Kleiner-Fisman G, Rogaeva E, Halliday W, Houle S, Kawarai T, Sato C, Medeiros H, St George-Hyslop PH, Lang AE. Benign hereditary chorea: clinical, genetic, and pathological findings. Ann Neurol. 2003;54:244-7.

110. Pohlenz J, Dumitrescu A, Zundel D, Martine U, Schonberger W, Koo E, Weiss RE, Cohen RN, Kimura S, Refetoff S. Partial deficiency of thyroid transcription factor 1 produces predominantly neurological defects in humans and mice. J Clin Invest. 2002;109:469-73.

111. Asmus F, Horber V, Pohlenz J, Schwabe D, Zimprich A, Munz M, Schoning M, Gasser T. A novel TITF-1 mutation causes benign hereditary chorea with response to levodopa. Neurology. 2005;64:1952-4.

112. Maquet E, Costagliola S, Parma J, Christophe-Hobertus C, Oligny LL, Fournet JC, Robitaille Y, Vuissoz JM, Payot A, Laberge S, Vassart G, Van Vliet G, Deladoëy J. Lethal respiratory failure and mild primary hypothyroidism in a term girl with a de novo heterozygous mutation in the TITF1/NKX2.1 gene. $J$ Clin Endocrinol Metab. 2009;94:197-203. 
113. Devriendt K, Vanhole C, Matthijs G, de Zegher F. Deletion of thyroid transcription factor-1 gene in an infant with neonatal thyroid dysfunction and respiratory failure. N Engl J Med. 1998;338:1317-8.

114. Doyle DA, Gonzalez I, Thomas B, Scavina M. Autosomal dominant transmission of congenital hypothyroidism, neonatal respiratory distress, and ataxia caused by a mutation of NKX2-1. J Pediat. 2004;145:190-3.

115. Iwatani N, Mabe H, Devriendt K, Kodama M, Miike T. Deletion of NKX2.1 gene encoding thyroid transcription factor-1 in two siblings with hypothyroidism and respiratory failure. J Pediatr. 2000;137:272-6.

116. Accornero S, Danesino C, Bastianello S, D'Errico I, Guala A, Chiovato L. Duplication of the pituitary stalk in a patient with a heterozygous deletion of chromosome 14 harboring the thyroid transcription factor-1 gene. J Clin Endocrinol Metab. 2010;95:3595-6.

117. Sussel L, Marin O, Kimura S, Rubenstein JL. Loss of Nkx2.1 homeobox gene function results in a ventral to dorsal molecular respecification within the basal telencephalon: evidence for a transformation of the pallidum into the striatum. Development. 1999;126:3359 -70.

118. Marin O, Baker J, Puelles L, Rubenstein JL. Patterning of the basal telencephalon and hypothalamus is essential for guidance of cortical projections. Development. 2002;129:761-73.

119. Ginsberg SD, Che S, Wuu J, Counts SE, Mufson EJ. Down regulation of trk but not p75 gene expression in single cholinergic basal forebrain neurons mark the progression of Alzheimer's disease. J Neurochem. 2006;97:475-87.

120. Siniscalchi A, Rodi D, Cavallini S, Marino S, Ferraro L, Beani L, Bianchi C. Effects of cholecystokinin tetrapeptide (CCK(4)) and of anxiolytic drugs on GABA outflow from the cerebral cortex of freely moving rats. Neurochem Int. 2003;42:87-92. 
121. Jung $H$, Parent AS, Ojeda SR. Hypothalamic hamartoma: a paradigm/model for studying the onset of puberty. Endocr Dev. 2005;8:81-93.

122. Heger S, Mastronardi C, Dissen GA, Lomniczi A, Cabrera R, Roth CL, Jung H, Galimi F, Sippell W, Ojeda SR. Enhanced at puberty 1 (EAP1) is a new transcriptional regulator of the female neuroendocrine reproductive axis. $J$ Clin Invest. 2007;117:2145-54.

123. Rampazzo A, Pivotto F, Occhi G, Tiso N, Bortoluzzi S, Rowen L, Hood L, Nava A, Danieli GA. Characterization of C14orf4, a novel intronless human gene containing a polyglutamine repeat, mapped to the ARVD1 critical region. Biochem Biophys Res Commun. 2000;278:766-74.

124. Matagne V, Mastronardi C, Shapiro RA, Dorsa DM, Ojeda SR. Hypothalamic expression of Eap1 is not directly controlled by ovarian steroids. Endocrinology. 2009;150:1870-8.

125. Marshall WA, Tanner JM. Variations in pattern of pubertal changes in girls. Arch Dis Child. 1969;44:291-303.

126. Marshall WA, Tanner JM. Variations in the pattern of pubertal changes in boys. Arch Dis Child. 1970;45:13-23.

127. Greulich WW PS. Radiographic atlas of skeletal development of the hand and wrist. 2nd ed. Stanford: Stanford University Press; 1959.

128. Brito VN, Batista MC, Borges MF, Latronico AC, Kohek MB, Thirone AC, Jorge BH, Arnhold IJ, Mendonca BB. Diagnostic value of fluorometric assays in the evaluation of precocious puberty. J Clin Endocrinol Metab. 1999;84:3539-44.

129. Lee PA. Laboratory monitoring of children with precocious puberty. Arch Pediatr Adolesc Med. 1994;148:369-76.

130. Brito VN, Latronico AC, Arnhold IJ, Mendonca BB. A single luteinizing hormone determination 2 hours after depot leuprolide is useful for therapy 
monitoring of gonadotropin-dependent precocious puberty in girls. $J$ Clin Endocrinol Metab. 2004;89:4338-42.

131. Layman LC. Hypogonadotropic hypogonadism. Endocrinol Metab Clin North Am. 2007;36:283-96.

132. Rogatko A, Pereira CAB, Frota-Pessoa O. A Bayesian method for the estimation of penetrance: application to mandibulofacial and frontonasal dysostoses. Am J Med Genet. 1986; 24:231-246.

133. Boyko OB, Curnes JT, Oakes WJ, Burger PC. Hamartomas of the tuber cinereum: CT, MR, and pathologic findings. Am J Neuroradiol. 1991;12:309-14.

134. Valdueza JM, Cristante L, Dammann O, Bentele K, Vortmeyer A, Saeger W, Padberg B, Freitag J, Herrmann HD. Hypothalamic hamartomas: with special reference to gelastic epilepsy and surgery. Neurosurgery. 1994;34:949-58.

135. Cummings CJ, Zoghbi HY. Fourteen and counting: unraveling trinucleotide repeat diseases. Hum Mol Genet. 2000;9:909-16.

136. Albrecht A, Mundlos S. The other trinucleotide repeat: polyalanine expansion disorders. Curr Opin Genet Dev. 2005;15:285-93.

137. Michaud JL. The developmental program of the hypothalamus and its disorders. Clin Genet. 2001;60:255-63.

138. Craig DW, Itty A, Panganiban C, Szelinger S, Kruer MC, Sekar A, Reiman D, Narayanan V, Stephan DA, Kerrigan JF. Identification of somatic chromosomal abnormalities in hypothalamic hamartoma tissue at the GLI3 locus. Am J Hum Genet. 2008;82:366-74.

139. Kelberman D, Rizzoti K, Avilion A, Bitner-Glindzicz M, Cianfarani S, Collins J, Chong WK, Kirk JM, Achermann JC, Ross R, Carmignac D, LovellBadge R, Robinson IC, Dattani MT. Mutations within Sox2/SOX2 are associated with abnormalities in the hypothalamo-pituitary-gonadal axis in mice and humans. J Clin Invest. 2006;116:2442-55. 
140. Kerrigan JF, Kruer MC, Corneveaux J, Panganiban CB, Itty A, Reiman D, $\mathrm{Ng}$ YT, Stephan DA, Craig DW. Chromosomal abnormality at 6p25.1-25.3 identifies a susceptibility locus for hypothalamic hamartoma associated with epilepsy. Epilepsy Res. 2007;75:70-3.

141. Parent AS, Matagne V, Westphal M, Heger S, Ojeda S, Jung H. Gene expression profiling of hypothalamic hamartomas: a search for genes associated with central precocious puberty. Horm Res. 2008;69:114-23.

142. Prigatano GP. Cognitive and behavioral dysfunction in children with hypothalamic hamartoma and epilepsy. Semin Pediatr Neurol. 2007;14:65-72.

143. Arita K, Ikawa F, Kurisu K, Sumida M, Harada K, Uozumi T, Monden , Yoshida J, Nishi Y. The relationship between magnetic resonance imaging findings and clinical manifestations of hypothalamic hamartoma. J Neurosurg. 1999;91:212-20.

144. Berkovic SF, Arzimanoglou A, Kuzniecky R, Harvey AS, Palmini A, Andermann F. Hypothalamic hamartoma and seizures: a treatable epileptic encephalopathy. Epilepsia. 2003;44:969-73.

145. Castro LH, Ferreira LK, Teles LR, Jorge CL, Arantes PR, Ono CR, Adda $\mathrm{CC}$, Valerio RF. Epilepsy syndromes associated with hypothalamic hamartomas. Seizure. 2007;16:50-8.

146. Freeman JL, Harvey AS, Rosenfeld JV, Wrennal JA, Bailey CA, Berkovic SF. Generalized epilepsy in hypothalamic hamartoma: evolution and postoperative resolution. Neurology. 2003;60:762-7.

147. Mahachoklertwattana P, Kaplan SL, Grumbach MM. The Luteinizing Hormone-Releasing Hormone-Secreting Hypothalamic Hamartoma Is a Congenital Malformation: Natural History. J Clin Endocrinol Metab. 1993;77:118-24. 
148. Palmini A, Paglioli-Neto E, Montes J, Farmer JP. The treatment of patients with hypothalamic hamartomas, epilepsy and behavioral abnormalities: facts and hypotheses. Epileptic Disord. 2003;5:249-55.

149. Frattali CM, Liow K, Craig GH, Korenman LM, Makhlouf F, Sato S, Biesecker LG, Theodore WH. Cognitive deficits in children with gelastic seizures and hypothalamic hamartoma. Neurology. 2001;57:43-6.

150. Debeneix C, Bourgeois M, Trivin C, Sainte-Rose C, Brauner R. Hypothalamic hamartoma: comparison of clinical presentation and magnetic resonance images. Horm Res. 2001;56:12-8.

151. Régis J, Bartolomei $F$, de Toffol B, Genton P, Kobayashi T Mori $\mathrm{Y}$, Takakura K, Hri T, Inoue H, Schröttner O, Pendi G, Wolf A, Arita K, Chauvel P. Gamma knife surgery for epilepsy related to hypothalamic hamartomas. Neurosurgery. 2000;47:1343-51.

152. Ong KK, Elks CE, Li S, Zhao JH, Luan J, Andersen LB, Bingham SA, Brage S, Smith GD, Ekelund U, Gillson CJ, Glaser B, Golding J, Hardy R, Khaw KT, Kuh D, Luben R, Marcus M, McGeehin MA, Ness AR, Northstone K, Ring SM, Rubin C, Sims MA, Song K, Strachan DP, Vollenweider P, Waeber G, Waterworth DM, Wong A, Deloukas P, Barroso I, Mooser V, Loos RJ, Wareham NJ. Genetic variation in LIN28B is associated with the timing of puberty. Nat Genet. 2009;41:729-33. 